Portland State University

PDXScholar

$1-1-2012$

\title{
Reflective Practice and Readiness for Self-directed Learning in Anesthesiology Residents Training in the United States
}

Amy Katrina Miller Juve

Portland State University

Follow this and additional works at: https://pdxscholar.library.pdx.edu/open_access_etds Let us know how access to this document benefits you.

\section{Recommended Citation}

Miller Juve, Amy Katrina, "Reflective Practice and Readiness for Self-directed Learning in Anesthesiology Residents Training in the United States" (2012). Dissertations and Theses. Paper 235.

https://doi.org/10.15760/etd.235

This Dissertation is brought to you for free and open access. It has been accepted for inclusion in Dissertations and Theses by an authorized administrator of PDXScholar. Please contact us if we can make this document more accessible: pdxscholar@pdx.edu. 
Reflective Practice and Readiness for Self-directed Learning in Anesthesiology Residents Training in the United States

by

Amy Katrina Miller Juve

A dissertation submitted in partial fulfillment of the requirements for the degree of

Doctor of Education

in

Educational Leadership: Postsecondary Education

Dissertation Committee:

Janine Allen, Chair

Christine Cress

Candyce Reynolds

Jackie Balzer

Leslie McBride

Portland State University

(C)2012 
Running head: Reflective Practice and Readiness for Self-directed Learning

\begin{abstract}
The science and technology of medicine is evolving and changing at a fast pace. With these rapid advances, it is paramount that physicians maintain a level of medical knowledge that is current and relevant to their practice in order to address the challenges of patient care and safety. One way physicians can maintain a level of medical knowledge that is current and relevant to their practice is through self-directed, lifelong learning, however little is known about how to develop these traits during clinical training. Schön $(1983,1987)$ theorized that one way learners can become self-directed, lifelong learners is through reflective practice.
\end{abstract}

This study utilized an experimental design and employed quantitative methods to investigate the effects of a reflective practice exercise, based on Gibbs' (1988) model of reflection, on readiness for self-directed learning as measured by Guglielmino's (1977) Self-Directed Learning Readiness Scale/Learning Preference Assessment (SDLRS/LPA). A total of 51 anesthesiology residents training in three residency programs in the United States participated in this study. A follow-up survey was administered to all study participants to determine if participation in the reflective exercises affected future engagement in or attitudes about reflective practice.

While the data analysis showed that participation in reflective practice did not affect readiness for self-directed learning in these study participants, this study has implications for medical education. Responses to the follow-up survey indicated that participants plan to engage in reflective practice in the future and that participating in 
Reflective Practice and Readiness for Self-directed Learning

reflective practice would have an impact on patient care. Chapter 5 includes ways to integrate the findings of this study into medical education and outlines next steps for future research utilizing both evidence from the literature and the qualitative responses from this study. 
Reflective Practice and Readiness for Self-directed Learning

\section{Dedication}

To my family.

Thank you for inspiring me, encouraging me and helping me to be the person I am today. I will be forever grateful to you for your love and support. 
Reflective Practice and Readiness for Self-directed Learning

\section{Acknowledgments}

This dissertation would not have been possible without the support, mentorship and guidance of many. First, my sincerest gratitude goes to Dr. Jeffrey Kirsch. Thank you for encouraging me to strive for excellence. Your passion for and commitment to medical education will never cease to amaze and inspire me. To my advisor and committee chair, Dr. Janine Allen, I am very appreciative for the advisement and support you gave me throughout this process. To my committee members, Dr. Jackie Balzer, Dr. Christine Cress, Dr. Leslie McBride and Dr. Candyce Reynolds, thank you for your thoughtful review of my project. Your feedback and guidance were greatly appreciated. Thank you to Dr. Christopher Swide and Dr. Dawn Dillman for listening to me and offering perspective when I needed it. In addition, thank you to Dr. Kathie Lasater and Dr. Tanya Ostrogorsky. You both provided me with support and resources that helped me through this process. To my doctoral colleagues, Shoshana Zeisman, Dr. Amanda Byron and Jolina Kwong Caputo... Thank you! You are all amazingly strong and brilliant women scholars and I will always be thankful for the comic relief, support sessions and late night social networking procrastination breaks!

To my amazing and loving husband, Rob Miller, you put your life on hold so that I could achieve one of my dreams. Thank you for your many sacrifices, patience and unwavering support. I am eternally grateful for your infinite love. You never once gave up on me and my quest to complete this degree. I love you! To my incredible parents, Eric Juve and Terry and Dion Kerr, you instilled in me a desire and passion for learning. 
Reflective Practice and Readiness for Self-directed Learning

You taught me that with dedication and perseverance I can do anything I put my mind to.

Thank you for being such good role models and supporters. Finally, thank you to my

friends. You now know that I was not blowing you off all of those times you asked me to "play" and I responded with "I'm working on my dissertation".

Thank you! You all have no idea how much your inspiration, guidance and support have helped me realize one of my biggest dreams. 
Reflective Practice and Readiness for Self-directed Learning

\section{Table of Contents}

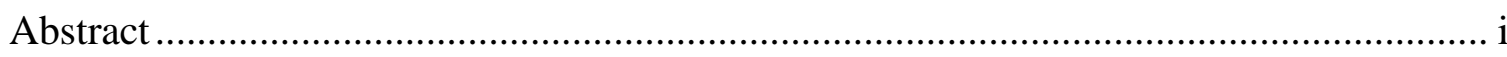

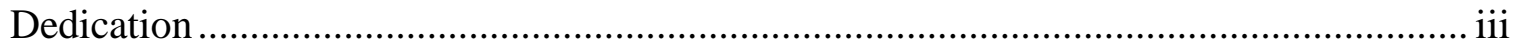

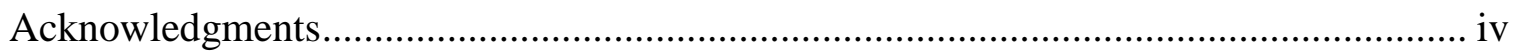

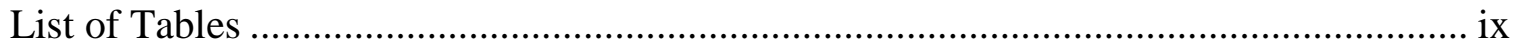

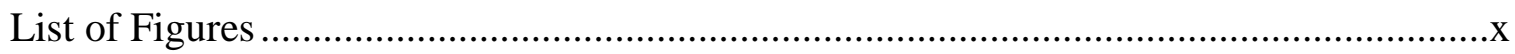

Chapter 1

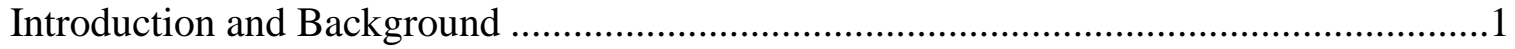

Self-directed Learning and the Connection to Lifelong Learning ..................................4

Reflection and Self-directed Learning ......................................................................

Medical Education and Reflective Learning ...................................................6

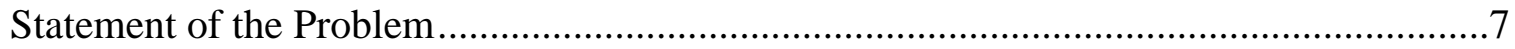

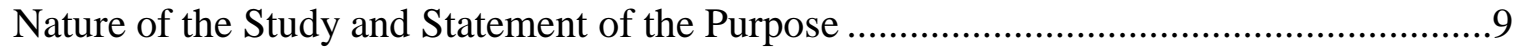

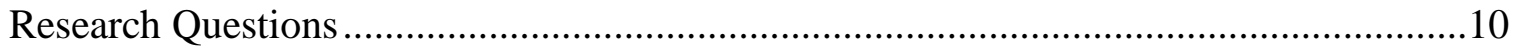

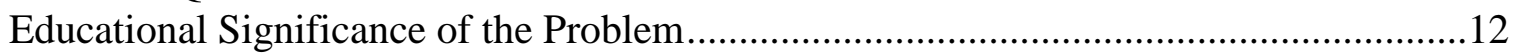

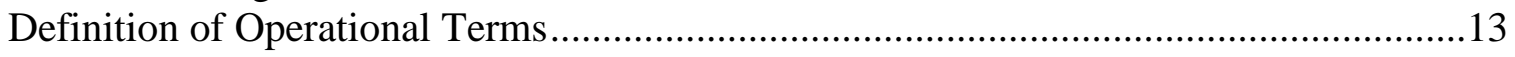

Organization of This Research Paper ................................................................... 14

Chapter 2

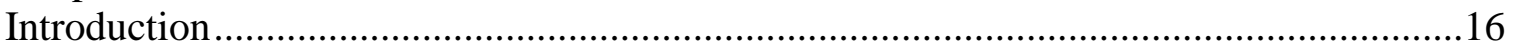

History and Current Status of Medical Education .....................................................17

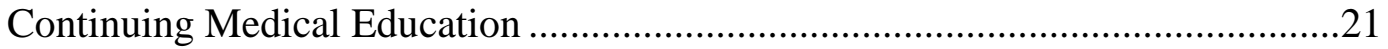

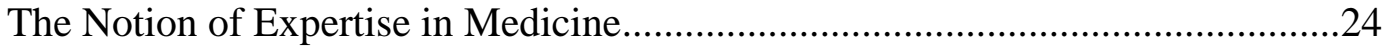

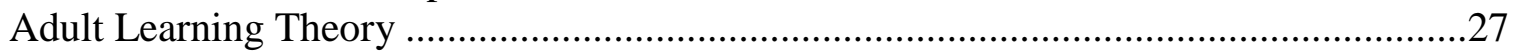

Andragogy and Self-directed Learning .......................................................2

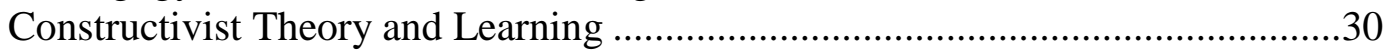

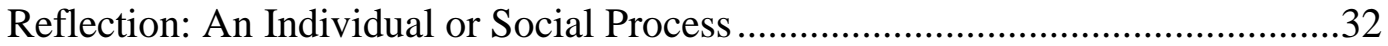

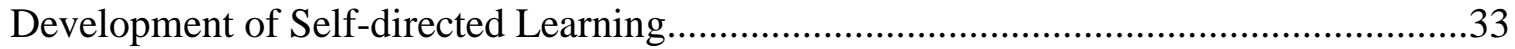

Self-directed Learning in Medical Education .................................................36

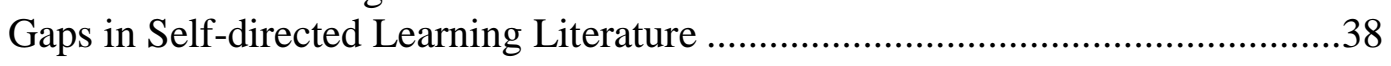

Theory and Development of Reflective Practice ........................................................39

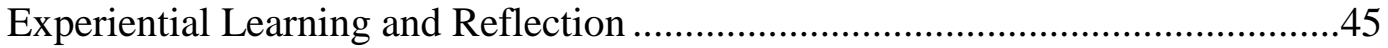

Kolb's Model of Experiential Learning and its Relation to Reflection .................48

Reflection in Healthcare ..........................................................................51

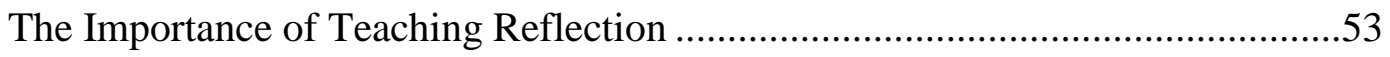

Gaps in the Reflective Practice Literature ......................................................54 
Reflective Practice and Readiness for Self-directed Learning

Summary

Chapter 3

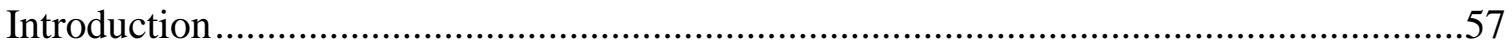

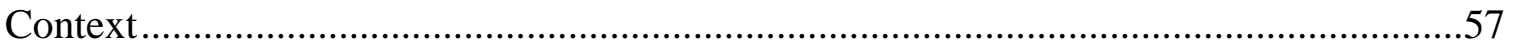

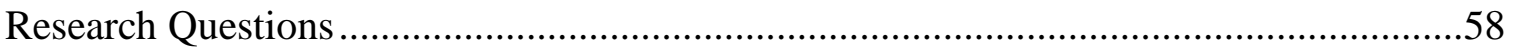

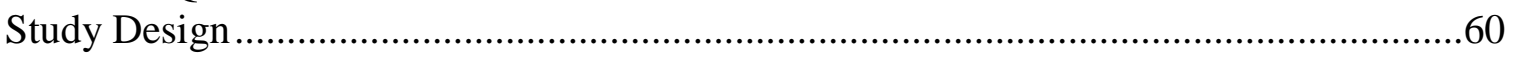

Intervention Tool: Gibbs' Model of Reflection ...............................................60

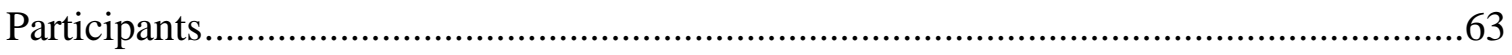

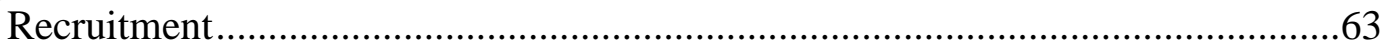

Obtaining Participant Consent ...................................................................65

Participant Demographics .........................................................................65

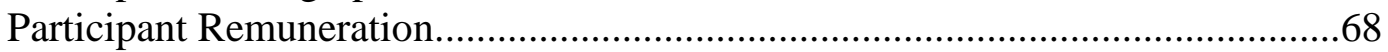

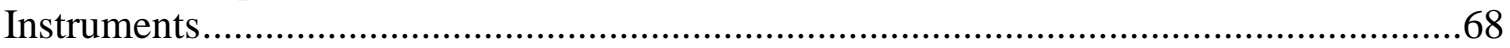

Self-directed Learning Readiness Scale/Learner Preference Assessment

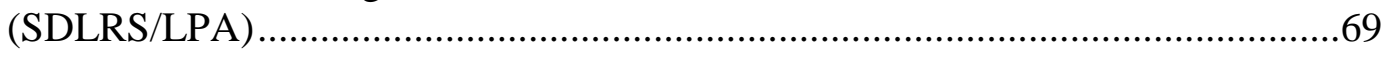

Support and Critique of the SDLRS/LPA ..........................................72

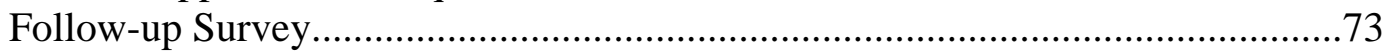

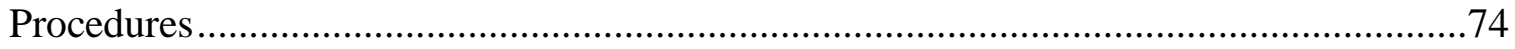

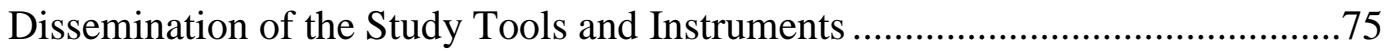

Self-guided Reflective Exercise.............................................................76

Self-directed Learning Readiness Scale/Learning Preference Assessment ...........77

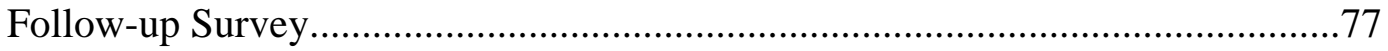

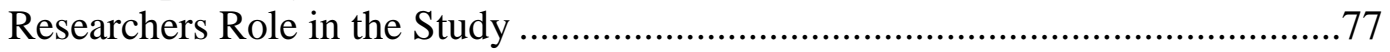

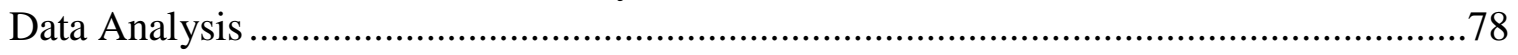

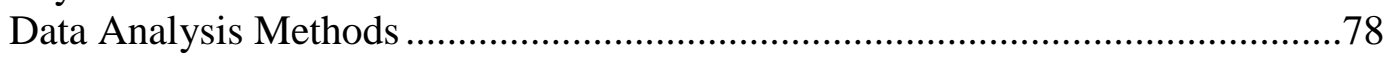

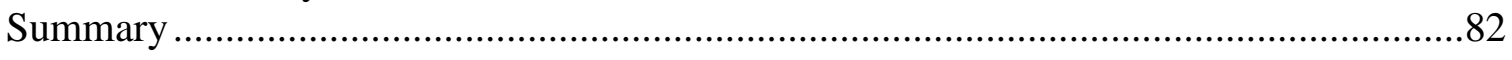

Chapter 4

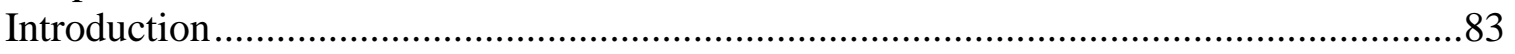

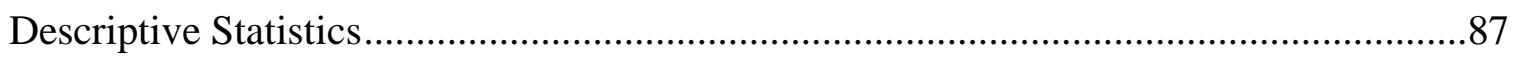

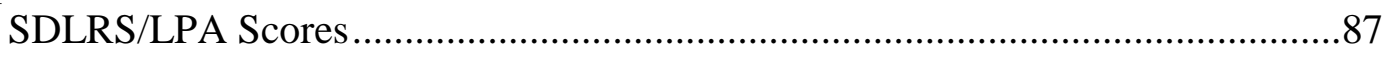

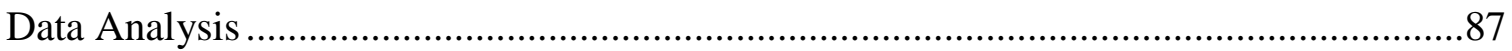

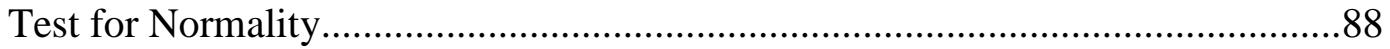

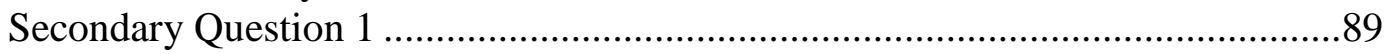

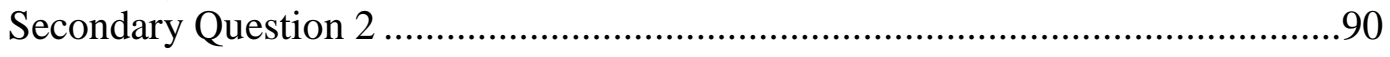

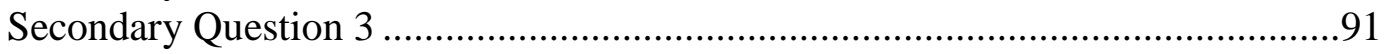

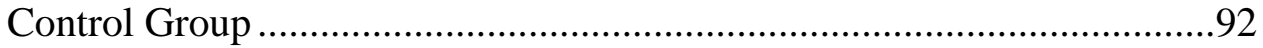

Experimental Group..................................................................99

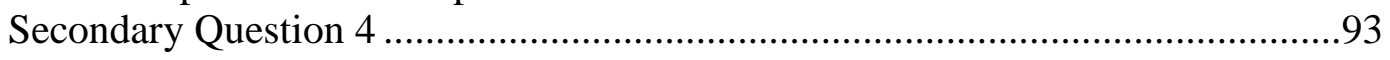

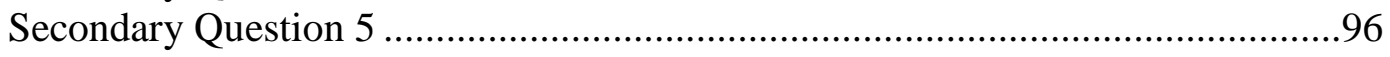

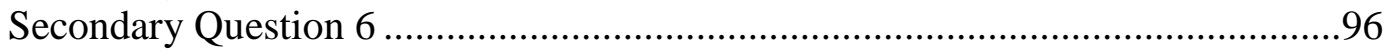


Reflective Practice and Readiness for Self-directed Learning

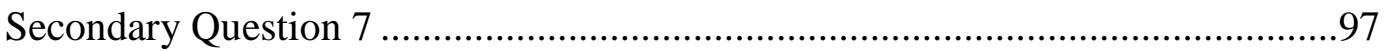

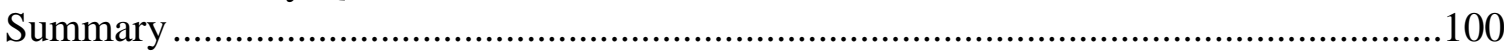

Chapter 5

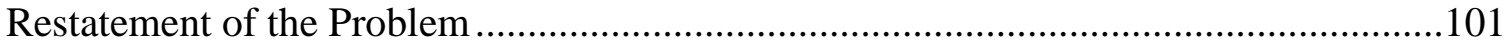

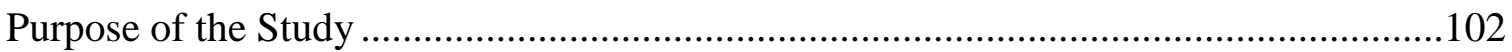

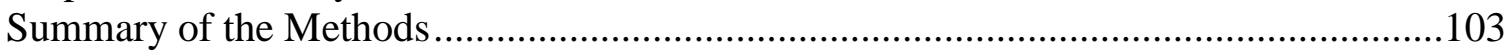

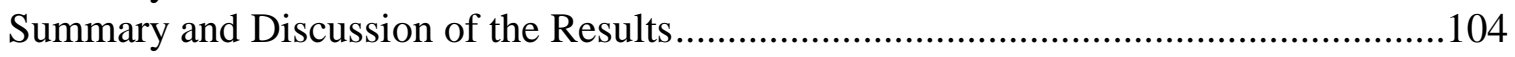

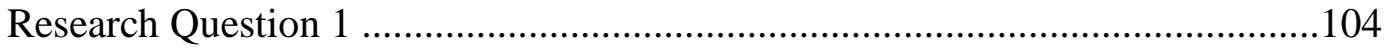

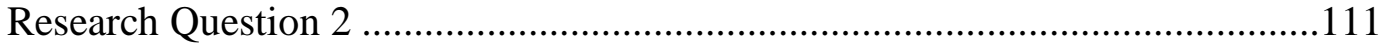

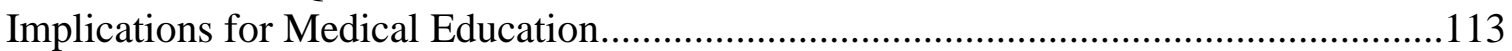

Implications for Future Research and Next Steps................................................... 116

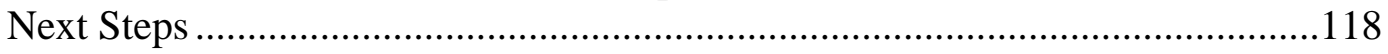

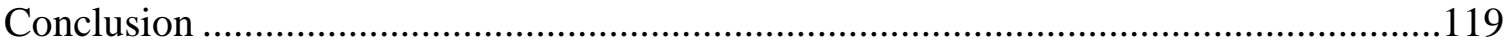

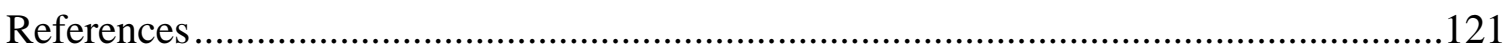

Appendices

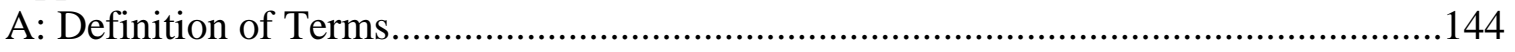

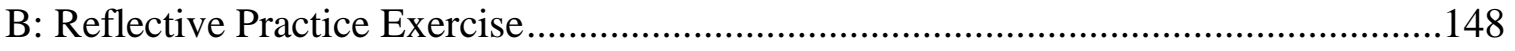

C: IRB-Approved Email Message to Residents to Solicit Participation..........................149

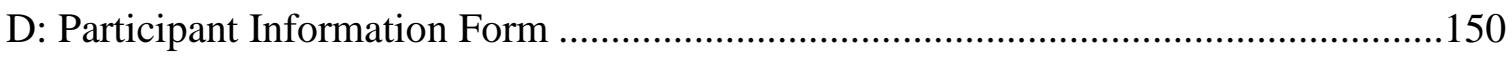

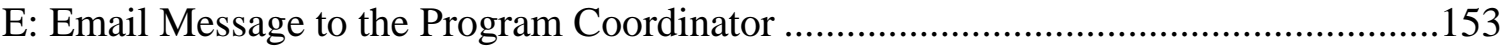

F: Self-directed Learning Readiness Scale/Learning Preference Assessment

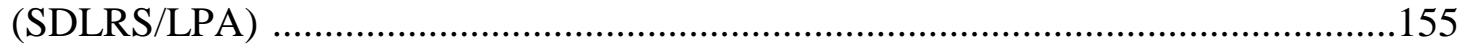

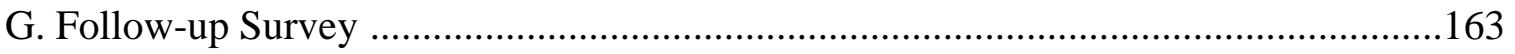


Reflective Practice and Readiness for Self-directed Learning

\section{List of Tables}

Table 1: Demographic Information for Study Participants...............................................67

Table 2: Dissemination of Study Tools to Participants ……….......................................76

Table 3: Data Analysis Methods ....................................................................................79

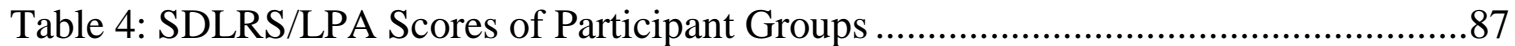

Table 5: Results for the Shapiro-Wilk Test for Normality of Distribution for All Sample Populations....................................................................................... 88

Table 6: Results of Null Hypothesis' for Secondary Questions 1 through 4 and Test Used to Analyze Each Hypothesis .95

Table 7: Response Frequency on the Follow-up Survey for the Control and Experimental Groups and Results of the Two-Way Contingency Table Analysis Using Crosstabs 
Reflective Practice and Readiness for Self-directed Learning

\section{List of Figures}

Figure 1: Years in Practice, Medical Knowledge and Medical Advances .......................27

Figure 2: Schön and Argyris' (1978) Double-loop Learning ............................................43

Figure 3: Gibbs' (1988) Model of Reflection ..................................................................46

Figure 4: Kolb's (1984) Model of Experiential Learning...............................................49 
Reflective Practice and Readiness for Self-directed Learning

\section{Chapter 1}

\section{Introduction and Background}

In 1996, the Institute of Medicine (IOM) convened a roundtable of experts to discuss the quality of healthcare in the United States. The National Roundtable on Health Care Quality met with the goal of identifying issues related to the quality of healthcare including how to measure, assess and improve patient care (Chassin, Galvin, \& the National Roundtable on Health Care Quality, 1998). The members of the roundtable met six times between February 1996 and January 1998. The group members engaged medical experts, convened conferences, commissioned papers and used their expertise to inform their conclusions about the quality of healthcare in the United States. The members concluded that there existed a serious and widespread problem with the quality of healthcare in America. The group further concluded that very large numbers of patients were harmed as a direct result of the poor quality of healthcare. In order to improve healthcare quality, the roundtable members articulated a major effort to overhaul healthcare would be needed which included the need to change the way physicians were educated and trained (Chassin et al., 1998).

In more recent years, studies looking at the quality of healthcare have come to similar conclusions as those made by the National Roundtable on Health Care. A study of 4,612 adult patients in the United States found that of the patients studied only 55\% received care consistent with recommendations made by established national guidelines and medical literature on best practices (McGlynn, Asch, Adams, Keesey, Hicks, 
Reflective Practice and Readiness for Self-directed Learning

DeCristofaro, \& Kerr, 2003). The examination of literature also discovered that between $20-30 \%$ of patients received care that was not recommended and, as such, the care ranged from being unnecessary to potentially harmful.

In medicine, the notion of expertise is viewed as a desirable trait to possess and many people believe expertise is gained through years of experience. Choudhry, Fletcher and Soumerai (2005) conducted a systematic review of patient care quality literature to assess the relationship between physicians' years in practice and the quality of healthcare delivery. The analysis found an inverse relationship between years in practice and the quality of care physicians provide. More specifically, of the 59 empirical studies reviewed, $52 \%$ reported a negative association between years in practice and quality of patient care leading the authors to contradict a popular belief that physician experience alone led to a better quality of care for patients and therefore experience alone does not necessarily lead to expertise.

Various medical organizations, professional associations and literature on best practices in medicine have put forth the importance of physician lifelong learning as one method to promote increased patient safety and healthcare quality (Association of American Medical Colleges, 2010; American Medical Association Code of Ethics, 2009; Institute of Medicine, 2003; Liaison Committee on Medical Education, 2010; Melnick, 2004; Regnier, Kopelow, Lane, \& Alden, 2005). The importance of lifelong learning was acknowledged by the Accreditation Council for Graduate Medical Education (ACGME) in 2001 with the introduction of their Outcomes Project. The Outcomes Project identified 


\section{Reflective Practice and Readiness for Self-directed Learning}

six general competencies that residents must achieve in order to graduate from training and move on to independent medical practice. The ACGME stated that creating the competencies was stimulated by increased attention to how adequately physicians are prepared to practice medicine in the changing health care delivery system (Accreditation for Graduate Medical Education, 2010). Maintaining a level of medical knowledge throughout a physician's career that is current and relevant to his or her practice enables physicians to provide services consistent with the most recent advances in medical care (Gonnella, Callahan, Louis, Hojat, \& Erdmann, 2004; Hojat, Veloski, Nasca, Erdmann, \& Gonnella, 2006; Plack, 2005).

Recognizing the importance of lifelong learning in medicine, specialty boards and licensing agencies began requiring education beyond what was acquired in residency training in order for practicing physicians to maintain credentials and licensure (Holm, 1998; Manning \& Petit, 1987). Continuing medical education (CME) was viewed by physicians and accrediting boards as a way to create opportunities for physicians to engage in lifelong learning. Although CME activities have been in existence since the 1950s, evidence of their impact on a physician's propensity to engage in lifelong learning or change a physician's practice to meet the needs of his or her patients is weak (Mazmanian \& Davis, 2002). Traditional CME activities are didactic in nature and include time-based training, where credits are earned for attending conferences and workshops that employ passive, teacher initiated educational models to teach physicians. In 2004, because of the lack of strong evidence in support of traditional CME delivery 
Reflective Practice and Readiness for Self-directed Learning

methods, the Association of American Medical Colleges (AAMC) recommended that the traditional model for lifelong learning should shift from attendance at weekly didactic

CME conferences to one that is individualized and self-directed.

\section{Self-directed learning and the connection to lifelong learning.}

Candy (1991), a well known researcher and contributor to the body of literature in self-directed learning (SDL), articulated that the characteristics associated with SDL are also associated with those of lifelong learning. The four principal domains of selfdirection, as outlined by Candy, are 1) personal autonomy 2) willingness and ability to manage one's overall learning endeavors 3) independent pursuit of learning without formal institutional support or affiliation and 4) learner control of instruction. Similarly learners who engage in learning activities throughout their lifetime exhibit characteristics including a drive to learn independently, motivation to learn by strong internal goals rather than external pressures, a desire for personal growth, an acceptance of personal responsibility for learning, and the ability to choose and employ strategies to further their learning (Alexander, 1995; Bolhuis, 2003; Ryan, 2003).

Self-directed learning as a means to encourage lifelong learning is an ideal that is becoming increasingly more accepted in medical education. Harvey, Rothman and Frecher (2003) stated that becoming an independent and self-directed lifelong learner is an important outcome of medical education. Self-directed learning skills are important for developing good physicians because self-directed learning skills have been linked with 
Reflective Practice and Readiness for Self-directed Learning

lifelong learning skills and the possibility for physicians to produce positive patient care outcomes (Li, Paterniti, Patrick \& West, 2010).

\section{Reflection and self-directed learning.}

One way physicians can acquire the skills necessary to become self-directed learners is through reflection. Schön $(1983,1987)$ theorized that an effective learner must be able to identify his or her own learning needs. He further stipulated that learners need to have a realistic sense of their strengths and weaknesses in order to direct their own learning in an efficient and productive direction. In order to do this, learners must know how to engage in reflective practice. Reflective practice as defined by Bennett, Casebeer, Zheng and Kristofco (2006) is thoughtful knowledge acquisition, after an unexpected phenomena, which helps a person gather information, integrate relevant ideas and evaluate results to incorporate new practices into his or her existing practice. In medicine, reflection is a particularly important skill to learn. In her article outlining reflection as a way to develop excellence in clinical practice, Plack (2005) states that reflection allows physicians to analyze their current knowledge base against best practices to provide the best care for their patients.

Reflection has emerged in the medical literature as one way to help practitioners understand what they do and do not know as a means to encourage lifelong learning. Gaining an understanding of how to engage in reflective practice can be a useful endeavor for medical trainees (Loughran, 2002; Mamede \& Schmidt, 2004; Plack, 2005). Teaching reflection can give trainees the skills needed to appropriately question his or her 


\section{Reflective Practice and Readiness for Self-directed Learning}

clinical practice, critically analyze new information, identify gaps in his or her skills and knowledge base and reflect critically on how to learn the skills needed to positively influence clinical outcomes (Kaufman, 2003; Mamede \& Schmidt, 2004). Furthermore, many speculate that reflection fosters self-directed learning because it encourages medical practitioners to recognize gaps in their knowledge and attend to their own learning needs to gain expertise in their field of practice (Bennett et al, 2006; Mamede \& Schmidt, 2004; Westberg \& Hilliard, 2001). Branch and Paranjape (2002) contend that reflection is essential to educating physicians and should be employed often.

\section{Medical education and reflective learning.}

Although the literature suggests that reflection is a key component in helping physicians acquire and maintain expertise, medical education has traditionally relied on didactic methods of teaching to give physicians the knowledge needed to care for patients (Mamede \& Schmidt, 2004). Modern medical education is fashioned after the Flexner Report (1910) which mandates medical trainees spend the first portion of their medical training in a lecture-style learning environment. Patrick and Williams (2009) assert that the lecture-style learning environment does little to help students develop the skills or attitudes for lifelong learning. Medical educators, concerned with what material they have "covered" fail to teach students how to learn effectively in order to enhance a student's propensity for lifelong, reflective learning (Towle \& Cottrell, 1996).

The Blue Ridge Academic Health Group (2003) reviewed a number of studies that looked at best practices in adult learning. Their review found that effective learners 


\section{Reflective Practice and Readiness for Self-directed Learning}

are involved in the reflection on and monitoring of their own learning and noted that there is little emphasis on learning reflective practice throughout medical education. Lujan and DiCarlo (2006) argue didactic learning is not enough to develop self-directed, lifelong learners. Lujan and DiCarlo further stipulate that medical training should be structured in a way that it increases a learner's self-directed learning and decreases the amount of time the learner spends in lectures.

Drain, Primack, Hunt, Fawzi, Holmes and Gardner (2007) stated that new ways of thinking and learning in medical education are needed to address the opportunities and challenges that present themselves with the rapid scientific and technological advances in medicine. Doctors, like other professionals, have an obligation to update their knowledge and skills throughout their careers in order to provide the best care possible to their patients. Reflection is one way that physicians can evaluate what they know and do not know, and they can mitigate gaps in their knowledge by applying self-directed lifelong learning practices (Izatt, 2007; Mazmanian \& Davis, 2002; Stewart, O’Halloran, Barton, Singleton, Harrigan \& Spencer, 2003). While reflection is seen as one way to mitigate gaps in knowledge and create lifelong, self-directed physician learners, little is known about how to cultivate reflective practice skills in physicians.

\section{Statement of the Problem}

Beginning in the year 2000, the Institute of Medicine (IOM) conducted a systematic review of healthcare and started producing a series of reports called the Quality Chasm Series outlining the need to reform the healthcare system to ensure patient 


\section{Reflective Practice and Readiness for Self-directed Learning}

safety. The first report, To Err is Human (1999) outlined that medical errors are a leading cause of death and injury in the United States. Several other studies have also called to question the quality of healthcare in the United States (Chassin et al., 1998; Choudhry et al., 2005; McGlynn, Asch et al., 2003). As such, organizations have called for reform in medical education to help improve patient safety and the quality of healthcare (Association of American Medical Colleges, 2010; Institute of Medicine, 2003; The Blue Ridge Academic Health Group, 2003).

Medical education has traditionally relied heavily on didactic teaching and teacher driven methods of learning to instill knowledge into residents in training. These methods have done little if anything to develop the skills needed to prepare residents to be lifelong learners. Too often, medical education has concentrated on "what material should be covered" rather than how to help residents achieve the necessary skills to be efficient, effective learners (Towle \& Cottrell, 1996).

The type of teaching and learning taking place in residency training programs today does not teach the learner how to learn, but rather what to learn. Residents need to be given the opportunity to practice and develop the skills necessary to direct their own learning in order to mitigate gaps in their knowledge. Kaufman (2003) asserts that the skills needed to improve self-directed learning include asking questions, reflecting critically on learning experiences, identifying gaps in knowledge, and being able to reflect critically on the learning process and outcomes. 
Reflective Practice and Readiness for Self-directed Learning

Because the science of medicine evolves and changes rapidly it is important that physicians continually seek opportunities to further their medical knowledge in order to help ensure patient safety and wellbeing. An important disposition that residency programs can instill in their residents is the skill to be lifelong learners. However, traditional medical education is taught in a way where lectures and tests are the mechanisms used for delivering knowledge and ensuring trainees are learning (Patrick \& Williams, 2009; Shaughnessy \& Slawson, 1999). The didactic nature and controlling environment, where faculty control learning and dissemination of information, of medical education does not give residents the skills needed to reflect upon their practice so they can seek information and learning opportunities on their own in order to direct their own learning. Ryan and Deci (2000) contend that learners, who are taught using a controlling, didactic approach, lose initiative to learn.

\section{Nature of the Study and Statement of the Purpose}

This study was quantitative in nature. Participants, who were anesthesiology residents in training, were randomly assigned to be in one of two groups, the experimental group or the control group. The experimental group participated in the intervention, which consisted of weekly reflective exercises, and the control group did not. Each group was given Guglielmino’s (1977) Self-directed Learning Preference Scale/Learning Preference Assessment (SDLRS/LPA), an instrument that measures an individual's readiness for self-directed learning, before and after the eight-week intervention. Quantitative data from the SDLRS/LPA for the experimental group and the 
Reflective Practice and Readiness for Self-directed Learning

control group were analyzed to determine if participating in reflective exercises affected readiness for self-directed leaning. Also, quantitative data from responses on a follow-up survey were analyzed to help gain insight into reflective practice including participant's attitudes about reflective practice and participant's engagement in future reflective practice.

The purpose of this study is to investigate the effects of reflective practice on readiness for self-directed learning and behaviors and attitudes about reflective practice in anesthesiology residents. This study aims to assist educators in understanding if reflective practice impacts a learner's readiness for self-directed learning. The findings of this study contribute to the body of literature on self-directed learning and reflective practice. The results of this study may help training programs identify if reflective practice should be included as part of a residency program's core curriculum.

\section{Research Questions}

The research questions for this study materialized after a comprehensive literature review was conducted on self-directed learning, adult learning theory, reflective practice and the epistemology of medical education. Two primary research questions drive this study: 1) Does reflective practice affect readiness for self-directed learning in anesthesiology residents? and 2) Does exposure to reflective practice affect anesthesiology residents' attitudes about reflective practice and the propensity to engage in future reflective practice? Several secondary questions will help further guide this study. Secondary questions 1 through 4 were developed to help answer research question 
Reflective Practice and Readiness for Self-directed Learning

1 and secondary questions 5 through 7 were developed to help answer research question

2. The research questions with associated secondary questions are listed below.

Research Question 1: Does reflective practice affect readiness for self-directed learning in anesthesiology residents?

Secondary Question 1: Do the pretest scores of the experimental group and control group differ from the average SDLRS/LPA score reported by Guglielmino?

Secondary Question 2: Do the posttest SDLRS/LPA scores differ between the control and experimental group?

Secondary Question 3: Do students' SDLRS/LPA scores before participating in reflective exercises, based on Gibbs' (1988) model of reflection, differ from the scores after participation?

Secondary Question 4: Are changes in pretest and posttest scores associated with participant characteristics or participation in reflective exercises?

Research Question 2: Does exposure to reflective practice affect anesthesiology residents' attitudes about reflective practice and the propensity to engage in future reflective practice?

Secondary Question 5: Do participants in the control group and experimental group differ on whether they engaged in reflective practice after the conclusion of the reflective exercises? 
Reflective Practice and Readiness for Self-directed Learning

Secondary Question 6: Do participants in the control group and experimental group differ in reporting that they plan on engaging in reflective practice in the future?

Secondary Question 7: Do participants in the control group and experimental group differ on their attitudes about reflective practice?

\section{Educational Significance of the Problem}

After a thorough literature search it is evident that there is little empirical evidence on the relationship between reflective practice and self-directed learning. Furthermore, the researcher was unable to find any empirical studies in the field of medical resident education directly related to reflective practice and self-directed learning. This study is timely in that the literature regarding learning in medical education is calling for more techniques to teach self-directed learning practices to physicians in order to help drive future educational inquiry and self-directed learning for individual physicians to improve patient care and safety (Dolmans, De Grave, Wolfhagen \& van der Vleuten, 2005; Li, Paterniti, Patrick, West, 2010).

Medical education is hard to study due to the secrecy surrounding physician performance. Considerably harder to study are physicians' training at institutions where the researcher does not have a professional or personal affiliation (Carney, Nierenberg, Pipas, Brooks, Stukel \& Keller, 2004). Therefore, this study is of particular significance because the researcher was able to gain access to physician's training at other institutions 


\section{Reflective Practice and Readiness for Self-directed Learning}

which lead to a larger, more diverse sample size than if the researcher was only able to access physician trainees at one institution.

Potential implications of this study could be far reaching. The findings could help change the curriculum in anesthesiology residency training programs including allocating time during each educational assignment for residents to reflect on his or her educational experience as well as teaching reflective practice techniques to residents to use throughout their career.

\section{Definition of Operational Terms}

For the purpose of this study, the following definitions were used:

Andragogy: "The art and science of helping adults learn" where the responsibility

for learning is more focused on the learner rather than the teacher (Knowles, 1980, p. 24).

Continuing Medical Education (CME): Continuing medical education consists of educational activities which serve to maintain, develop, or increase the knowledge, skills and professional performance and relationships a physician uses to provide services for patients, the public, or the profession (Marinopoulos et al., 2007).

Lifelong learning: The continuous building and development of knowledge and skills, people attain throughout their lives, through formal or informal experiences.

Problem-Based Learning (PBL): A student centered pedagogy where students are encouraged to take responsibility for their own leaning. PBL is used to enhance current knowledge by engaging students in a self-directed learning process intended to help them build upon previous knowledge to create new knowledge. 
Reflective Practice and Readiness for Self-directed Learning

Reflective Practice: Reflective practice is thoughtful knowledge acquisition after a person experiences an unexpected phenomena which helps him or her gather information, integrate relevant ideas, and evaluate results to incorporate new practices into his or her existing practice (Bennett, Casebeer, Zheng and Kristofco 2006).

Resident: A resident is a physician training in an accredited graduate medical education program (The Accreditation Council for Graduate Medical Education, 2010).

Residency: A medical training program that takes place after medical school that is accredited to provide a structured educational experience for a medical specialty, such as anesthesiology (Accreditation of Graduate Medical Education, 2010).

Self-directed Learning: Self-directed learning is a process where learners take the initiative to diagnose their learning needs, develop learning goals, indentify resources needed to meet their needs and goals, select and implement learning strategies and evaluate and indentify learning outcomes (Knowles, 1975, p. 18).

Self-Directed Learning Readiness Scale/Learner Preference Assessment (SDLRS/LPA): The SDLRS/LPA is the most commonly used valid quantitative tool to measure an individual's existing readiness for managing his or her own learning (Merriam, Caffarella, \& Baumgartner, 2007).

\section{Organization of This Research Paper}

This study examined the relationship between reflective practice and self-directed learning in anesthesiology residents. This paper is divided into five chapters. The first chapter contained an introduction and background of the problem, statement of the study 
Reflective Practice and Readiness for Self-directed Learning

problem, statement of the purpose, nature of the study, research questions, educational significance, study limitations and operational definitions. A review of the literature relevant to this study, including literature on reflective practice, medical education, continuing medical education, problem-based learning, self-directed learning and adult learning theory follows in chapter two. Chapter three explains the study methodology including description of the subjects, study instruments, data collection methods and procedures, and details the quantitative research design that was used for data analysis. Chapter four presents the results of this study as they relate to the research questions. Finally, chapter 5 guides the reader through the main discussion points including final conclusions, possible explanations for the study findings, suggestions for future research and implications for the results of this study. 


\section{Reflective Practice and Readiness for Self-directed Learning}

\section{Introduction}

\section{Chapter 2}

Chapter 2 focuses on research and literature pertaining to undergraduate, graduate and post-graduate medical education, reflective practice, self-directed learning and adult learning theory. This literature review includes both empirical and theoretical studies. Several seminal pieces of literature help guide this review. Seminal works reviewed in this chapter include the Flexner Report (1910) on medical education, John Dewey (1933) and Donald Schön's (1983) work on reflective practice, Houle (1961), Knowles (1975), Guglielmino (1977) and Tough's (1971, 1979) work on self-directed learning and Knowles (1970), Kolb (1984) and Gibbs’ (1988) work on adult learning.

Various methods were utilized to collect literature for this review. Government and professional association web sites, databases including EBSCO, PubMed, Education Full Text, Proquest, Sage eReference and Dissertations and Masters Theses and the Google Scholar search engine provided pertinent empirical and theoretical publications for this chapter. Key terms used to identify literature outlined in this review included selfdirected learning, reflection, medical education, lifelong learning, nursing education, continuing medical education, learning preference assessment, self-directed learning readiness scale, undergraduate medical education and residency training.

The organization of this chapter is based on the prominent themes found during the review of literature pertinent to the research questions outlined in Chapter 1 . The review starts with an overview of medical education including gaps needing to be addressed in the literature. The chapter progresses with a review of adult learning theory 
Reflective Practice and Readiness for Self-directed Learning

including the history of the concept of self-directed learning and self-directed learning in medical school. This chapter concludes with key concepts related to reflective practice including the history and operational definition of reflective practice, experiential learning and reflective practice, reflection in healthcare, the importance of teaching reflection in the medical practice, and a brief discussion of gaps in the reflective practice literature.

\section{History and Current Status of Medical Education}

Today's medical training is steeped in tradition. In 1908 the Carnegie Foundation commissioned Abraham Flexner to study medical education in Canada and America. Most of his findings and recommendations are ever present in American medical education today, continuing the tradition of a highly didactic and controlling learning environment (Beck, 2004; Commonwealth Fund, 2002). A prominent example of Flexner's influence on American medical education is the format in which medical education is delivered. After visiting the 155 medical colleges in existence in North America in 1908, Flexner found medical education to be fragmented and not consistent across campuses. In order to create a standard of practice, Flexner recommended that medical education consist of four years of training, two years of intensive didactic curricula followed by two years of clinical training. He also dictated that teaching methods be scientific in nature and focused on knowledge attainment. To this day, a majority of medical schools in America operate using Flexner's model of training (Cooke Irby, Sullivan, \& Ludmerer, 2006; Patrick \& Williams, 2009). 


\section{Reflective Practice and Readiness for Self-directed Learning}

Over the past century, leaders in the field of medical education have been challenged to overhaul how the nation's medical professionals are trained (Flexner, 1910; Hoff, Pohl \& Bartfield, 2004; Osler, 1913). From the inception of the Flexner Report (1910), which outlines the need for reform in medical education, the way in which America trains its medical professionals has been under scrutiny (Cooke et al., 2006). On the list of criticisms is the notion that medical education emphasizes scientific knowledge over practical skills such as training physicians to be lifelong, self-directed learners (Shaughnessy \& Slawson, 1999; The Commonwealth Fund, 2002). Also of contention is the lack of pedagogical training received by teaching faculty and the didactic nature of medical training (Branch \& Paranjape, 2002; Patrick \& Williams, 2009; Shaughnessy \& Slawson, 1999).

Individually, over the last decade, The Commonwealth Fund (2002), The Blue Ridge Academic Health Group (2003), The Committee on the Roles of Academic Health Centers (2003) and the Association of American Medical Colleges (2004) took on the challenge of analyzing medical training in America. Their findings outlined that Academic Medical Centers (AMCs) were not putting a high priority on teaching trainees. Specifically, the groups discovered that AMCs were pushing faculty to see more patients in order to maintain or increase revenue. Because of this cost containment measure, the opportunities for faculty to have meaningful teaching interactions with trainees had decreased. The reports concluded that AMCs valued faculty research activities far more 
Reflective Practice and Readiness for Self-directed Learning

than faculty teaching practices. Furthermore they found that AMCs were allowing faculty not trained in pedagogical practices to train medical students and residents.

Studies looking at a resident's perception of his or her preparedness to competently care for patients confirmed the findings of The Commonwealth Fund (2002), The Blue Ridge Academic Health Group (2003), The Committee on the Roles of Academic Health Centers (2003) and the Association of American Medical Colleges (2004). Sharp, Wang and Lipsky (2003) examined 265 family medicine residents' perceived competency for procedures commonly performed by family medicine practitioners. Of the 265 respondents, $43 \%$ did not feel competent to perform 25 or more of the 31 procedures listed on the study questionnaire. Bowen, Salerno, Chamberlain, Eckstrom, Chen and Brandenburg (2005) conducted a meta-analysis of literature related to the training of residents in internal medicine. The meta-analysis discovered several studies that found residents lacked confidence and competence for addressing outpatient health issues.

Other studies observed similar findings among other specialties. An important aspect of providing patient care as an internal medicine physician is being able to conduct a medical interview of patients (Muller et al, 2006). Medical interviews help diagnose and treat patients for various diseases and morbidities. Mueller et al. (2006) looked at new internal medicine faculty's perceived preparedness and competence in their ability to conduct medical interviews. Although the faculty participating in the study $(n=58)$ rated the importance of medical interviewing high, they regarded their competence and 
Reflective Practice and Readiness for Self-directed Learning adequacy of training low. Of the respondents, a majority, 57\%, felt they would benefit from more training in medical interviewing. Similarly, Blumenthal, Gokhale, Campbell and Weissman (2001) conducted a national study of graduating residents in eight different specialties. The goal of their research was to examine how prepared residents felt to practice medicine after graduation. When new medical professionals were asked if they felt adequately prepared to address problems they would face in their clinical practice more than $10 \%$ in each specialty responded that they felt inadequately prepared to perform one or more patient care task related to their discipline (Blumenthal et al., 2001).

One reason that resident graduates may feel unprepared to perform some aspects of clinical practice could be due to the lack of training in reflective practice during graduate medical training. During their assessment, The Blue Ridge Academic Health Group (2003) discovered that trainees were not being taught how to reflect upon and integrate the knowledge they learned in their medical lectures into their clinical training. This lack of reflection left students uncertain of what they were learning. Trainees were realizing that true gaps in their knowledge existed which made them unsure about their performance upon graduating from residency.

As one method of helping physicians address gaps in knowledge and stay current on the ever evolving and growing body of medical literature, accrediting bodies and state agencies implemented an educational component to the professional practice of medicine called continuing medical education (CME) (Mansouri \& Lockyer, 2007). Although 


\section{Reflective Practice and Readiness for Self-directed Learning}

CME has been in existence for several decades, studies continue to point out gaps in physician knowledge and patient care (Blumenthal et al., 2001; Bowen et al. 2005;

Muller et al., 2006). In order to understand the potential impact CME activities can have on patient care and physician learning, it is important to look at studies that have assessed the effectiveness of CME.

\section{Continuing medical education.}

Continuing medical education has been a part of physician education in America for several decades and was established as a means to impose physician lifelong learning. As early as the 1950's, documented, yet voluntary, CME events were occurring across the nation to assist physicians in maintaining and increasing their knowledge to improve patient care (Manning \& Petit, 1987). Soon after CME programs were developed, studies were conducted and published about the effectiveness of CME (Hazlett, Bachynski \& Embleton, 1973; Mansouri, Lockyer, 2007; Williamson, Alexander \& Miller 1967). Since its inception, researchers, physicians and accrediting bodies have questioned the effectiveness of CME programs on physician learning and increase patient safety (Bloom, 2005; Kilian, Binder \& Marsden, 2007; Spivey, 2005).

The usefulness of CME programs has been studied for decades. Most of the studies identified that the didactic nature of CME activities do not produce better learning outcomes for physicians and better care for patients than would be produced by not having physicians participate in CME activities. In an early study assessing continuing education and patient care, Williamson, Alexander and Miller (1967) demonstrated that 


\section{Reflective Practice and Readiness for Self-directed Learning}

the widely accepted methods of CME, particularly conferences, did not mitigate identified problems in physician practice. More recently, in 1995, Davis, Thompson, Oxman and Haynes conducted a meta-analysis of over 99 studies related to the delivery methods of CME. They found that activities, purely didactic in nature, had little impact on improving professional practice. Furthermore, Davis and his colleagues found that a mixed methods approach to CME delivery, such as practice-based interventions and outreach visits, was more effective than didactic CME sessions but seldom used. Related studies found CME activities that focused on specific objectives, targeted one specialty group, and utilized active pedagogy as the main method of knowledge delivery had a greater impact on changing physician practices to improve patient care and did a better job of identifying and mitigating physician gaps in knowledge (Davis, O'Brien, Freemantle, Wolfe, Mazmanian \& Taylor-Vaisey, 1999; Grol, 2002; Monsouri \& Lockyer, 2007; Pippalla, Riley \& Chinburapa, 1995). Although a mixed methods approach to CME delivery has had positive outcomes, flaws in the CME process still exist.

The effectiveness of CME programs relies on physicians to assess their own gaps in knowledge and self-select the CME programs that best fit their learning needs (Davis, et al., 2006; Duffy \& Holmboe, 2006). Evidence exists however, that physicians have had limited success with conducting self-assessments of competency and thus their learning needs. A 2007 study conducted by Evans, Leeson and Petrie examined how 38 different surgery residents rated their performance, compared to how their peers and teaching 


\section{Reflective Practice and Readiness for Self-directed Learning}

faculty rated them, on oral surgery procedures. The study found that the surgical residents over-scored their performance compared to their peer and faculty assessments. Also seeking to identify how physicians self-rate their performance, Davis, Mazmanian, Fordis, Harrison, Thorpe and Perrier (2006) conducted a meta-analysis of studies looking at the accuracy of physician self assessment. After reviewing 725 articles, 17 were found to fit all inclusion criteria set forth for the meta-analysis. Studies were included in the analysis if they compared physician self-assessment with external observations, used replicable measures, included at least 50\% practicing physicians (including residents) and were conducted in the United States, Canada, New Zealand or Australia. The analysis found that physicians had a limited ability to assess their skill level.

More work still needs to be done to explore the effectiveness of CME on physician learning and patient outcomes. Belfield et al. (2001) found little exploration in the literature about the relationship between educational interventions and physician performance and patient outcomes (Belfield et al., 2001). Similarly, Mazmanian and Davis (2002) called for more research in the area of learning outcomes for physicians including how CME programs change clinical practice. After careful review of the CME literature, those gaps mentioned by Belfield et al. and Mazmanian and Davis still exist. Mazmanian, Davis \& Galbraith (2009), in their quest to look at patient care outcomes and the effects of CME activities point out that no single measure for evaluating clinical outcomes and the effects of individual CME activities exists, making it hard to assess what CME activities produce the best patient outcomes. 
Reflective Practice and Readiness for Self-directed Learning

In conclusion, CME was developed as a means to help promote physician lifelong learning and close gaps in physicians' medical knowledge in order to increase patient safety (Bennett et al., 2000). Although formal CME programs have been in existence since the 1950's little empirical evidence exists that demonstrates the effectiveness of CME activities and a positive increase in patience safety or physician learning. One reason $\mathrm{CME}$ may not be an adequate means for addressing physicians' gaps in knowledge could be due to tendency for physicians to over-rate their clinical performance thus making it hard for physicians to deduce their true learning needs. In order to appropriately assess physician learning, it is important to understand theory related to adult learning and how it can be utilized to help increase physician learning.

\section{The notion of expertise in medicine.}

In medicine, expertise is seen as an attribute to emulate. The notion of medical expertise was most notably explored first by Elstein, Shulman and Sprafka in 1978. Wanting to help other physician's become experts, Elstein et al. sought to determine the differences between expert and non-expert diagnosticians. Through soliciting peers, Elstein et al. found physicians who were considered to be expert diagnosticians. They then studied the differences between the experts and "regular" physicians through a series of videotaped physician and simulated-patient encounters. In their extensive study, Elstein et al. found no statistical differences in the objective performance or thought process of a perceived expert and regular physician. In a later review of their study, Elstein et al. (1990) recognized flaws in their initial study design and contended that 


\section{Reflective Practice and Readiness for Self-directed Learning}

expertise is recognized by years of experience, specialty board certification and occasionally through academic rank.

Other research has also looked at the notion of expertise in medicine. Unlike Elstein et al. (1978, 1990) some studies put forth the notion that expertise is not gained by years in practice, academic rank and specialty board certification but rather knowledge in a particular subject matter. In their review of literature pertaining to medical expertise Schmidt and Rikers' (2007) found cognitive theories of expertise posit that expertise is largely a matter of knowledge expansion and that expertise develops as learners acquire more and more information relevant to their practice. Similarly, medical simulation, which allows a learner-centered approach to practicing procedural skills, allows trainees to develop technical expertise (Kneebone, 2009). It is the practice of skills and reflection on performance, rather than the length of time someone has been practicing medicine that garners expertise from simulation. Although seen as a best practice, simulation is not offered to all medical specialties in all hospitals due to competing demands. Simulation is often expensive and time-consuming and not all patient issues can be reproduced during simulation (Kneebone, 2009).

Although expertise is seen as a favorable asset, research suggests that expertise may carry some limitations. Inflexibility, difficulty viewing problems from multiple perspectives and adapting to new rules or conditions are seen as a few or the drawbacks to professional expertise (Dane, 2010). Dane contends that experts, when faced with new situations that are similar to previous situations, become fixated with their previous 


\section{Reflective Practice and Readiness for Self-directed Learning}

response and cannot see alternative solutions. While acceptable in some situations, this type of thinking can potentially lead to patient harm. An extremely simple example is the progression of drug regimens used to mitigate the effects of HIV. If a physician merely relied upon previous situations and previously attained knowledge to treat his or her patients with HIV, the physician may not know about the new advances in HIV medications and the subsequent increase in life expectancy and quality of life for patients by using the new drugs.

Because advances in medicine develop quickly it is important to explore the notion of medical expertise and how it relates to self-directed learning. In 1900, Sir William Osler identified that lifelong learning would be necessary for physicians to maintain a level of competence and knowledge needed to properly care for their patients (Figure 1). Without self-directed lifelong learning, expertise could serve as a detriment to physicians and their patients. It is important that physicians continue to reflect upon their practice and find gaps in their knowledge to serve their patients rather than relying on the expertise obtained through years of experience, specialty board certification and academic rank. 
Reflective Practice and Readiness for Self-directed Learning

Figure 1. Years in Practice, Medical Knowledge and Medical Advances

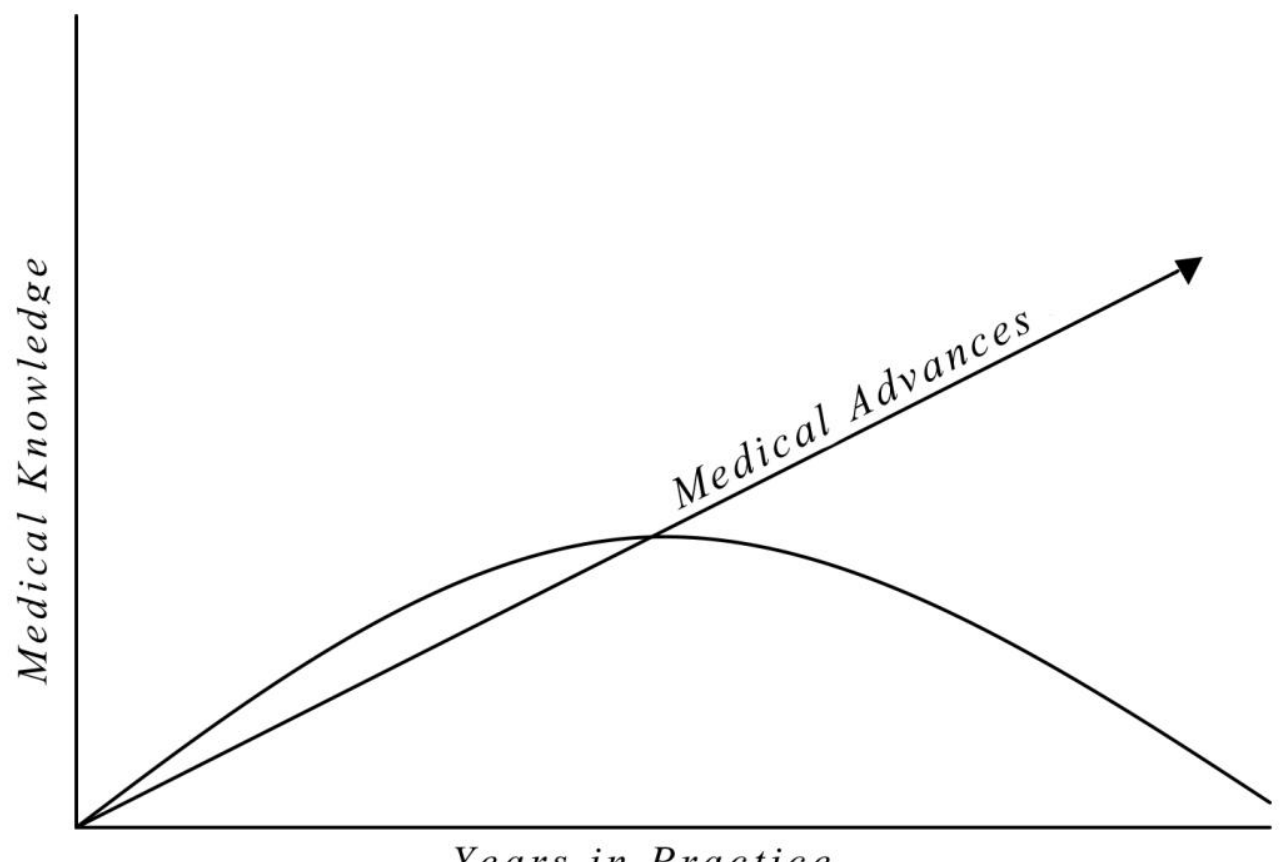

Figure 1. Medical knowledge peaks and then decreases as years in practice increase while medicine continues to make advances.

\section{Adult Learning Theory}

\section{Andragogy and self-directed learning.}

The field of adult education has been highly influenced by theorist Malcolm Knowles. In his seminal work, The Modern Practice of Adult Education: Andragogy Versus Pedagogy Knowles (1970) popularized the term andragogy to define the way adults learn. He theorized that adults cannot learn in the same classroom oriented, didactic centered way children learn. Andragogy was defined by Knowles as "the art and 
Reflective Practice and Readiness for Self-directed Learning

science of helping adults learn" (p. 38). Knowles (1970) developed four assumptions to explain how adults differ in their learning process from children. A fifth assumption was added later in 1984. The five assumptions are:

1) Self-Concept: As a person matures her self-concept moves from being dependent to being self-directed.

2) Experience: As a person matures she accumulates experiences that become an increasing reservoir for learning.

3) Readiness to learn: As a person matures her readiness to learn becomes oriented to the developmental tasks in her social roles.

4) Orientation to learning: As a person matures her time perspective changes from one of postponed application of knowledge to immediacy of application, and accordingly her orientation toward learning shifts from one of subjectcenteredness to one of problem centeredness.

5) Motivation to learn: As a person matures the motivation to learn is internal rather than external (Knowles, 1984).

As outlined in the first assumption, Knowles (1975) believed that adults are selfdirected in regards to their learning. He described self-directed learning as a process in which individuals, with or without the help of others, diagnose their own learning needs, formulate learning goals, identify resources for learning, chose and implement appropriate learning strategies and evaluate their learning outcomes. Knowles argued that there are three essential reasons for adults to be self-directed learners: 


\section{Reflective Practice and Readiness for Self-directed Learning}

1) There is convincing evidence that adults who are proactive learners learn more things and learn better than those who are passive learners. Furthermore self-directed learners enter into learning with greater motivation to learn and proactive learners tend to retain and make use of what they learn better and longer than passive learners.

2) An essential aspect of maturing is developing the ability to take increasing responsibility for one's own life - becoming more self-directed.

3) Developments in education are ever evolving which puts a heavy responsibility on the learner to take initiative for his or her own learning. Knowles (1975) theorized that students entering into academic programs without having learned the skills of self-directed inquiry will experience anxiety, frustration and often failure and so will their teachers.

Although Knowles' theory of andragogy is widely used and accepted in adult learning literature, it does not come without criticism. In his critique, Rachal (2002) stated that although Knowles' definition of andragogy includes the word "science" much of the controversy surrounding the theory is not about the empirical evidence, but rather the theory's theoretical underpinnings. Knowles does not give an operational definition to andragogy which makes it hard to examine the validity of the theory. Hartree (1984) brought forth another criticism of andragogy stating that andragogy is not a theory at all, but rather a set of principles of good practice for learning (Hartree, 1984). Knowles (1989) himself has agreed that andragogy is less of a theory and more of a model or 
Reflective Practice and Readiness for Self-directed Learning

framework from which future theory can be developed. Although not a direct critique of

Knowles' theory, Candy (1991) postulated that not all individuals are equally self-

directed and that self-directness may not be the same in all situations. Therefore

understanding learners' readiness to be self-directed may help them be better selfdirected learners.

Furthermore, critiques of Knowles' theory state that andragogy also describes the way children learn. Knowles (1979) himself modified his model of andragogy by describing it as a continuum of pedagogy. Knowles stated that both andragogy and pedagogy were appropriate at different times, in different situations and regardless of the age of the learner. Houle (1972) and London (1973) contended that andragogy and pedagogy could be used interchangeably and both models could be used to educate adults or children.

\section{Constructivist theory and learning.}

The constructivist theory of learning encompasses various perspectives on how people learn. The basis of constructivism was derived from the work of Jean Piaget (1952) and Lev Vygotsky (1978). The main assumption is that learners make sense of their experiences by building upon previous knowledge to construct new knowledge (Merriam, Caffarella \& Baumgartner, 2007). In the constructivist paradigm, learning is less dependent on age (adult vs. child) and more dependent on active learning. Divergent views within the arena of constructivism articulate that knowledge is either socially or individually constructed (Ernst, 1994). However, the notion that reflective practice helps 


\section{Reflective Practice and Readiness for Self-directed Learning}

the learner build upon previous knowledge to construct new meaning is woven throughout both social and individual constructivist paradigms. Due to the emphasis on active inquiry and reflection, the constructivist view of learning is particularly relevant to the notion of self-directed learning (Candy, 1991).

Reflective practice is one component of the constructivist theory. Specifically, the constructivist paradigm emphasizes critical reflection on previous experiences as a means to create new knowledge (Merriam, Caffarella \& Baumgartner, 2007). In order to construct new knowledge, a learner must reflect upon his or her previous experiences, questioning previous understanding and assumptions and integrate what he or she learned from reflection into future experiences. An important underpinning of constructivism, reflection drives the development of new knowledge, whether or not the reflective practice is individually or socially driven.

A constructivist belief of the locus of learning is that learning takes place through both an individual process and a social process (Ernst, 1996). Sfard (1998) uses acquisition and participation metaphors to illustrate ways that learners gain or create knowledge. Sfard's acquisition metaphor describes learning as being individually, rather than socially constructed and portrays the learner as a passive participant in the learning process. The term knowledge acquisition constructs an image of a brain being passively filled with knowledge by a teacher, similar to how knowledge is constructed throughout medical education. However, the participation metaphor as described by Sfard (1998) implies that the learner takes part in or is a part of the creation of knowledge. The student 
Reflective Practice and Readiness for Self-directed Learning

participates in his or her own learning which shifts the focus from a teacher filling the mind with knowledge to knowledge being created by the bonds and discourse between the learner and others, therefore the assumption is that knowledge is socially constructed (Sfard, 1998).

\section{Reflection: an individual or social process.}

Similar to the individual or social nature of the constructivist view of knowledge creation, reflective practice has been theorized to be either an individual process or a social process, potentially requiring guidance from others. According to Lockyer, Gondoc and Thivierge (2005) reflective practice can be stimulated by a physician faculty member questioning a trainee regarding a case or discussing patient care issues and feelings of uncertainty. Other learning methods such as small group discussions, group debriefings, team-based reflections and critical incident analysis can also elicit reflective thought (Cheethan \& Chivers, 2001; Rolfe et al., 2001). However, Cheethan and Chivers (2001) stipulate that in order for collaborative reflection to occur, a suitable framework and process need to be in place. Although the above methods of evoking reflective practice contain a social context, they still require the individual to think about his or her experiences to gain new insight or knowledge.

In Schön (1978, 1987), Argyris (1978) and Dewey’s (1933) work, reflective practice is primarily viewed to be an individual process. In Schön and Argyris' single and double-loop learning, it is the individual that reflects on prior experiences to impact future experiences or organizational norms, strategies and assumptions. Schön (1987) 
Reflective Practice and Readiness for Self-directed Learning

theorizes that it is an individual's reflection-in-action and reflection-on-action that leads to a change in action the next time an individual faces the same or similar experience. Schön stipulates that during reflection-in-action the learner is in conversation and has a transactional relationship with the experience rather than other people. Similarly, Dewey (1933) contends that reflection is a process led by the learner wherein reflection is the learners "active, persistent and careful consideration of any belief or supposed form of knowledge in the light of the grounds that support it and the further conclusion to which it tends"' (p. 9).

\section{Development of self-directed learning.}

The idea and study of self-directed learning (SDL) has a long and rich history. Brockett and Hiemstra (1991) contended that the notion of SDL, which includes several other name iterations, has been around since ancient Greek times. Guglielmino, Long and Hiemstra (2004), in their account of the history of SDL research, asserted that it was Houle's work in 1961 that really laid the groundwork for much of the research that exists about SDL. Houle (1961), said to be the founder of the first doctoral program in adult education, conducted a qualitative study of 22 adult learners. His work concluded that there were three types of adult learners 1) goal-oriented, those who participate mainly to achieve some end goal; 2) activity oriented, those who participate for social reasons; 3) learning-oriented, those who perceive learning as an end in itself. The third group, learning-oriented, has been identified as self-directed learners in later research conducted by Guglielmino, Long and Hiemstra (2004). 


\section{Reflective Practice and Readiness for Self-directed Learning}

Houle contributed to SDL theory development beyond the scope of his work. He served as a doctoral advisor to two other well known SDL researchers. The first researcher Houle worked with was Malcolm Knowles. Knowles (1970) introduced the concept of andragogy to the United States and in his seminal work titled Modern Practice of Adult Education he asserts that adults are self-directed in areas of their lives and therefore also want to be self-directed in their learning. According to Guglielmino et al. (2004), Knowles' definition of SDL is the most cited and quoted definition. Knowles' (1975) definition of SDL:

"In its broadest meaning, "self-directed learning" describes a process in which individuals take the initiative, with or without the help of others, in diagnosing their learning needs, formulating learning goals, identifying human and material resources for learning, choosing and implementing appropriate learning strategies, and evaluating learning outcomes" (Knowles, 1975, p.18).

Houle's second student and major contributor to SDL literature was Allen Tough. Tough (1971) conducted an in-depth study of 66 adult learners from various backgrounds which lead to the development of an interview protocol that many researchers use today. Through his research he shattered the traditional notion of how adults learn, through formal class work, and argued that adults participate in learning through various aspects of their life. In his interviews of 66 adults, he discovered that all but one was involved in learning projects. Less than $1 \%$ of the learning projects were done as part of formal academic work and 68\% were self-planned (Tough, 1971, 1979). Tough $(1971,1979)$ 


\section{Reflective Practice and Readiness for Self-directed Learning}

states that $70 \%$ of all learning projects are self-initiated and the rest rely on instructors, private lessons or some other form of learning. Tough's work on self-directed learning looked at all cases of self-directed learning including learning for personal interest and enjoyment.

Hiemstra (1975) also made significant contributions to the body of SDL research. Following Tough's interview protocol, Hiemstra (1975) interviewed 256 older adult learners to explore barriers to learning and how older adults learn. In 1980 and 1982 Hiemstra published several articles on policy recommendations regarding self-directed learners and implications for practice (Guglielmino et al. 2004). In 1991, Brockett and Hiemstra provided a comprehensive survey and analysis on the literature related to selfdirected learning. From their review, they developed the Personal Responsibility Orientation (PRO) model for self-directed learning. The PRO model sought to outline the differences and similarities between self-directed learning as an instructional method and personality characteristic. The Major points to the PRO model are (Guglielmino et al., 2004):

1) individuals taking responsibility for their own learning is central;

2) self-direction can be seen as both an instructional method and a personality characteristic; and

3) the social context in which learning takes place is important.

Building on the work of the previous SDL researchers, Guglielmino (1977) developed the Self-Directed Learning Readiness Scale/Learning Preference Assessment 
Reflective Practice and Readiness for Self-directed Learning

(SDLRS/LPA). The SDLRS/LPA was developed to measure a learner's readiness to engage in self-directed learning. Various forms of the SDLRS/LPA have been used in hundreds of research studies and in over two dozen countries and are considered to be the most widely used and accepted measures of self-directed learning in adults (Brockett \& Hiemstra, 1991; Guglielmino et al., 2004).

\section{Self-directed learning in medical education.}

In the medical field, in particular, self-directed learning skills are important because medical knowledge is constantly changing and advancing. Being able to attend to one's own learning needs in order to remain current on best practices and medical innovations is an important part of increasing desirable patient safety outcomes (Ainoda,

Onishi \& Yasuda, 2005). Chastonay, Brenner, Peel and Guilbert (1996) contend that SDL is one way to efficiently approach the continuum of medical education. Although medical literature suggests that SDL is an important trait for physicians to possess, little is known about how to develop this trait during clinical training (Li et al., 2010).

Nurse education was one of the first medical fields to embrace SDL curriculum. O'Shea (2003) conducted a comprehensive review of the literature on SDL in nurse education and found that nurse education programs are moving away from didactic teaching and placing an increased importance on self-directed learning. The literature reviewed by O'Shea outlined that self-directed learning has several benefits for medical professions including increased confidence, autonomy, motivation and preparation for lifelong learning. Nurse education has implemented a plethora of educational methods 
Reflective Practice and Readiness for Self-directed Learning

designed to intentionally increase self-directed learning in nursing students, with positive outcomes including portfolios, online learning modules, and self-reflection (RileyDouchet \& Wilson, 1997; Williams, 2001).

Some resident education models have also been designed to implement learning methods meant to increase a learner's propensity for self-directed learning. A group of researchers used Guglielmino’s (1977) SDLRS/LPA to measure resident's perception of their readiness for SDL before and after the implementation of an internet-based learning portfolio (Fung Kee Fung et al., 2000). The researchers found the internet-based learning portfolio had significant increases on a residents' perception of their readiness to engage in SDL. Other studies on resident readiness for SDL have found that implementing curricula specifically designed to improve SDL, such as portfolios, reflection exercises, goal articulation and web-based learning modules is positively associated with an increase in SDL tendencies (Bravata, Hout, Abernathy, Skeff \& Bravata, 2003; Schilling, Steiner, Lundahl \& Anderson, 2005).

Studies that have looked at medical students' readiness for SDL have focused on the undergraduate medical student curriculum. Problem-based learning (PBL) curriculum is one approach to medical education that has garnered a lot of recent attention (Schmidt, Vermeulen \& van der Molen, 2006). Shokar, Shokar Romero and Bulik (2002) examined 182 third-year medical students participating in problem based learning (PBL) curriculum at a large academic medical center. They used the SDLRS/LPA to measure the level of readiness for self-directed learning among medical students participating in PBL 
Reflective Practice and Readiness for Self-directed Learning

curriculum during their first two years of medical school. Shokar et al. (2002) found that students exposed to PBL took greater initiative and control of their learning activities including exhibiting a higher tendency to spontaneously read extra material compared to those students not participating in a PBL curriculum. Further, the students in Shokar et al.'s study engaged in more self-directed learning than their counterparts by asking more questions in and out of the classroom. Schmidt et al., (2006) sent a questionnaire to all medical graduates who graduated in the Netherlands since 1980 to determine if a difference existed between those who participated in PBL curriculum and those who did not. The study concluded that the graduates who participated in PBL curriculum scored themselves higher in 14 of 18 competencies, including problem solving skills, research skills, use of information resources, ability to work independently and self-directed learning than those who did not participate in a PBL curriculum.

\section{Gaps in the self-directed learning literature.}

More work needs to be done to find the best possible method to help medical trainees learn how to engage in self-directed learning. A recent study of residents demonstrated that they were engaged in less than eight hours of self-directed learning per week, which Dinkevich and Ozuah (2003) contended were not an adequate amount of to prepare residents for self-directed learning after completion of training. Medical educators have articulated a need to improve resident training in self-directed learning, but the best methods of providing such training have yet to be discovered (Sparling, 2001). 
Reflective Practice and Readiness for Self-directed Learning

Other gaps also exist in the self-directed learning literature. Caffarella and O’Donnel (1991) recommend that the relationship between SDL and group or peer interactions should be explored. Important particularly for medical training, Brockett (as cited in Merriam, 2001) called for a review of how power differentials and various practice settings impact self-directed learning. Thorough review of the PBL literature shows that these gaps still exist.

\section{Theory and Development of Reflective Practice}

Reflection is a broad term and has been defined differently across multiple disciplines and by multiple people. Although the practice of reflection has been broadly defined and used, it has its roots in the work of John Dewey (1933) and Donald Schön (1983). The notion of reflection was first discussed in 1933 by John Dewey. Dewey (1933) defined reflection as "active, persistent and careful consideration of any belief or supposed form of knowledge in the light of the grounds that support it and the further conclusion to which it tends"' (p. 9). He further theorized that reflective thought is brought on by an event in one's life that causes doubt, perplexity or uncertainty and leads an individual to search for solutions or explanation. He described a five-stage process that individuals go though that comprises his notion of reflective thought. The five stages as described by Dewey (1933) are 1) doubt, perplexity or uncertainty due to difficulty in understanding an event or solving a problem, 2) defining the difficulty by understanding the nature of the problem, 3) proposing a possible explanation or solution for the problem through inductive reasoning, 4) rational elaboration of ideas and deductive thought 


\section{Reflective Practice and Readiness for Self-directed Learning}

focusing on their implications and 5) testing the hypothesis by obvious or imaginative action.

Theorist Donald Schön (1983) built upon Dewey's work on reflection. Schön studied the notion of reflective practice in professional fields including engineering, medicine, business and teaching. Schön stipulated that the knowledge base of a profession is thought to have four essential properties including being specialized, firmly bounded, scientific and standardized. He suggested that this type of thinking leads to gaps between theory and professional practice. Schön further argued that "general principles" taught in the classroom setting are considered by society as being more important than “concrete problem solving" and that educating professionals with scientific theory and general principles does not adequately prepare professionals for practice. He described the gap between theory and practice by stating: "On the high ground, manageable problems lend themselves to solution through the application of researched-based theory and technique. In the swampy lowland, messy, confusing problems defy technical solutions" (1987, p.3). He referred to this gap in his review of medical education stating:

"The separation of the medical school curriculum into two distinctive stages, the preclinical and the clinical reflects the division between theory and practice. The division also appears in the location of training and in medical school facilities. The sciences of biochemistry, physiology, pathology and pharmacology are learned from classrooms and laboratories, that is, in formal academic settings. More practical training, 
Reflective Practice and Readiness for Self-directed Learning

in clinical arts such as internal medicine, obstetrics and pediatrics, takes place in hospital clinics, within actual institutions of delivery" (Schön, 1987, p28).

To help mitigate the gap between theory and practice, Schön (1983) defined what he called reflection-in-action and reflection-on-action. Both reflection-on-action and reflection-in-action were a direct rebuttal to what Schön called "Technical Rationality." The term technical rationality refers to a traditional method of professional training that involves "filling" student's brains with knowledge from books and teachings from a traditional classroom setting and sending the student out into the world to practice. Schön believed the technical rationality method of training professionals was inadequate and identified reflection-on-action and reflection-in-action as more fundamental sources of knowledge. Similar to Dewey's theory of reflection, Schön theorized that the reflectionin-action and reflection-on-action take place when a practitioner experiences surprise, confusion or uncertainty and seeks to build new understandings to inform future actions. Schön states:

"The practitioner allows himself to experience surprise, puzzlement, or confusion in a situation which he finds uncertain or unique. He reflects on the phenomenon before him, and on the prior understandings which have been implicit in his behavior. He carries out an experiment which serves to generate both a new understanding of the phenomenon and a change in the situation" (Schön, 1983 pg. 68). 


\section{Reflective Practice and Readiness for Self-directed Learning}

Reflection-in-action occurs when a practitioner reflects upon their practice while still engaging in an activity. Many people consider this type of reflection as "thinking on your feet”. Schön hypothesized that it is important to think on your feet because every situation is unique and that drawing from previous experiences will help individuals inform decisions that need to be made immediately. Reflection-in-action is done by the individual engaging in the action whereas reflection-on-action is done by an individual as well but with the help of a group, mentor or a more senior practitioner. Reflection-onaction occurs after an event and is intended to allow individuals time to explore their actions and develop questions and insights about their actions in order to grow professionally.

Another contribution to the literature on reflective practice, briefly described earlier in this chapter, is Schön and Argyris' (1978) single-loop and double-loop learning (Figure 2). Schön and Argyris believed that learning involves the detection and correction of error through reflection. In single-loop learning, a person evaluates his or her performance through simple reflection and then corrects or improves their performance based on and working within the confines of known variables, rules and assumptions. Single-loop learning is best used to solve easy tasks performed on a daily basis. Schön and Argyris (1978) described double-loop learning as a means to solve complex, illstructured and evolving tasks. Double-loop learning involves a higher level of reflection compared to that of single-loop. In double- loop learning, a person not only reflects upon the technical aspects of completing a task but they also reflect upon the governing 
Reflective Practice and Readiness for Self-directed Learning

variables, rules and assumptions. Double-loop learning requires a person go beyond simple reflection, looking at only success and failure, to a deeper reflection on the validity and usefulness of beliefs and governing variables.

Figure 2. Schön \& Argyris' (1978) Double-loop and Single-loop Learning

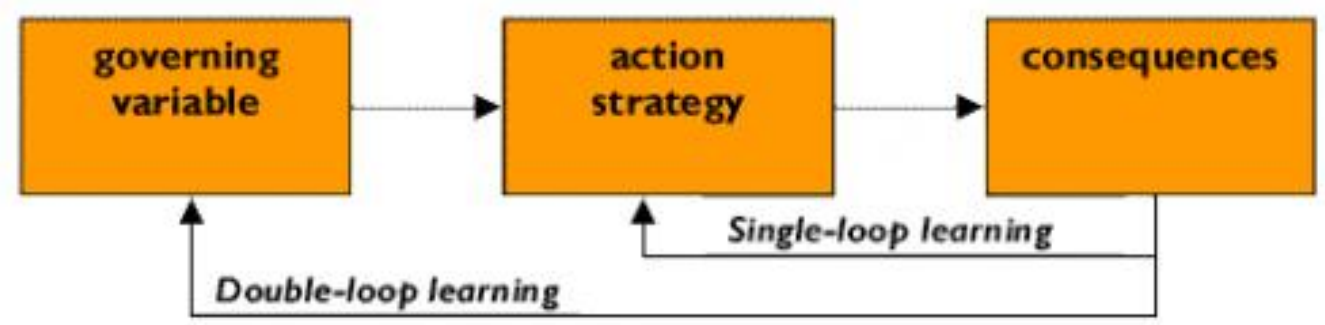

Figure 2. Adapted from Argyris, C., Schon, D. A. (1978). Organizational learning: A theory of action perspective. Reading, MA: Addison-Wesley.

Although Schön produced several seminal works on how professionals learn through reflection, the term reflective practice lacked a widely accepted definition. In 1993, Atkins and Murphy conducted a meta-analysis of literature about reflective practice in order to help define the meaning of reflective practice. Of the many definitions, they found that three common elements exist as being essential to reflection. The first element is an event that triggers reflection which typically embodies some type of uncomfortable thought or feeling. The second element is the critical analysis of the thought or feeling and lastly, the third element is discovering a new perspective based on the critical analysis. The elements as defined by Atkins and Murphy (1993) are similar to ideas presented by both Schön (1983) and Dewey (1933). 


\section{Reflective Practice and Readiness for Self-directed Learning}

Mamede and Schmidt (2004) conducted a study to determine the nature of reflective practice in medicine. They surveyed 202 primary care doctors using a selfreport instrument. Their study found that reflective practice takes place through no more and no less than a 5 component process. The 5 components Mamede and Schmidt (2004) outlined are 1) deliberate induction where a practitioner takes time to generate alternative explanations for an unfamiliar problem, 2) deliberate deduction in which a practitioner may logically deduct the consequences of multiple hypotheses from step 1, if multiple hypotheses are generated, in order to come up with the best one 3) testing the hypothesis against the problem at hand 4) possessing an attitude that is open towards reflection and 5) meta-reasoning which is defined as the ability to critically review one's own beliefs about a problem or situation. According to Mamede and Schmidt (2004) these components are not intended to be linear but that all need to be present in order for a physician to engage in reflective practice.

Although reflective practice carries many definitions, there are common themes throughout. For the purpose of this paper I will utilize the definition Bennett et al. (2006) developed which asserts that reflective practice is thoughtful knowledge acquisition after a practitioner experiences an unexpected phenomena that helps her gather information, integrate relevant ideas, and evaluate results to incorporate new practices into her existing practice. 
Reflective Practice and Readiness for Self-directed Learning

\section{Experiential learning and reflection.}

Having an experience alone is not enough to induce learning. Gibbs (1988)

theorized that without reflection, an experience may be forgotten and therefore the potential to learn from the experience is lost. Reflection draws out feelings and thoughts that emerge from a particular experience and it is the act of reflection that allows generalizations or concepts to be derived from an experience. The generalizations and concepts are what allow a learner to effectively deal with new experiences (Gibbs, 1988). Therefore, Gibbs (1988) theorized that experience and reflection are vital to the learning process.

Gibbs' (1988) model of reflection is based on an educational framework of experiential learning as described by Kolb (1984). Gibbs' model of reflection is a dynamic and cyclical process. Gibbs stated that, for learning to occur, learners need to be open to the reflective process. Gibbs contended that reflection takes place through a sequence of six steps. Gibbs' six steps of reflection are presented in Figure 1. 


\section{Reflective Practice and Readiness for Self-directed Learning}

Figure 3. Gibbs' (1988) Model of Reflection

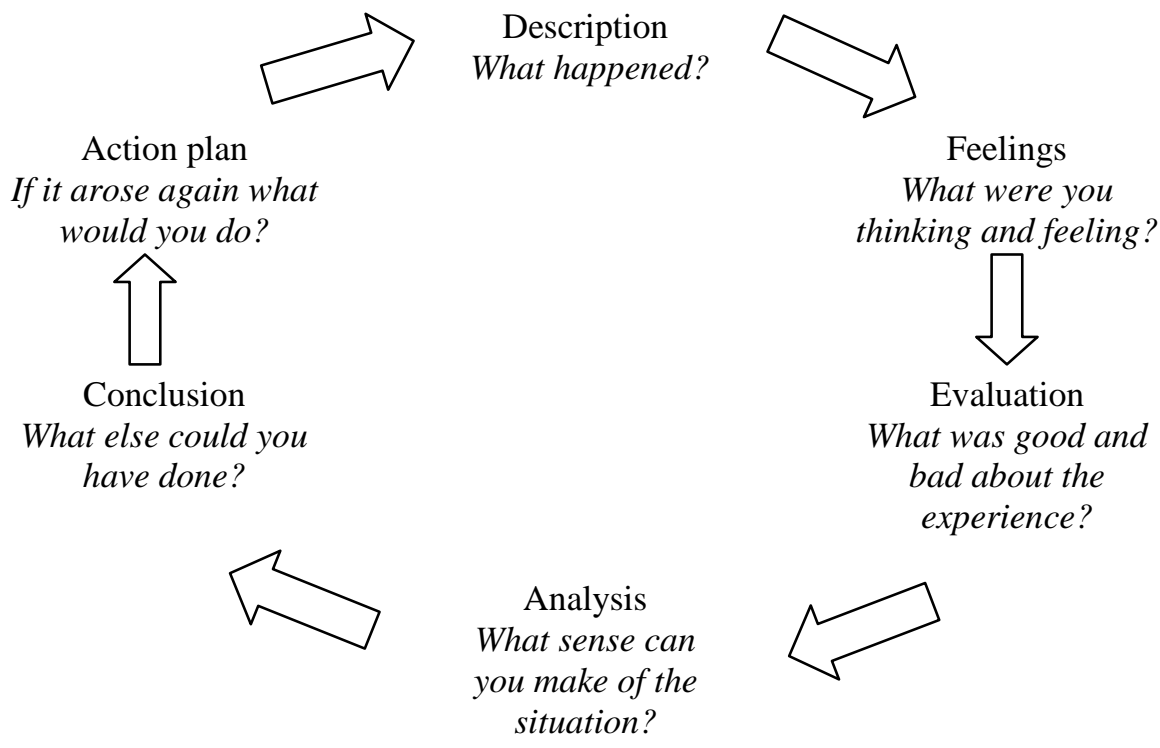

Figure 3. Adapted from Gibbs, G. (1988). Learning by doing: A guide to teaching and learning methods. London: Further Education Unit.

In the first step, Gibbs' (1988) model prompts participants to describe the event upon which they want to reflect. The second step dictates participants describe the feelings that manifested when the event occurred. The next step involves participants evaluating the event including reflecting upon what was good about the event and what was bad about the event. In step 4, the analysis, participants are asked to describe what sense they could make of the event i.e. what is the participants interpretation of the event or experience. Step 5, conclusion, participants are asked to describe what else they could have done to influence the outcome of the event. The last step involves making an action plan about what the learner would do if the event happened again. Jasper (2003) states 


\section{Reflective Practice and Readiness for Self-directed Learning}

that Gibbs' model does not adequately prompt the learner to reflect on what actions need to be taken to carry out their action plan.

Gibbs' (1988) model of reflection is a seminal theory and is included in most research on reflective practice conducted in the last 15 years (Jasper, 2003). Gibbs' model is unique in that it has the learner reflect on her feelings as well as the details of the event. The cyclical nature of Gibbs' model is also unique in that many models of reflection are linear (Bulman \& Schutz, 2004). Although Gibbs' model has been widely used, it has not been fully accepted without criticism.

Gibbs' (1988) model of reflection is underpinned by Schön's (1983) theory of reflection in and on action and Schön and Argyris' (1978) single and double-loop learning. Schön's model of reflection in and on action and Schön and Argyris' single and double-loop learning dictate that a high level competence in reflective practice is needed in order for a practitioner to reflect in a way that allows the practitioner to change their practice. Schön and Argyris' single and double-loop learning stipulates that the learner has to go beyond just reflecting on a task, considering governing rules and assumptions, in order to deeply reflect on current practice and make changes to future practice. As such, Gibbs' (1988) model has been criticized for the lack of attending to a novice or an incompetent learner's ability to reflect. Burton (2000) stated that a novice or incompetent learner should not use Gibbs' (1988) model alone when reflecting. Burton asserted that novice or incompetent learners should use tools, such as reflective journals or case studies, either along side of or instead of Gibbs' model. 
Reflective Practice and Readiness for Self-directed Learning

Rolfe, Freshwater and Jasper (2001) refuted the likelihood of Gibbs’ (1988) model to promote reflective practice beyond stage 1 due to the generic and unspecific prompts provided to guide reflective practice. Rolfe et al. also stated that the focus of Gibbs' model is poised to help learners learn from experience rather than change the experience in the future. Another critique of Gibbs' model is that it is too remedial for high level practitioners and that reflection tools should help learners look at both macro and micro levels of reflection (Rolfe et al. 2001). Lastly, Johns (1994) stated that merely using a structured model of reflection may not be enough to change practice, but rather learners should adapt and develop their own models to elicit reflective thought.

\section{Kolb's model of experiential learning and its relation to reflection.}

David Kolb (1984) developed the theory of experiential learning drawing heavily from the works of John Dewey, Jean Piget and Kurt Lewin. Kolb (1984) described adult learning as cyclical process in which knowledge is created through the transformation experience. Depicted in figure 2, Kolb's model sets out a four-stage cycle where learners can start at any one stage however each stage must follow the other in sequence: 
Reflective Practice and Readiness for Self-directed Learning

Figure 4. Kolb's (1984) Model of Experiential Learning

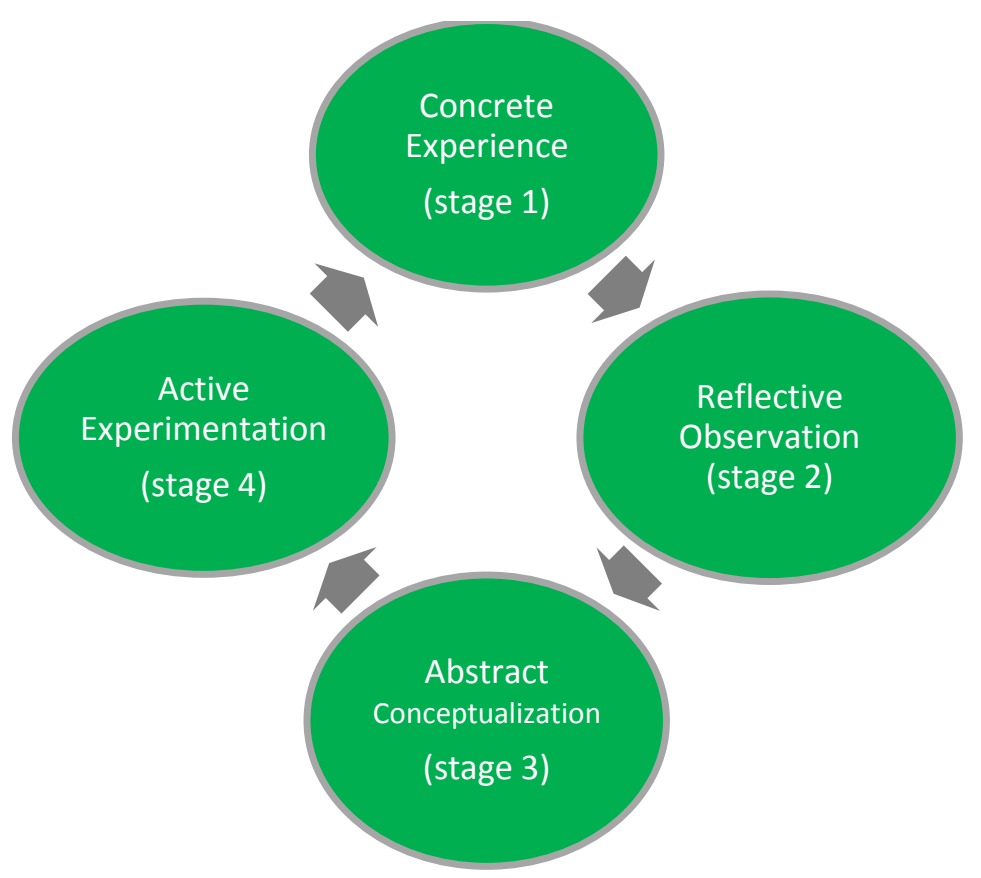

Figure 4. Adapted from Kolb, D. A. (1984). Experiential learning: Experience as he source of learning and development. Englewood Cliffs, N.J.: Prentice-Hall, Inc.

In stage one, concrete experience, a learner actively experiences an activity or situation such as an event that happened in the operating room, with a patient or an interaction that took place between the surgical team and the trainee. The theory dictates that stage one, concrete experiences are the basis for step two, reflective observation. In step two, the learner consciously and actively reflects on the experience that occurred in stage one. The reflections from step two are assimilated into abstract concepts where the learner tries to conceptualize a theory or model to help explain what was observed during reflective observation. In the final stage, active experimentation, the learner actively tests 


\section{Reflective Practice and Readiness for Self-directed Learning}

the theories and models developed in stage three which serves as a guide in creating and reacting to new experiences.

Kolb, Boyatzis and Mainemelis (1999) conducted a comprehensive review of literature focusing on experiential learning. They found that Kolb's (1984) theory of experiential learning was a useful framework in developing educational interventions including those that focus on lifelong learning. However, Seaman (2008) contended that Kolb's interpretation of Dewey's work was incorrect and the mere concept of an immediate, concrete experience is not epistemologically sound, meaning that Kolb's model narrowed "experiencing and learning" to one concrete experience rather than a continuum of events. Miettinen (2000) concluded that Kolb did not illustrate that empirical thinking based on action has its limitations including:

1) It may result in false conclusions

2) It may not help the learner understand and explain changes in new experiences

3) It may cause mental laziness and inflexible thinking

4) The affects of reflective practice on learning outcomes/self-directed learning Although Kolb's model of experiential learning has been critiqued, it remains one of the most widely recognized and utilized learning models in education (Kolb et al., 2000). Kayes (2002) contends that Kolb's model is one of the only learning models that is comprehensive and has the ability to be generalized for use across disciplines. Kolb's model of experiential learning dictates that reflection is an essential function of the adult learning process. In order to understand how reflection can be utilized for increased 
Reflective Practice and Readiness for Self-directed Learning

learning in the medical profession, a review of the literate on reflection in healthcare is warranted.

\section{Reflection in healthcare.}

The health care environment is rapidly changing. New technologies, techniques and patient morbidities are being introduced into the medical culture every day.

Physicians cannot rely on basic skills gained early in their medical training to sustain competency throughout his or her career (Horsley, O’Neill, McGowan, Perrier, Kane \& Campbell, 2010). Reflection helps physicians find gaps in their knowledge and attend to

their learning needs to meet the ever changing realities of medicine (Westberg \& Hilliard, 2001). In her 2003 article outlining ways to strive for excellence in medical practice, Plack (2005) stated that reflection allows learners to recognize their limits of knowledge which leads to further exploration of their practice. She further argued that the continuous practice of reflection encourages physicians to learn throughout their lifetime.

In 2001 the Accreditation Council for Graduate Medical Education (ACGME) unveiled a new outcomes project that every accredited graduate medical education program in the United States is required to participate. The outcomes project dictates that trainees need to be competent in six core competencies before graduating from his or her training program to practice medicine independently. One of the core competencies, practice based learning and improvement, prescribes that residents must demonstrate the ability to reflect upon their practice utilizing constant self-evaluation to improve patient care skills and ensure lifelong learning (Accreditation Council for Graduate Medical 


\section{Reflective Practice and Readiness for Self-directed Learning}

Education, 2010). Because of the outcomes project institutions have looked at self reflection as a key component for professional development (Davis et al., 2006).

Reflection has not only been linked to lifelong learning practices, but it has been associated with perceptions of higher quality patient care. Clouder (2000) conducted a study that employed qualitative interviews and workshops to determine how reflective practice was conceptualized and used by students and practitioners in the medical field. Her findings outlined several broad themes including practitioners and students used reflective practice to benefit their patients and improve upon their patient care. In 2001, Glaze explored reflective experiences with 14 nurse practitioner students. Students completed two reflective practice exercises, one prior to entry into the program and one during the training period. The reflective practice exercises were progressive and included using simple problem solving to using more complex theory and literature to analyze patient care scenarios. Students in Glaze's study were asked to keep reflective journals and were interviewed about their reflective practice experiences. The interviews revealed the nursing students perceived improvement of clinical practice through reflection. The improvement in clinical practice was viewed by the nursing students as a way to make nurses more thoughtful, have increased awareness of uncertainty and to underscore that there is not always one right answer to solving a problem. Other studies have reported that reflection enhanced perceptions of competence and critical thinking and judgment in complex situations, which thereby enhanced perceived quality of patient care (Paget, 2001; Platzer, Blake \& Ashford 2000; Riley-Doucet \& Wilson, 1997). 
Reflective Practice and Readiness for Self-directed Learning

Therefore, one possibility to aid physicians in becoming safer practitioners is to teach them how to reflect so they can better identify their limitations and learning needs (Stewart, O’Halloran, Barton, Singleton, Harrigan \& Spencer, 2003).

\section{The importance of teaching reflection.}

Although reflection is important for professional growth and patient safety not all physicians engage in reflective practices. Mamede and Schmidt (2004) found that some physicians engage in reflective practices quite often while others almost never do.

Stewart et al. (2003) conducted a qualitative study to look at the nature of confidence and competence in a medical training program. They found that trainees were unable to accurately assess their competence but able to accurately reflect upon their performance and gaps in knowledge. They further concluded that a trainee who reflects upon his or her performance will know their limitations in regards to patient care and that those who were over confident and unable to reflect upon their practice will undertake unnecessary risks when caring for patients. These risks could lead to poor patient outcomes including mortality.

Teaching students how to reflect upon their experiences helps increase their desire to learn and reflection has been shown to help students take more responsibility for their learning (Elwood \& Klenowsli 2002; Riley-Doucet \& Wilson, 1997; Shepard 2000). In 2000, Sobral studied 103 medical students to assess self-regulated learning as it related to reflection. He found that students garnered a greater benefit from course materials and enjoyed their medical studies more if they reflected upon their learning than if they did 
Reflective Practice and Readiness for Self-directed Learning

not reflect upon their learning. Cox (2005) studied adult learners who used self-guided reflection as part of their course curriculum to explore how refection impacted what they learned. Cox found that students using guided reflection learned more independently then students not using reflective practice.

Medical practitioners practice in isolation, free from continuous feedback from observers or peers. Being able to reflect on practice allows physicians the opportunity to learn from their actions rather than having to be evaluated by peers. Ward et al. (2002) asserted that medical practitioners are self-regulating and that to hold the values true to medicine, they need to recognize, independently, their capabilities and limitations. Recognizing their capabilities and limitations may help physicians provide the highest quality patient care.

\section{Gaps in the reflective practice literature.}

The definition of reflective practice has been redefined by authors from various disciplines and by various practitioners from around the globe (Clouder, 2000; Loughran, 2002; Mamede \& Schmidt, 2005; Ruth-Sahd, 2003; Sobral, 2000). One of the major criticisms of the two seminal pieces of work, one by Dewey (1933) and one by Schön (1987) is that they failed to succinctly define or offer a framework for reflective practice. In general the definitions, terms, concepts and framework describing the notion of reflective practice, at a very basic level, lack clarity (Mackintosh, 1998). In order to see the true impact of reflective practices, researchers should work together in order to 


\section{Reflective Practice and Readiness for Self-directed Learning}

promote a better understanding of the meaning of and a framework for studying reflective practice.

Much of the literature on reflection is theoretical in nature. Few empirical studies have been conducted to support the theories about reflective practice and its impact on learners (Duke \& Appleton, 2000; Ruth-Sahd, 2003). When empirical evidence about reflective practice does exist, it is usually qualitative in nature, which is in direct contrast to the underpinnings of medical teaching where quantitative, number driven data is often seen as more valuable (Mays \& Pope, 2000). More empirical studies need to be conducted in order to appropriately test theory and come to conclusions about how reflection can be utilized to assist with the learning process.

Also missing from the literature on reflective practice is consideration of the differences of reflection-in-action and reflection-on-action as defined by Schön (1987). One process, reflection-in-action is highly driven by an individual process whereas reflection-on-action is driven by a mentor or more senior professional trying to help a novice professional grow within their field of practice. Knowing which one of these processes better facilitates growth, development and self-directed learning can help training programs focus their efforts to best serve their trainees.

Finally, the literature reviewed about reflection did not yield any studies looking at how reflection impacts self-directed learning in medical residents. Although literature exists that theorizes about or helps to explain the role that reflective practice plays in the learning process, much of it is focused on the classroom setting. Very little has been 
Reflective Practice and Readiness for Self-directed Learning

written about reflection in a clinical setting (Plack, 2005; Sargeant, Mann, van der

Vleuten \& Metsemakers, 2008). Additional research by practitioners who are trained in both clinical work and reflection is needed to determine the impact the reflection process has on medical trainees (Plack, 2005).

\section{Summary}

This chapter included a review of the literature on medical education, adult learning theory, self-directed learning and reflection, and as they pertain to this study. The literature reviewed the history and current status of medical education. A discussion concerning the ability to cultivate self-directed, lifelong physician learners within the current structure of graduate and continuing medical education was presented in this chapter. The literature on adult learning theories supported the need for adult learners to learn how to direct their own educational inquiry in order to mitigate gaps in their knowledge and increase their engagement in self-directed, lifelong learning. Chapter 2 concluded by presenting reflective practice as one way to help increase an adult learner's readiness for self-directed learning.

Chapter 3 will outline the methodology used for this study. The context of the methods, research questions and study design will be presented. Next, the chapter will outline participant engagement and demographics. The study instruments, procedures and general methods for data analysis will conclude chapter 3. 


\section{Reflective Practice and Readiness for Self-directed Learning}

\section{Introduction}

\section{Chapter 3}

The purpose of this study was to investigate the effects of reflective practice on readiness for self-directed learning in anesthesiology residents, as measured by Guglielmino's (1977) SDLRS/LPA. This chapter outlines the methods used to answer the main and secondary research questions. The study context, research questions to be addressed in this study, study design and description of participant recruitment, selection and engagement are presented. This chapter also details the instruments used in this study, the data collection methods, the researcher's role in this study, and the techniques that were used to analyze the data. The chapter concludes with a summary.

\section{Context}

The medical specialty of anesthesiology was chosen for this study for two reasons. The first reason anesthesiology was chosen is that the researcher works in a professional capacity for an anesthesiology training program at an Academic Medical Center (AMC), thus making anesthesiology residents more accessible to her than residents training in other specialties. The second reason anesthesiology was chosen is the nature of anesthesiologist practice. In general, anesthesiology physicians practice in isolation with little peer interaction taking place during their clinical work (Rose \& Brown, 2010). Because of this limited peer interaction, anesthesiologists are less likely to experience peer feedback to help them assesses their skills and potential gaps in knowledge, therefore giving anesthesiologists the skills needed to accurately reflect upon their practice may help them engage in self-directed, lifelong learning. 
Reflective Practice and Readiness for Self-directed Learning

Because this study sought to determine if a self-guided reflective practice exercise would increase the propensity for self-directed learning, the design of this study did not allow for programs already engaging their residents in formal reflective practice, to participate. Before programs solicited participation from their residents, the researcher asked the residency coordinator of each participating program if his or her program engaged in formal self-directed reflective practice exercises as part of the program curriculum. None of the programs solicited to participate in this study used self-directed reflective practice in their program curriculum.

\section{Research Questions}

Two research questions drive this study 1) Does reflective practice affect readiness for self-directed learning in anesthesiology residents? and 2) Does exposure to reflective practice affect anesthesiology residents' attitudes about reflective practice and the propensity to engage in future reflective practice? Several secondary questions will help further guide this study. Secondary questions 1 through 4 were developed to help answer research question 1 and secondary questions 5 through 7 were developed to help answer research question 2 . The research questions with associated secondary questions are listed below.

Research Question 1: Does reflective practice affect readiness for self-directed learning in anesthesiology residents?

Secondary Question 1: Do the pretest scores of the experimental group and control group 
Reflective Practice and Readiness for Self-directed Learning differ from the average SDLRS/LPA score reported by Guglielmino?

Secondary Question 2: Do the posttest SDLRS/LPA scores differ between the control group and experimental group?

Secondary Question 3: Do students' SDLRS/LPA scores before participating in reflective exercises, based on Gibbs' (1988) model of reflection, differ from the scores after participation?

Secondary Question 4: Are changes in pretest and posttest scores associated with participant characteristics or participation in reflective exercises?

Research Question 2: Does exposure to reflective practice affect anesthesiology residents' attitudes about reflective practice and the propensity to engage in future reflective practice?

Secondary Question 5: Do participants in the control group and experimental group differ on whether they engaged in reflective practice after the conclusion of the reflective exercises?

Secondary Question 6: Do participants in the control group and experimental group differ in reporting that they plan on engaging in reflective practice in the future? 
Reflective Practice and Readiness for Self-directed Learning

Secondary Question 7: Do participants in the control group and experimental group differ on their attitudes about reflective practice?

\section{Study Design}

This study utilized an experimental design and employed quantitative methods to answer the main and secondary research questions. An experimental design is one in which the researcher studies the impact of an intervention on study participants. Key characteristics of an experimental design are random assignment of participants to a control group or experimental group, utilization of pretests and posttests and identifying outcome measures (Creswell, 2003). Participants in this study were randomly assigned to either an experimental group or control group and the researcher utilized a pretest and posttest in order to better understand the impact of the intervention. The experimental group in this study was exposed to an intervention, once per week, for eight weeks whereas the control group received no intervention.

\section{Intervention tool: Gibbs' model of reflection.}

The theoretical framework for this study's intervention was Gibbs' (1988) model of reflection. Gibb's model includes prompts to help guide participants assigned to the experimental group through a reflective exercise. Gibbs' (1988) model is based on the educational framework of experiential learning as described by Kolb (1984). Gibbs contended that reflection takes place through a sequence of six steps. Gibbs' six steps of reflection are (Figure 3):

1) Description - What happened? 


\section{Reflective Practice and Readiness for Self-directed Learning}

2) Feelings - What are you thinking and feeling?

3) Evaluation - What was good and bad about the experience?

4) Analysis - What sense can you make of the situation?

5) Conclusion - What else could you have done?

6) Action Plan - If it arose again what would you do?

Participants assigned to the experimental group used Gibbs' (1988) model of reflection to help them reflect, one time per week, upon incidents that occurred during a consecutive eight-week period. John Dewey (1933) hypothesized that reflective thought is brought on by an event in one's life that causes doubt, perplexity or uncertainty. Therefore, for the current study, the self-guided reflective exercise tool instructed participants to reflect on an incident that occurred during the current week and within the scope of their residency training and that caused the participant to experience doubt, perplexity or uncertainty.

Participants engaged in the reflective exercise in a self-directed manner with no directions other than those directions included on the reflective exercise. The reflective exercise (Appendix B) was based upon the six steps in Gibbs' (1988) reflective model. Jasper (2003) stated that Gibbs' model does not adequately guide the learner to reflect on what actions need to be taken in order to carry out their action plan. Therefore, for this study, the researcher added two questions to the final step in Gibbs' model to guide the participant to explicitly reflect on the knowledge and skills they needed to carry out their action plan. The two questions were: 1) What skills or information, if any, do you need to 


\section{Reflective Practice and Readiness for Self-directed Learning}

learn/acquire to carry out your action plan? and 2) How would you learn/acquire the skills/information previously mentioned?

The directions for the reflective exercise (Appendix B) were indicated at the top of the reflective exercise provided to each participant each week. Specifically, the directions for the reflective exercise were as follows:

"The questions below are intended to help guide you through a reflective exercise. Please choose one event that took place this past week, within the scope of your residency training that caught you by surprise, caused you confusion or made you feel uncertain about what you were doing. Please answer the questions below to help guide you through the reflective exercise."

The first question on the reflective exercise asked participants to describe the event upon which they want to reflect. The second question directed participants to describe the feelings that manifested when the event they described in the first question occurred. Next, participants were asked to evaluate the event that they reflected on which included reflecting upon what was good about the event and what was bad about the event. In question 4, the analysis, participants were asked to describe what sense they could make of the event. Question 5 directed participants to describe what else they could have done to impact the outcome of the event. The last question asked the participant to make an action plan about what he/she would do if the event were to happen again including what skills?" or information, if any, did the participant need to learn/acquire to 
Reflective Practice and Readiness for Self-directed Learning

carry out their action plan and how the participant would learn/acquire the skills/information previously mentioned.

\section{Participants}

This study included anesthesiology residents from three residency programs in the United States, including one program on the east coast, one on the west coast, and one in the midwest. Each residency program is housed at a large public hospital, and a total of 247 residents train in all three programs combined. This study solicited participation from residents varying in age, year in training, medical degree, gender and ethnicity.

\section{Recruitment.}

Participants were recruited by utilizing contacts through Department Chairs of leading academic anesthesiology departments in the United States. The Department Chair at the institution sponsoring this research asked Department Chairs of leading academic medical centers to support their residents' participation in this study. Once a Department Chair agreed to participate, the researcher contacted the administrative program coordinator for the participating program via email in order to solicit resident participants.

The researcher sent all study related materials including the study design, Institutional Review Board (IRB) approved text for a participant solicitation email message (Appendix C) and participant information form (Appendix D) to the program coordinator for each participating program. The text of the email message (Appendix E) to the program coordinator included a short description of the study and a request from 


\section{Reflective Practice and Readiness for Self-directed Learning}

the researcher to send an email message containing the IRB-approved participant solicitation email message and the participant information form to all residents in her respective program. The email message to the program coordinator also included a request for the program coordinator to provide information to the researcher about the residents who volunteered for the study so that the researcher could contact the resident volunteers.

The email message from the program coordinator to her respective residents included the text of the participant solicitation email (Appendix C) as well as an attachment that contained the participant information form (Appendix D). The residents were instructed to respond directly to his or her program coordinator to express interest in participating in the study. Once the program coordinator identified all interested participants, she forwarded participant names, email addresses and selected demographic information to the researcher. A total of 53 names from all three programs were forwarded to the researcher for inclusion in this study.

Residents in their first year of post-graduate medical training (PGY1) were excluded from this study for multiple reasons which included: 1) the curriculum differs greatly between the first year of post-graduate medical training and subsequent years' clinical anesthesia training, 2) at the time of this study and before the 2011 Accreditation Council for Graduate Medical Education (ACGME) duty hour revisions were implemented, first year residents worked extremely long hours which limited the time they had to participate in a multiple week study, and 3) many first year residents do not 
Reflective Practice and Readiness for Self-directed Learning

train at the hospital where their anesthesia residency training program will eventually be located which made it difficult for the researcher to solicit participation from first year residents.

\section{Obtaining participant consent.}

Once the researcher obtained a list of participants from the program coordinator, the researcher emailed the participants to thank them for participating in the study. Attached to the email message was the IRB-approved participant information form (Appendix D) that included the purpose of the study, data collection methods, data analysis methods, procedures for withdrawing from the study and procedures to ensure confidentiality to the participants. Informed consent was implied when the participants choose to engage in the weekly reflective exercises.

\section{Participant demographics.}

A total of 53 residents volunteered to participate in this study. Since this study was experimental in design, participants were randomly assigned to either the control group or the experimental group and all participants had an equal opportunity to be a member of either group. Procedures used to assign participants to either the control group or the experimental group were employed using the following protocol. First, all of the initial 53 participants were alphabetized by last name, and placed into an excel spreadsheet. Next, a random number generator, selected from the World Wide Web, was utilized to randomly order all numbers from 1 to 53. After the numbers were randomly ordered, they were placed next to each participants name in the order the number 


\section{Reflective Practice and Readiness for Self-directed Learning}

appeared in the random number generator (i.e. the first participant in the alphabet received the first number generated by the random number generator). Next, the alphabetized list was resorted into numerical order where the participant with the number 1 next to their name was the first on the list and the participant with 53 next to their name, the last on the list. Finally, the participants were assigned to the control group (i.e., those who would not participate in the reflective exercise) or experimental group (i.e., those who would participate in the reflective exercise) with the first half of the list assigned to the control group and the second half of the list assigned to the experimental group. Although a total of 53 residents volunteered to participate, one participant dropped out after the second week of reflective exercises and one decided not to start the study. Of the remaining 51 participants, 26 were assigned to the control group and 25 were assigned to the experimental group. A participant was considered to have completed the study if he or she participated in at least six of the eight reflective exercises. A total of 25 participants completed at least six of the eight reflective exercises.

The demographics for both the control group and the experimental group were fairly evenly distributed between the two groups with the exception of ethnicity and gender. Of the control group, $31 \%$ (8) reported being non-white whereas only $8 \%$ (2) of the experimental group reported being non-white. Females comprised $31 \%$ (8) of the control group whereas $56 \%$ (14) of the experimental group were females. The remainder of the demographic information of the participants of both the control group and the experimental group is displayed in table 1. 
Reflective Practice and Readiness for Self-directed Learning

Table 1

Demographic Information for Study Participants

\begin{tabular}{|c|c|c|c|c|}
\hline & & Control & Experimental & All Participants \\
\hline & & Freq. $(\% *)$ & Freq. $(\% *)$ & Freq. $(\% *)$ \\
\hline Ethnicity & White & $18(69)$ & $23(92)$ & $41(80)$ \\
\hline & Non-White & $8(31)$ & $2(8)$ & $10(20)$ \\
\hline Age & $25-30$ & $15(58)$ & $13(52)$ & $28(55)$ \\
\hline Range & & & & \\
\hline & $31-35$ & $9(35)$ & $11(44)$ & $20(39)$ \\
\hline & $>35$ & $2(7)$ & $1(4)$ & $3(6)$ \\
\hline Gender & Male & $18(69)$ & $11(44)$ & $29(57)$ \\
\hline & Female & $8(31)$ & $14(56)$ & $22(43)$ \\
\hline Year in & Year 1 & $9(35)$ & $7(28)$ & $16(31)$ \\
\hline Training & & & & \\
\hline & Year 2 & $9(35)$ & $9(36)$ & $18(35)$ \\
\hline & Year 3 & $8(30)$ & $8(32)$ & $16(31)$ \\
\hline & Missing & $0(0)$ & $1(4)$ & $1(2)$ \\
\hline Degree & $\mathrm{MD}$ & $25(96)$ & $24(96)$ & $49(96)$ \\
\hline & $\mathrm{DO}$ & $1(4)$ & $1(4)$ & $2(4)$ \\
\hline
\end{tabular}

Note. * Represents the percentage of total number of participants for that respective group i.e. control vs. experimental vs. all participants. 
Reflective Practice and Readiness for Self-directed Learning

\section{Participant remuneration.}

Studies have shown that participant rates in studies in the US are declining (Steeh, Kirgis, Cannon \& DeWitt, 2001). The participants in this study were offered a monetary incentive to help elicit a high response rate.

Each resident who signed up to participate for the full twelve-week duration of this study received a $\$ 20.00$ Visa check card during week one of the study period. Recent studies have presented data that show participants who are given an incentive before taking a survey, as opposed to a promised incentive given after completion of a survey, are less likely to omit answers and are more likely complete a study tool and provide meaningful data (Edwards et al., 2001; Newby, Watson \& Woodliff, 2003). In the e-mail containing the study information form, participating residents were asked to email the researcher their preferred mailing address so that their $\$ 20.00$ gift card could be mailed to them.

\section{Instruments}

Two instruments were used to collect the pre- and post-intervention data. One instrument, the SDLRS/LPA was used to analyze readiness for self-directed learning in the experimental group both before and after they participated in reflective exercises. The control group also took the SDLRS/LPA before and after the interval of time during which the experimental group participated in the reflective exercises. The second instrument was developed by the researcher to assess a participant's attitude towards reflective practice as well as their propensity to engage in future reflective practice after 
Reflective Practice and Readiness for Self-directed Learning

the completion of the eight-week intervention. Each instrument is described in the following paragraphs.

\section{Self-directed learning readiness scale/Learning preference assessment (SDLRS/LPA).}

The SDLRS/LPA (Appendix F), also known as the SDLRS, was developed by Guglielmino (1977) and at the time of this study, was the most commonly used tool to assess readiness for self-directed learning (Fisher, King \& Tague, 2001). The SDLRS/LPA specifically measures the complex attitudes, abilities and characteristics deemed to be associated with self-directed learning (Guglielmino \& Associates, 2010). According to Guglielmino \& Associates (2010)

"The SDLRS has been used by more than 500 major organizations from around the world. More than 300,000 adults and 10,000 children have taken the Guglielmino SDLRS. It is the most widely used instrument of its kind in the world and it has been translated into more than 20 languages. The Guglielmino SDLRS has an extensive bibliography of research. More than 100 doctoral dissertations have been completed from universities throughout the world using the SDLRS” (Guglielmino \& Associates, 2010).

The content of the tool was determined by a panel of 13 highly regarded SDL researchers and writers. Guglielmino (1977) used a modified version of the Delphi technique to query members of the panel on the personality characteristics attributed to individuals who are deemed as highly self-directed learners (Guglielmino, 1977). The 
Reflective Practice and Readiness for Self-directed Learning

panel listed and rated characteristics which helped Guglielmino deduce personality characteristics the experts agreed were either desirable, necessary or essential for selfdirected learning (Guglielmino \& Associates, 2010). The agreed upon questions were then developed into the first iteration of the SDLRS/LPA and piloted with a group of 10 individuals enrolled in an adult education graduate program.

After revisions were made to the pilot instrument, Guglielmino administered the SDLRS/LPA to 307 individuals including high school juniors and seniors, college undergraduates and adults enrolled in noncredit college courses. In order to determine validity of the SDLRS/LPA, Guglielmino conducted an item intercorrelation matrix and a factor analysis. A reliability of .87 was estimated for the SDLRS/LPA. Based on the analysis some items were eliminated and some items were revised to reveal the questions that are included on the final 58-item, 5-point Likert-type scale questionnaire (Guglielmino, 1977; Guglielmino \& Associates, 2010). Brockett \& Hiemstra (1991) reported that the SDLRS has a .94 Pearson split-half reliability. After conducting a factor analysis, Guglielmino (1977) reported that the SDLRS measured eight constructs:

1) openness to learning opportunities,

2) self-concept as an effective learner,

3) initiative and independence in learning,

4) informed acceptance of responsibility for one's own learning,

5) love of learning,

6) creativity, 
Reflective Practice and Readiness for Self-directed Learning

7) positive orientation to the future, and

8) ability to use basic study and problem-solving skills

The test instructions on the self-scoring version of the SDLRS/LPA indicate that in order to control for participant response bias, the respondent should not be aware of the name or purpose of the instrument as such, the self-scoring questionnaire is now called the Learner Preference Assessment (LPA) (Findley, 2009).

The range of scores on the SDLRS/LPA is between 58 and 290 and the instrument has an average score of $214.00 \pm 25.59$ for adults. The SDLRS/LPA is scored by adding the Likert-type scale responses of 41 of the 58 questions, reverse scoring the remainder 17 questions and adding the scores together to derive the final score. The SDLRS/LPA designates score ranges to help decipher between below average, average and above average readiness for self-directed learning. A score between 58-201 indicates a below average readiness for self-directed learning, a score that falls between 202 and 226 specifies an average readiness for self-directed learning and a score between 227 and 290 designates an above average readiness for self directed learning. For the purpose of this study, study participants will be compared to the average score $(M=214)$ for adults.

The initial administration of the SDLRS/LPA contained questions at the beginning of the survey for participants to answer regarding their demographic information including ethnicity, medical school and age range. 
Reflective Practice and Readiness for Self-directed Learning

Support and critique of the SDLRS/LPA. Although Guglielmino's

SDLRS/LPA has been used by hundreds of researchers across multiple disciplines in several countries, it has been widely criticized regarding its validity, cost and use

(Ellinger 2004; Fisher et al., 2001). Several researchers have suggested discontinuing the use of this tool due to issues with validity testing (Candy 1991; Field, 1989). In a study conducted in 2005, Hoban, Lawson, Mazmanian, Best and Seibel concluded that researchers should consider alternative measures to determine self-directed learning in medical students.

Early studies of the SDLRS/LPA maintained the internal validity of the tool was problematic based on the reverse scoring of several items, the confusing wording of the Likert-type scale and use of double-negatives in the instrument (Brockett, 1985; Leeb, 1983). Most notably, Field (1989) argued the structure, validity and reliability of the SDLRS/LPA was flawed. Field raised concerns about the definitions used to define selfdirected learning in the Delphi technique, the reverse-scored items, the lack of definition of the terms "readiness" and "self-directed learner" and the method employed by Guglielmino to develop the SDLRS/LPA.

Guglielmino responded to the criticism of the SDLRS/LPA by articulating that the scale was developed to measure an individual's current level of readiness for selfdirected learning. Guglielmino (1989) continued to defend the SDLRS/LPA by stating the Delphi process was not used to determine the individual items on the scale but rather the characteristics most often found in self-directed learners. Also in response to Field's 
Reflective Practice and Readiness for Self-directed Learning

(1989) critique, Guglielmino (1989) contended that the purpose of the reverse-items used in the scale was to combat the potential for "response set" where respondents stop reading the questions carefully because of the assumption that all items will follow a similar Likert-type pattern.

Other research supports Guglielmino's argument that the SDLRS/LPA is a valid and reliable measure of readiness for self-directed learning. In their study looking at the degree of readiness for self-directed learning among medical students participating in problem based learning curriculum, Shokar et al., (2002) reported the students score on the SDLRS/LPA correlated with clinical performance, and therefore, the SDLRS/LPA likely represented readiness for self-directed learning. Hassan (1981) looked at the number of self-directed projects completed by adults and SDLRS/LPA and found a significant positive relationship. After reviewing literature on self-directed learning, Finestone (1984) found the results of the Delphi study conducted by Guglielmino to be accurate. Although criticism of the SDLRS/LPA exists, several studies have shown that the instrument is the most reliable measure of readiness for self-directed learning currently available.

\section{Follow-up survey.}

The follow-up Survey (Appendix G) was six questions in length. Because this

study was not longitudinal, the survey was developed by the researcher as a way to assess if study participants used and will continue to use reflective practice in their professional 


\section{Reflective Practice and Readiness for Self-directed Learning}

practices after the study concluded. The follow-up survey also asked questions regarding participant attitudes about reflective practice.

\section{Procedures}

The data collection procedures for this study were approved by the IRB at the institution sponsoring this research as part of a protocol started by the Department of Anesthesiology \& Perioperative Medicine (APOM). The IRB at the sponsoring institution gave the study an exempt status and the study protocol submitted to the sponsoring institution was followed during the data collection process. However, no data had been collected and no residents had been solicited to participate prior to IRB approval at Portland State University (PSU), the institution where the researcher was enrolled in a doctoral program. The proposal submitted to the IRB at PSU was approved after the dissertation proposal was approved by the researcher's committee.

This study was twelve-weeks in duration. The intervention was eight-weeks in length with a pretest administered before the start of the intervention and a posttest administered at the end of the eight-week intervention period. A follow-up survey was administered four-weeks after the posttest was administered. The researcher chose an eight-week intervention period because each educational assignment during anesthesiology training is typically four-weeks in length. The researcher reasoned that engaging in reflective exercises over two educational assignments would allow the participants to familiarize themselves with and integrate reflective practice into their training during the study period. Also, although the literature review did not find 
Reflective Practice and Readiness for Self-directed Learning

extensive evidence linking the development of reflective practice with a prescribed duration of time, the researcher did find one study that looked at reflective practice and 48 physical therapy students that reported evidence indicating eight-weeks of reflective practice was a long enough period of time to develop reflective thinking (Williams \& Wessel, 2004).

An electronic data collection program, Zoomerang ${ }^{\circledR}$ was used to collect the data for this study. Individual participant responses were linked to each participant's email addresses. Collecting data using this method enabled the researcher to link each individual's pretest and posttest SLDRS/LPA responses together in order to analyze his or her responses. This method also allowed the researcher to send a reminder via email to participants who did not complete a reflective exercise or SDLRS/LPA survey by the allotted timeframe as specified below (Table 2). The SDLRS/LPA, the intervention tool which contained questions based on Gibb's (1988) model of reflection, the follow-up survey and the participant's email addresses and demographic query were entered into Zoomerang ${ }^{\circledR}$ by the researcher.

\section{Dissemination of study tools and instruments.}

Both the control group and the experimental group were asked to take the pretest and posttest SDLRS/LPA and the follow-up survey at the same time intervals (Table 2) during the study period. Only the experimental group received weekly reflective exercises. Both groups received the follow-up survey four-weeks after the conclusion of the reflective exercises. 
Reflective Practice and Readiness for Self-directed Learning

Table 2

Dissemination of Study Tools to Participants

\begin{tabular}{|c|c|c|c|c|c|c|c|c|c|}
\hline & $\begin{array}{l}\text { Week } \\
1\end{array}$ & $\begin{array}{l}\text { Week } \\
2\end{array}$ & $\begin{array}{l}\text { Week } \\
3\end{array}$ & $\begin{array}{l}\text { Week } \\
4\end{array}$ & $\begin{array}{l}\text { Week } \\
5\end{array}$ & $\begin{array}{l}\text { Week } \\
6\end{array}$ & $\begin{array}{l}\text { Week } \\
7\end{array}$ & $\begin{array}{l}\text { Week } \\
8\end{array}$ & $\begin{array}{l}\text { Week } \\
12\end{array}$ \\
\hline *SDLRS & Monday & & & & & & & Sunday & \\
\hline$* * \mathrm{RE}$ & Friday & Friday & Friday & Friday & Friday & Friday & Friday & Friday & \\
\hline$* * * \mathrm{FS}$ & & & & & & & & & Friday \\
\hline
\end{tabular}

Note. $\quad$ *SDLRS: Self-Directed Learning Preference Scale/Learning Preference Scale
**RPE: Reflective Exercise
***FS: Follow-up Survey

\section{Self-guided reflective exercise.}

The reflective exercise based on Gibbs' (1988) model of reflection was entered into Zoomerang ${ }^{\circledR}$. A link to access the reflective exercise was emailed out to all participants in the experimental group every Friday of the study period. Participants were given up to three days to complete the reflective exercise. Participants who did not complete the reflective exercise within the allotted three day period were sent an email reminder via Zoomerang ${ }^{\circledR}$ to complete the reflective exercise. Participants who did not complete a reflective exercise were sent up to three email reminders, two days apart for two weeks.

The amount of time it took each participant to fill out the reflective questionnaire was up to each individual participant and how much time he or she wanted to allocate to answering the questions listed on the reflective exercise. 
Reflective Practice and Readiness for Self-directed Learning

\section{Self-directed learning readiness scale/Learning preference assessment.}

Zoomerang ${ }^{\circledR}$ was also used to deploy the SDLRS/LPA to study participants.

Participants were asked to fill out the SDLRS/LPA (Guglielmino, 1977) the week before the first reflective exercise and after completing the final reflective exercise at the end of week eight of the study period (Table 2).

\section{Follow-up survey.}

A link to the follow-up survey was distributed using Zoomerang ${ }^{\circledR}$. It was expected to take approximately 10-15 minutes for participants to answer the six questions on the follow-up survey. The survey was distributed four-weeks after the posttest SDLRS/LPA to all participants. A total of 37 study participants completed the follow-up survey.

\section{Researcher's Role in the Study.}

The researcher's professional role in the Department of Anesthesiology and Perioperative Medicine made it possible for her to gain access to the participant population needed for this study. The researcher is employed as an administrative staff member in the Department of APOM at the sponsoring institution. As part of her professional responsibilities, she participates in all aspects of educational research for her department including conceptualization of ideas, research design, IRB submission, participant enrollment, data collection, data analysis, reporting of results and the submission of papers for publication in peer-reviewed journals. The researcher has no 
Reflective Practice and Readiness for Self-directed Learning

responsibilities related to evaluating the clinical performance of residents in her department or any other department participating in this study.

\section{Data Analysis}

After the eight-week intervention and the administration of the posttest

SDLRS/LPA, the researcher abstracted and coded the SDLRS/LPA scores from Zoomerang ${ }^{\circledR}$ in order to maintain confidentiality. Although individual responses were linked to email addresses; the researcher kept individual responses private and did not disclose individual responses to programs, program directors or any other person/entity. When data were analyzed participants were coded with numbers (1-51) and letters whereas " $a$ " represented a participant from the control group and " $b$ " represented a participant from the experimental group. Responses for this study are reported in aggregate form. The findings of this study will be presented as a partial requirement for the fulfillment of doctoral degree in education.

\section{Data analysis methods.}

This study utilized quantitative data to answer two main research questions; does reflective practice affect readiness for self-directed learning in anesthesiology residents and does exposure to reflective practice affect anesthesiology residents' attitudes about reflective practice and the propensity to engage in future reflective practice? Seven secondary questions were developed in order to answer the two main research questions. Quantitative data from the SDLRS/LPA and the follow-up survey were analyzed using SPSS software. Before a complete analysis was conducted, a Shipiro-Wilk test for 


\section{Reflective Practice and Readiness for Self-directed Learning}

normality was conducted to determine if the data were normally distributed. If the data were non-normally distributed, non-parametric tests were used to analyze the data. The different groupings of samples used to answer each secondary question were shown to be normally and non-normally distributed therefore both parametric and non-parametric tests were used to analyze the data. The data analysis methods are outlined in the table below.

Table 3

\section{Data Analysis Methods}

\section{Secondary Question}

Do the pretest scores of the experimental and control group differ from the average SDLRS/LPA scores reported by Guglielmino?

\section{Comparison Group/Score $\quad$ Test Used}

Pretest score of Control Group

One Sample $t$-test

with Guglielmino Reported

Adult Average
Pretest score of Experimental

Group with Guglielmino

Reported Adult Average

One Sample $t$-test

Pretest score of the Control Group and Experimental Group

Independent

Samples $t$-test

Posttest score of Control Group Mann-Whitney U and Experimental Group
Test
Do students' SDLRS/LPA scores before participating in reflective exercises, based on Gibbs' (1988) model of reflection, differ from the scores after participation?
Pretest and Posttest score of Experimental Group
Wilcoxon Signed-

Rank
Are changes in pretest and posttest scores of students who participated in the reflective exercises associated with participant characteristics?
Pretest and Posttest scores of

Experimental Group and Participant Characteristics
Multiple Linear

Regression

Do participants in the control group 
Reflective Practice and Readiness for Self-directed Learning

\begin{tabular}{lll}
\hline $\begin{array}{l}\text { and experimental group differ on } \\
\text { whether they engaged in reflective } \\
\text { practice after the conclusion of the } \\
\text { reflective exercises? }\end{array}$ & $\begin{array}{l}\text { Control Group and } \\
\text { Experimental Group }\end{array}$ & $\begin{array}{l}\text { Two-Way } \\
\text { Contingency Table } \\
\text { Analysis Using } \\
\text { Crosstabs }\end{array}$ \\
\hline $\begin{array}{l}\text { Do participants in the control group } \\
\begin{array}{l}\text { and experimental group differ in } \\
\text { reporting that they plan on engaging in } \\
\text { reflective practice in the future? }\end{array}\end{array}$ & $\begin{array}{l}\text { Control Group and } \\
\text { Experimental Group }\end{array}$ & $\begin{array}{l}\text { Two-Way } \\
\text { Contingency Table } \\
\text { Analysis Using } \\
\text { Crosstabs }\end{array}$ \\
\hline $\begin{array}{l}\text { Do participants in the control group } \\
\text { and experimental group differ on their } \\
\text { attitudes about reflective practice? }\end{array}$ & $\begin{array}{l}\text { Control Group and } \\
\text { Experimental Group }\end{array}$ & $\begin{array}{l}\text { Two-Way } \\
\text { Contingency Table } \\
\text { Analysis Using } \\
\text { Crosstabs }\end{array}$ \\
\hline
\end{tabular}

For the first secondary question, do the pretest scores of the experimental group and the control group differ from the average SDLRS/LPA scores reported by Guglielmino, was answered using a parametric test. Because the pretest SDLRS/LPA scores were normally distributed for both groups a parametric one sample $t$-test was used to analyze the data. The pretest SDLRS/LPA scores for both the control group and the experimental group were analyzed to determine if a statistically significant difference existed in scores before the intervention.

Secondary question two, do posttest SDLRS/LPA scores differ between the control group and experimental group was answered using a parametric and a nonparametric test. The data for the pretest SDLRS/LPA for the control group and the experimental group were observed to be normally distributed; therefore, an independent samples $t$-test was performed to compare the means of the pretest scores to determine if a statistically significant difference existed before the intervention. The posttest SDLRS/LPA scores for the experimental group were observed to be non-normally 


\section{Reflective Practice and Readiness for Self-directed Learning}

distributed and thus a Mann-Whitney U test was performed to compare the medians of the posttest SDLRS/LPA scores.

Secondary question three, do students' SDLRS/LPA scores before participating in reflective exercises, based on Gibbs' (1988) model of reflection, differ from the scores after participation, the Shipiro-Wilk test revealed that the pretest and posttest scores of the experimental group were non-normally distributed, therefore a non-parametric Wilcoxon Signed-Rank paired samples test was used. The Wilcoxon Signed-Rank test was used for a within group comparison and compared the median of the pretest and posttest SDLRS/LPA scores of the experimental group in order to determine if a statistical significance existed between the pretest and posttest SDLRS/LPA scores.

The fourth secondary question, are changes in pretest and posttest scores of students who participated in the reflective exercises associated with participant characteristics or participation in reflective exercises, was answered using a regression analysis. A regression analysis was conducted to determine the degree of association between the dependent variables, participant characteristics including year in training, gender, treatment group (control vs. experimental) and age, and independent variable, the change in pretest to posttest scores on the SDLRS/LPA.

Finally, secondary questions 5 through 7 , do participants in the control group and the experimental group differ on whether they engaged in reflective practice after the conclusion of the reflective exercises, do participants in the control group and the experimental group differ in reporting that they plan on engaging in reflective practice in 


\section{Reflective Practice and Readiness for Self-directed Learning}

the future, and do participants in the control group and the experimental group differ on their attitudes about reflective practice were answered using a two-way contingency table analysis using crosstabs. The assumption for normal distribution does not need to be met with a two-way contingency table analysis using crosstabs due to the categorical nature of the data used for the test therefore a Shipiro-Wilk test was not conducted.

\section{Summary}

This chapter discussed the methodology that was used in this research study. After a short introduction to the chapter, the context of the study was described and the main research questions along with the secondary were stated. Next the study design, how participants were selected, solicited and engaged, and a description of the study instruments was described. The procedures including data collection, dissemination of study tools and the researcher's role in the study was also discussed in this chapter. Lastly, this chapter outlined the data analysis methods. Chapter 4 of this paper presents the findings of this study, utilizing the methods discussed in this chapter. 
Reflective Practice and Readiness for Self-directed Learning

\section{Chapter 4}

\section{Introduction}

Two main research questions guided this study: 1) Does reflective practice affect readiness for self-directed learning in anesthesiology residents? and 2) Does exposure to reflective practice affect anesthesiology residents' attitudes about reflective practice and the propensity to engage in future reflective practice? Several secondary questions will help further guide this study. Secondary questions 1 through 4 were developed to help answer research question 1 and secondary questions 5 through 7 were developed to help answer research question 2 . The research questions with associated secondary questions are listed below.

Research Question 1: Does reflective practice affect readiness for self-directed learning in anesthesiology residents?

Secondary Question 1: Do the pretest scores of the experimental group and the control group differ from the average SDLRS/LPA score reported by Guglielmino?

Secondary Question 2: Do the posttest SDLRS/LPA scores differ between the control group and the experimental group?

Secondary Question 3: Do students' SDLRS/LPA scores before participating in reflective exercises, based on Gibbs' (1988) model of reflection, differ from the scores after participation? 
Reflective Practice and Readiness for Self-directed Learning

Secondary Question 4: Are changes in pretest and posttest scores associated with participant characteristics or participation in reflective exercises?

Research Question 2: Does exposure to reflective practice affect anesthesiology residents' attitudes about reflective practice and the propensity to engage in future reflective practice?

Secondary Question 5: Do participants in the control group and the experimental group differ on whether they engaged in reflective practice after the conclusion of the reflective exercises?

Secondary Question 6: Do participants in the control group and the experimental group differ in reporting that they plan on engaging in reflective practice in the future?

Secondary Question 7: Do participants in the control group and the experimental group differ on their attitudes about reflective practice?

From the main research questions, null and alternative hypotheses were formulated for each secondary research question to facilitate the data analysis: $\mathrm{H} 1_{0}$ : There is no difference between pretest SDLRS/LPA scores of the experimental group or the control group and the average SDLRS/LPA score reported by Guglielmino. 
Reflective Practice and Readiness for Self-directed Learning

$\mathrm{H} 1_{\mathrm{A}}:$ There is a difference between pretest SDLRS/LPA scores of the experimental group or the control group and the average SDLRS/LPA score reported by Guglielmino.

$\mathrm{H} 2_{0}$ : There is no difference in posttest SDLRS/LPA scores between the control group and the experimental group.

$\mathrm{H} 2_{\mathrm{A}}$ : There is a difference in posttest SDLRS/LPA scores between the control group and the experimental group.

$\mathrm{H}_{3}$ : There is no difference in the students' SDLRS/LPA scores before and after participating in reflective exercises, based on Gibbs' (1988) model of reflection.

$\mathrm{H} 3_{\mathrm{A}}$ : There is a difference in the students' SDLRS/LPA scores before and after participating in reflective exercises, based on Gibbs' (1988) model of reflection.

$\mathrm{H} 4_{0}$ : Changes in pretest and posttest scores of students who participated in the reflective exercises are not associated with the demographic variables of year in training, gender, treatment group (control vs. experimental) and age.

$\mathrm{H} 4_{\mathrm{A}}$ : Changes in pretest and posttest scores of students who participated in the reflective exercises are associated with the demographic variables of year in training, gender, treatment group (control vs. experimental) and age.

H5 $5_{0}$ Participation in reflective exercises does not change whether or not participants engaged in reflective practice after the conclusion of the reflective exercise intervention. 
Reflective Practice and Readiness for Self-directed Learning

$\mathrm{H} 5_{\mathrm{A}}$ : Participation in reflective exercises did change whether or not participants engaged in reflective practice after the conclusion of the reflective exercise intervention.

$\mathrm{H6}_{0}$ : Participation in reflective exercises does not affect a participants' plan to engage in reflective practice in the future.

$\mathrm{H6}_{\mathrm{A}}$ : Participation in reflective exercises does affect a participants' plan to engage in reflective practice in the future.

$\mathrm{H} 7_{0}$ : Attitudes about reflective practice do not differ between participants in the control group and participants in the experimental group.

$\mathrm{H} 7_{\mathrm{A}}$ : Attitudes about reflective practice do differ between participants in the control group and participants in the experimental group.

Data were collected from 51 participants who were anesthesiology residents from three different academic medical centers through the use of a self-directed learning inventory called the SDLRS/LPA which contains 58 questions with Likert-type scale responses at two different points in time, at the beginning and at the end of the eightweek intervention. A follow-up survey, developed by the researcher to look at the participants' propensity to engage in future reflective practice and attitudes about reflective practice, was distributed to all study participants four-weeks after the posttest SDLRS/LPA was administered. The follow-up survey contained six questions with multiple choice and open ended answers. 
Reflective Practice and Readiness for Self-directed Learning

\section{Descriptive Statistics}

\section{SDLRS/LPA scores.}

A total of 51 participants completed the study. Of the 51 participants, 26 were randomly assigned to the control group which did not participate in the in reflective exercises and 25 were randomly assigned to the experimental group which participated in eight-weeks of reflective exercises. Table 4 below presents the mean score, standard deviation, median score and range of the pretest and posttest SDLRS/LPA scores for the control group and the experimental group.

Table 4

SDLRS/LPA Scores of Participant Groups

\section{Control Group}

\section{Experimental Group}

\begin{tabular}{lllll|llll}
\hline & Mean & SD & Mdn & Range & Mean & SD & Mdn & Range \\
\hline $\begin{array}{l}\text { Pretest } \\
\text { SDLRS/LPA }\end{array}$ & & & & & & & & \\
Scores & 223.31 & 20.48 & 223 & $178-272$ & 221 & 20.66 & 227 & $174-269$ \\
\hline $\begin{array}{l}\text { Posttest } \\
\text { SDLRS/LPA }\end{array}$ & & & & & & & & \\
Scores & 226.54 & 20.58 & 227 & $171-250$ & 221 & 24.45 & 225 & $139-255$ \\
\hline
\end{tabular}

\section{Data Analysis}

For all statistical tests, a 95\% confidence level was used to determine statistical significance. For the relationships or differences to be statistically significant, the obtained $p$-value should be equal to or less than .05 . 
Reflective Practice and Readiness for Self-directed Learning

\section{Test for normality.}

Before the comparison of means was done for each research question, the data were tested for normality to determine if they were normally distributed. The distribution of data determined what type of statistical analysis, parametric or non-parametric, was used to answer each hypothesis. One of the assumptions of parametric tests is that the data to be analyzed are normally distributed; therefore, parametric tests were used to analyze data that was normally distributed. However, when data were determined to be non-normally distributed, non-parametric tests were used as they are more powerful in detecting sample differences when the underlying assumptions of parametric tests are not met (Cleophas \& Zwinderman, 2011).

The Shapiro-Wilk test for normality was used to determine the distribution of pretest and posttest SDLRS/LPA scores for both the control group and the experimental group. For the data to be of normal distribution, the $p$-value must be $>.05$. The results of the Shipiro-Wilk test for normality of the four sets of data are displayed in table 5.

Table 5

Results for the Shapiro-Wilk Test for Normality of Distribution for All Sample Populations

\section{Control Group $\quad$ Experimental Group $\quad$ Entire Sample}

\begin{tabular}{lccc}
\hline $\begin{array}{l}\text { Pretest SDLRS/LPA } \\
\text { Scores }\end{array}$ & Normal & Normal & Normal \\
\hline $\begin{array}{l}\text { Posttest SDLRS/LPA } \\
\text { Scores }\end{array}$ & Normal & Non-normal & Non-normal \\
\hline
\end{tabular}


Reflective Practice and Readiness for Self-directed Learning

The data for the pretest SDLRS/LPA scores for the entire sample of participants were observed to be normally distributed $(W=.982, d f=51, p=.638)$. However, the posttest SDLRS/LPA scores for the entire sample were observed to be non-normally distributed $(W=.943, d f=51, p=.017)$. The pretest scores for the control group were observe to be normally distributed $(W=.977, d f=26, p=.799)$, as were the pretest SDLRS/LPA scores for the experimental group $(W=.928, d f=25, p=.076)$. Finally, the posttest SDLRS/LPA scores for the control group were normally distributed $(W=.968, d f$ $=26, p=.576)$ but, the posttest SDLRS/LPA scores for the experimental group were not normally distributed $(W=.869, d f=25, p=.004)$.

The following are the findings associated with each secondary question. To guide the reader, table 6 provides an overview of the results of each null hypothesis associated with research question 1 as well distribution of data and the statistical test used to analyze each null hypothesis. Table 6 can be found on page 95.

\section{Secondary question 1.}

The first secondary question, do the pretest scores of the experimental and control group differ from the average SDLRS/LPA score reported by Guglielmino, was addressed using a parametric one sample $t$-test. The $t$-test was used to compare the mean of the pretest SDLRS/LPA scores of the participants in the control group and the mean of the pretest SDLRS/LPA scores of the experimental group with the average adult score on the SDLRS/LPA reported by Guglielmino. The comparison was conducted using separate $t$-tests for each group, the mean pretest SDLRS score of the control group to the adult 
Reflective Practice and Readiness for Self-directed Learning

average SDLRS/LPA score and the mean pretest SDLRS/LPA score of the experimental group to the adult average SDLRS/LPA score.

\section{Secondary question 2.}

The second secondary question, do the posttest SDLRS/LPA scores differ between the control group and the experimental group, was addressed by using both an independent samples $t$-test and a Mann-Whitney U test. A comparison of the mean pretest SDLRS/LPA scores of the control group to the mean pretest SLDRS/LPA scores of the experimental group was conducted in order to determine whether a statistically significant difference existed before the experimental group participated in the reflective exercises. As previously described, the pretest SDLRS/LPA scores for both the control group and the experimental group were normally distributed. Therefore, a parametric independent samples $t$-test was used to analyze the data. Because the posttest SDLRS/LPA scores for the experimental group were not normally distributed a nonparametric Mann-Whitney U test was used to compare the median of the posttest SDLRS/LPA scores of the participants in the control group to the median posttest SDLRS/LPA scores of the participants in the experimental group.

As shown in table 4, there was a slight difference in the mean score between the pretest SDLRS/LPA of the control group $(\mathrm{M}=223.30, \mathrm{SD}=20.48)$ and pretest SDLRS/LPA score of the experimental group $(M=221, S D=20.66)$ however, the independent samples $t$-test showed no statistically significant difference, $t(49)=.401, p=$ .691 . 
Reflective Practice and Readiness for Self-directed Learning

To determine statistical significance for the Mann-Whitney U test, the MannWhitney U value (U = 294) should fall below the least Sum of Ranks (619) or above the highest Sum of Ranks (707), and the $p$-value should be equal to or less than .05. The descriptive statistics revealed that there was a slight difference in the median score between the posttest SDLRS/LPA score of the control group $(\mathrm{Mdn}=227)$ and the posttest SDLRS/LPA score of the experimental group $(\mathrm{Mdn}=225)$ however, the MannWhitney U test indicated that the posttest SDLRS/LPA scores were not significantly different between the two groups after participating in the reflective exercises as the $p$ value was not equal to or less than $.05, U=294, z=-.584, p=.559, r=41.18$.

The null hypothesis for secondary question 3 is accepted, where there is no statistically significant difference between the posttest SDRLS/LPA scores of students who participated in the reflective exercises as compared to those who did not.

\section{Secondary question 3.}

The third secondary question, do students' SDLRS/LPA scores before participating in reflective exercises, based on Gibbs' (1988) model of reflection, differ from the scores after participation was addressed using a non-parametric Wilcoxon Signed-Rank test to compare the medians of the students' SDLRS/LPA scores before and after participating in reflective exercises, based on Gibbs' (1988) model of reflection.

As the posttest SDLRS/LPA scores for the experimental group were observed to be not normally distributed, a Wilcoxon Signed-Rank test was performed to compare the median pretest and median posttest SDLRS/LPA scores. It can be observed by reviewing 
Reflective Practice and Readiness for Self-directed Learning

table 4 that the median pretest SDLRS/LPA score $(\mathrm{Mdn}=227)$ was higher than the posttest SDLRS/LPA score $(\mathrm{Mdn}=225)$. The Wilcoxon Signed-Rank test revealed that 12 of the 25 participants in the experimental group had higher pretest SDLRS/LPA scores than post scores whereas 13 of the 25 had lower posttest SDLRS/LPA scores than pretest scores. The results of the analysis indicated that there was no statistically significant difference in changes of the median score, $z=-.65, p=.518, r=-.129$. There is no difference in the SDLRS/LPA scores for the experimental group before and after participating in the reflective exercise; therefore, the null hypothesis is accepted.

Control group. The critical $t$-value with 25 degrees of freedom at a $95 \%$ confidence level with a $p$-value of .05 is 2.060 . For the difference between the pretest SDLRS/LPA scores and the Guglielmino reported score to be statistically significant, the $t$-test values should be higher than the critical $t$-value, while the $p<.05$. The $t$-test showed a statistically significant difference in the pretest SDLRS/LPA scores $(M=$ 223.31, $\mathrm{SD}=20.48)$ of the control group and the adult average $(\mathrm{M}=214)$ reported by Guglielmino, $t(25)=2.31, p=.029$.

Experimental group. The critical $t$-value with 24 degrees of freedom at a $95 \%$ confidence level with a $p$-value of .05 is 2.064 . For the difference between the pretest SDLRS/LPA scores and the Guglielmino reported score to be statistically significant, the $t$-test values should be higher than the critical $t$-value, while the $p<.05$. The data showed no statistically significant difference between the pretest SDLRS/LPA 
Reflective Practice and Readiness for Self-directed Learning

scores $(M=221, S D=20.66)$ of the experimental group and the adult average $(M=214)$ reported by Guglielmino, $t(24)=1.69, p=.103$.

Given the data analysis for secondary question 3, the null hypothesis is rejected because there is a statistically significant difference between the pretest SDLRS/LPA scores of the control group and the Guglielmino reported mean. However, it should be noted that the hypothesis is rejected on the grounds that only the pretest SDLRS/LPA scores of the control group, not the experimental group, have a significantly higher mean than the Guglielmino reported mean.

\section{Secondary question 4.}

A multiple linear regression analysis was run to answer the fourth secondary question, are changes in pretest and posttest scores associated with participant characteristics or participation in reflective exercises. Through a regression analysis the research sought to determine if the independent variables of year in training, gender, treatment group (control vs. experimental) or age predicted change in pretest and posttest SDLRS/LPA scores (the dependent variable). The results for the regression analysis indicated that none of the variables were statistically significant $\left(\mathrm{R}^{2}=.102, \mathrm{~F}(4,45)=\right.$ $1.28, p=.293)$. Beta coefficients for the four variables are as follows: age, $\beta=.136 t=$ $.946 p=.349$, gender, $\beta=-.098 t=-.664 p=0.510$, year in training, $\beta=-.275 t=-1.917$ $p=.062$ and control group versus experimental group, $\beta=-.044 t=-0.297 p=.768$. 


\section{Reflective Practice and Readiness for Self-directed Learning}

The null hypothesis for secondary question 4 is accepted as participant characteristics are not associated with the changes observed in pretest and posttest SDLRS/LPA scores of students who participated in the reflective exercises. 
Reflective Practice and Readiness for Self-directed Learning

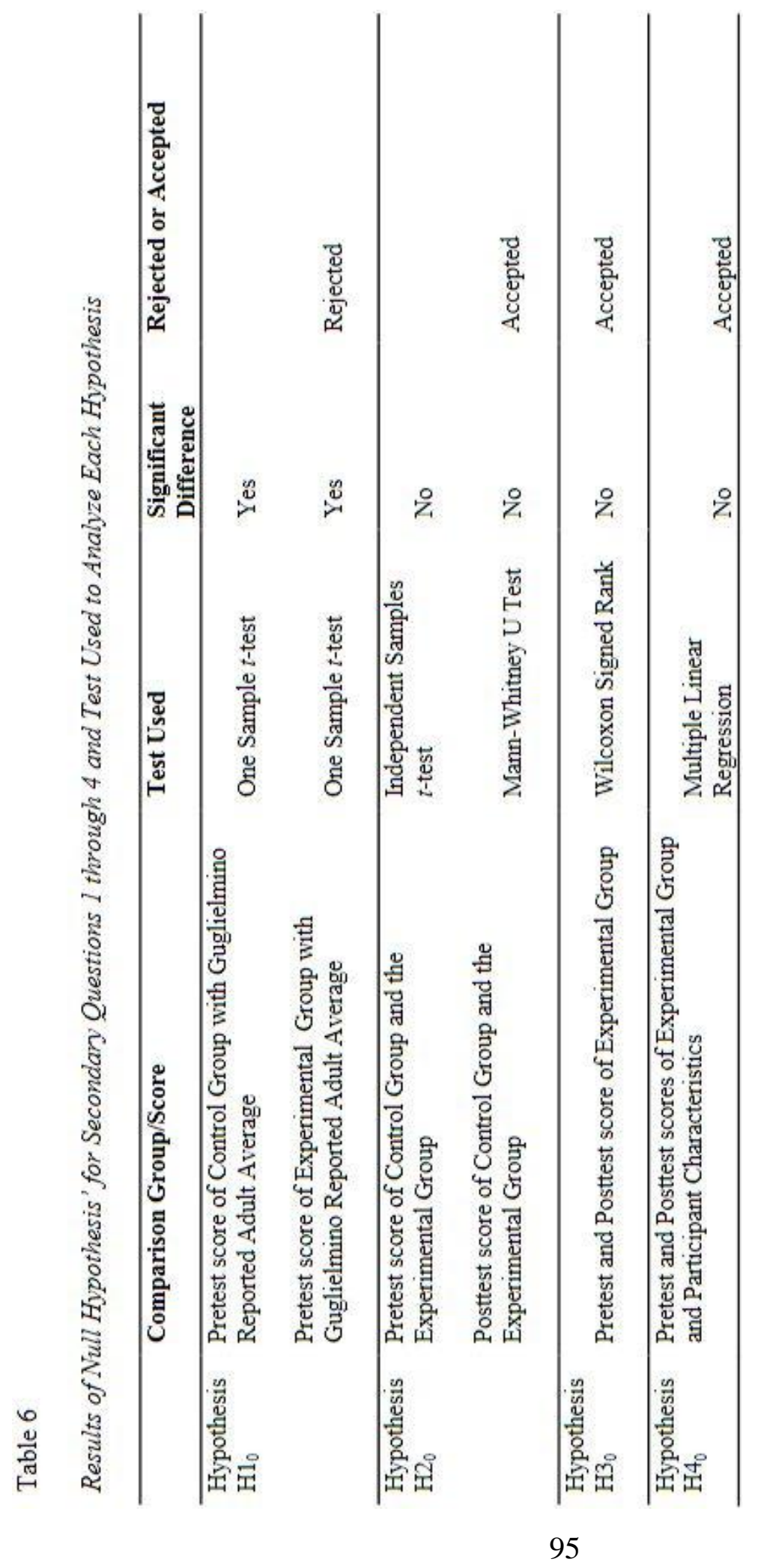


Reflective Practice and Readiness for Self-directed Learning

\section{Secondary question 5.}

The fifth secondary question, do participants in the control group and the experimental group differ on whether they engaged in reflective practice after the conclusion of the reflective exercises, was addressed using a two-way contingency table analysis using crosstabs for the variables of exposure to the reflective exercises and future engagement in reflective practice. The number and percentage of participants in both the control group and the experimental group who indicated they had engaged in reflective practice since the completion of this study are shown in table 7 which can be found on page 99 . Results of the two-way contingency table analysis using crosstabs

show no difference between the control group and the experimental group, Pearson $x^{2}(1$, $N=37)=1.273, p=.259$, Cramer's $V=.185$. Of the participants in the experiment group only 4 out of 21 reported engaging in reflective practice after the conclusion of the study. Of the control group, only 1 out of 16 reported engaging in reflective practice since the conclusion of the study.

\section{Secondary question 6.}

Secondary question six, do participants in the control group and the experimental group differ in reporting that they plan on engaging in reflective practice in the future revealed that a majority of participants in the control group and the experimental group answered in the affirmative, 13 out of 16 and 18 out of 21 respectively. The results of the two-way contingency table analysis using crosstabs did not produce a statistically significance difference between the control group and the experimental group, Pearson $x^{2}$ 
Reflective Practice and Readiness for Self-directed Learning

$(1, N=37)=.133, p=.715$, Cramer's $V=.060$. These results reveal that those in the control group, who did not receive the reflective exercises, are just as likely to engage in reflective practice after the conclusion of the study as those who participated in the reflective exercises.

\section{Secondary question 7.}

Several additional questions, developed to help answer secondary question 7 , do participants in the control group and the experimental group differ on their attitudes about reflective practice, were also analyzed using a two-way contingency table analysis using crosstabs. The additional questions and results of the analysis are outlined below.

The first question, do participants recommend that all physicians reflect upon his or her practice revealed no statistically significant difference between the control group and the experimental group, Pearson $x^{2}(1, N=36)=.735, p=.391$, Cramer's $V=-.143$. A majority of participants in the control group and the experimental group recommend that physicians reflect upon their practice, 16 out of 16 and 20 out of 21 respectively. One participant chose not to answer this question.

The next question, do you think engaging in reflective practice would have an impact on the quality of patient care you or your colleagues provide, was answered by almost all participants in the control group and the experimental group in the affirmative, 16 out of 16 and 19 out of 21 respectively. The results of the two-way contingency table analysis using crosstabs did not produce a statistically significant difference between the 
Reflective Practice and Readiness for Self-directed Learning

control group and the experimental group, Pearson $x^{2}(1, N=37)=1.611, p=.204$, Cramer's $V=-.209$.

The last question asked participants if they felt that by engaging in reflective practice they were more or less likely to learn throughout their career. A majority of participants in both the control group and the experimental group answered that they were more likely to learn throughout their career if they were to engage in reflective practice, 16 out of 16 and 18 out of 21 respectively. The results of the two-way contingency table analysis using crosstabs did not produce any statistically significant difference between the control group and the experimental group, Pearson $x^{2}(1, N=37)$ $=2.487, p=.115$, Cramer's $V=-.259$.

Table 7 , located on page 100, provides the reader with a review of the results for secondary questions 5 through 7 . Table 7 outlines the response frequencies and the results of the two-way contingency table analysis using crosstabs for both the control group and the experimental group for secondary questions 5 and 6 . Table 7 also outlines the frequencies and the results of the two-way contingency table analysis using crosstabs for both the control group and the experimental group for the questions that were derived to help answer secondary question 7. 
Reflective Practice and Readiness for Self-directed Learning

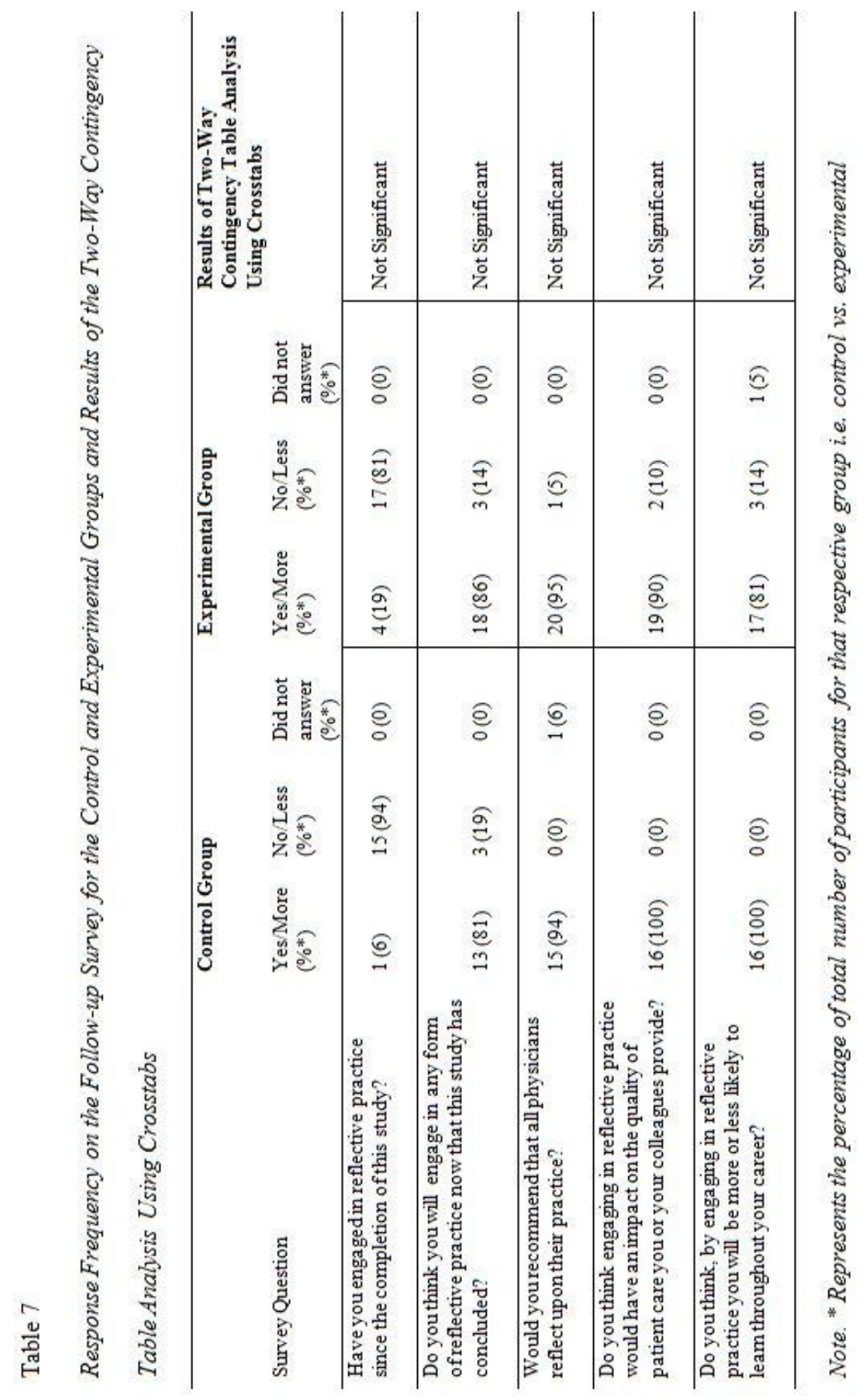


Reflective Practice and Readiness for Self-directed Learning

\section{Summary}

Chapter 4 summarizes the results of the analysis of the main research questions along with the analysis of the five secondary questions. After a short introduction, the research questions and secondary questions were presenting along with the hypothesis and null hypothesis. Next the chapter detailed the tests used to answer each secondary question along with the results of each test. The results indicated that overall, there is no statistical difference in pretest and posttest SDLRS/LPA scores between the experimental group and the control group after participation in reflective exercises. The results further articulated that there was no statically significant difference between the control group and the experimental group in regards to participation in reflective exercises after the study concluded or regarding attitudes about reflective practice.

Chapter 5 will offer a discussion of the results. The discussion will include final conclusions as they relate to the literature reviewed for this study. Chapter 5 will also offer possible explanations for the findings and give recommendations for future research. The chapter concludes with the significance of this study and the study's implications. 
Reflective Practice and Readiness for Self-directed Learning

\section{Chapter 5}

\section{Restatement of the Problem}

The science of medicine is evolving rapidly. Because it is evolving and changing so quickly it is important that physicians continually seek opportunities to further their medical knowledge in order to provide quality healthcare. One way physicians can keep abreast of these rapid changes is through self-directed, lifelong learning. Traditional medical education is not preparing physicians to engage in self-directed, lifelong learning. Currently medical education is taught in a way where lectures and tests are the mechanisms used for delivering knowledge and ensuring trainees are learning (Patrick \& Williams, 2009; Shaughnessy \& Slawson, 1999). The didactic nature and controlling environment of medical education, where faculty control learning and the dissemination of information, does not give residents the skills needed to reflect upon their practice so they can seek information and learning opportunities on their own in order to direct their own learning. An important disposition that residency programs can instill in their residents is the skill to be self-directed, lifelong learners.

Schön $(1983,1987)$ theorized that one way learners can become self-directed, lifelong learners is through reflective practice. Gaining an understanding of how to engage in reflective practice can be a useful endeavor for medical trainees (Loughran, 2002; Mamede \& Schmidt, 2004; Plack, 2005). Reflective practice through self-guided reflective exercises is one way that physicians can learn to engage in self-directed, lifelong learning. Teaching learners how to reflect upon their experiences helps increase 


\section{Reflective Practice and Readiness for Self-directed Learning}

their desire to learn and reflection has been shown to help learners take more responsibility for learning throughout their lifetime (Elwood \& Klenowsli 2002; RileyDoucet \& Wilson, 1997; Shepard 2000). As such, this study sought to determine if the introduction of a self-guided reflective exercise affected the readiness for self-directed learning in anesthesiology residents.

\section{Purpose of the Study}

This study sought to examine whether engaging in reflective exercises affected readiness for self-directed leaning and if the use of reflective exercises influenced future reflective practice or attitudes about reflective practice in anesthesiology residents training in the United States. The findings of this study contribute to the limited body of literature on self-directed learning and reflective practice in residency training programs. This study aimed to assist educators in understanding if participating in reflective exercises impacted a learner's readiness for self-directed learning, as measured by Guglielimino’s (1977) Self-Directed Learning Readiness Scale/Learning Preference Assessment (SDLRS/LPA).

The medical specialty of anesthesiology was chosen for this study for two reasons. The first reason anesthesiology was chosen is that the researcher works in a professional capacity for an anesthesiology training program at an Academic Medical Center (AMC), thus making anesthesiology residents more accessible to her than residents training in other specialties. More importantly, anesthesiology was chosen because of the nature of anesthesiologist practice. In general, anesthesiology physicians 
Reflective Practice and Readiness for Self-directed Learning

practice in isolation with little peer interaction taking place during their clinical work (Rose \& Brown, 2010). Because of this limited peer interaction, anesthesiologists are less likely to experience peer feedback to help them assess their skills and potential gaps in knowledge, therefore self-directed, lifelong learning may be of particular importance to the practice of anesthesiology.

\section{Summary of Study Methods}

This study utilized an experimental design and employed quantitative methods to answer the main and secondary research questions. Participants, who were anesthesiology residents in training, were randomly assigned to be in one of two groups, the experimental group or the control group. The experimental group participated in eightweeks of weekly reflective exercises based on Gibbs' (1988) model of reflection, whereas the control group did not. To measure the participants' readiness for selfdirected learning, both the control group and the experimental group were asked to complete Guglielmino's (1977) SDLRS/LPA, before and after the eight-week intervention. Quantitative data from the SDLRS/LPA for the experimental group and the control group were analyzed to determine if participating in reflective exercises affected readiness for self-directed leaning. In addition, both the control group and the experimental group were asked to complete a follow-up survey which was administered four-weeks after the posttest SDLRS/LPA. Quantitative data from responses on the follow-up survey were analyzed to help gain insight into reflective practice. The followup survey contained questions about a participant's use of reflective practice since the 
Reflective Practice and Readiness for Self-directed Learning

conclusion of the reflective exercises, whether they planned to engage in reflective practice in the future and their general attitudes about reflective practice as they relate to medical practice and patent care.

\section{Summary and Discussion of Results}

Two primary research questions guided this study: 1) Does reflective practice affect readiness for self-directed learning in anesthesiology residents? and 2) Does exposure to reflective practice affect anesthesiology residents' attitudes about reflective practice and the propensity to engage in future reflective practice? The results of the two primary research questions and related secondary questions are discussed below.

\section{Research question 1: Does reflective practice affect readiness for self- directed learning in anesthesiology residents?}

The first secondary research question, do the pretest scores of the experimental group and control group differ from the average SDLRS/LPA score reported by Guglielmino, was developed to help further understand if the participants in this study were more or less ready to engage in self-directed learning, as compared to other adult learners, before engaging in reflective exercises. The mean pretest SDLRS/LPA score (M $=223$ ) for the control group was found to be significantly higher than the average adult

score $(M=214)$ as reported by Guglielmino however, no statistically significant difference was observed between the mean pretest score $(M=221)$ of the experimental group and the Guglielmino reported adult average. 


\section{Reflective Practice and Readiness for Self-directed Learning}

The next two secondary questions: Do the posttest SDLRS/LPA scores differ between the control group and the experimental group? and Do students' SDLRS/LPA scores before participating in reflective exercises, based on Gibbs' (1988) model of reflection, differ from the scores after participation, sought to add depth to the understanding of the main research question by exploring if participating in reflective exercises increased readiness for self-directed learning. In this study, no statistical significance was found between the pretest and posttest scores of the participants who engaged in the reflective exercises and those who did not. Furthermore, no statistically significant difference was found in the posttest SDLRS/LPA scores between the control group and the experiential group. From these results it can be concluded that involvement in self-guided reflective exercises did not increase the readiness for self-directed learning in these study participants.

The final secondary question developed to help answer the first research question was: Are changes in pretest and posttest scores associated with participant characteristics or participation in reflective exercises? This secondary question was developed in order to determine if participant characteristics or participating in reflective exercises was associated with any changes between pretest and posttest SDLRS/LPA scores. The variables of year in training, gender, treatment group (control vs. experimental) and age were analyzed to help answer this question. No statistically significant difference was observed between participant characteristics or participation in reflective exercises and changes between pretest and posttest SDLRS/LPA scores. It can be concluded, from the 
Reflective Practice and Readiness for Self-directed Learning

results of this analysis, that the participant characteristics analyzed in this study and participation in reflective exercises were not associated with changes between pretest and posttest SDLRS/LPA scores. It should be noted that year in training is approaching significance $(p=0.062)$ however, the association is negative. The negative association means that the more training a resident had the less change in pretest and posttest SDLRS/LPA scores was observed.

The results outlined for research question one are contrary to findings in previous studies. In a study comparing the readiness for self-directed learning in medical trainees to other adult learners, Sokar et al. (2002) found that the average SDLRS/LPA score of third-year medical students was higher than the Guglielmino reported adult average. Other literature has further indicated that as a group, students training in medical education programs are highly self-directed in their learning as compared to other adults (Pilling-Cormick \& Bulik, 1999, 2000). These findings are in contradiction with the results of secondary question one examining if the pretest scores of the experimental group and control group differ from the average SDLRS/LPA score reported by Guglielmino as only the control group pretest scores were found to be significantly higher than the adult average.

Cox (2005) found that adult learners who engaged in self-guided reflective exercises were more self-directed in their learning than learners who did not engage in reflective exercises. Furthermore, other studies have found that reflective exercises partnered with other learning strategies, such as portfolios and on-line learning modules, 
Reflective Practice and Readiness for Self-directed Learning

increased the readiness for self-directed learning (Bravata, Hout, Abernathy, Skeff \& Bravata, 2003; Fung Kee Fung et al., 2000; Riley-Douchet \& Wilson, 1997; Schilling, Steiner, Lundahl \& Anderson, 2005; Williams, 2001).

Before outlining the possible explanations for the above results, it is important to recognize and discuss the outlier in the posttest scores of the experimental group. One participant in the experimental group had a negative gain of 81 points from the pretest to the posttest. This drop in score was 40 points higher than the next highest drop (-41) and 68 points higher than the average drop in score (-13) for both the experimental group and control group combined. When the outlier was taken out of the dataset and the data rerun, the results did not vary significantly from the results reported in chapter 4 . The changes observed were: 1) the posttest scores for the experimental group and entire sample population were observed to be normally distributed, 2) there was a significant difference between the Guglielmino adult average (214) and the pretest scores of the experimental group, and 3) a negative association was observed between years in training and change in scores from pretest to post-test $(t=-2.55, p=0.014)$.

Although a few differences were observed when the outlier was removed from the dataset and the data was rerun, the researcher kept the outlier in the dataset for her final report. There are several reasons why the outlier was left in the dataset. The participant had nothing to gain or lose from intentionally skewing the results of the posttest. Higher pre or posttest results did not result in a financial gain to the participant, performance in the study was not reported back to participant's program and the participant's results 


\section{Reflective Practice and Readiness for Self-directed Learning}

were confidential. Another reason the outlier was kept in the dataset was because the posttest was not missing any data, all questions were answered, indicating the participant completed the posttest, as opposed to leaving several answers blank or not finishing the posttest due to time or lack of interest. Lastly, when the posttest answers were reviewed by the researcher, there was no pattern to the responses which lead the researcher to hypothesize that the participant took time to answer the questions thoughtfully rather than haphazardly answering the questions in order to complete the posttest in a quick manner. Because of the reasons outlined above, the researcher felt that she had no reason to disregard the pre and posttest scores of the outlier.

There are several reasons why the results of this study might differ from previous research. The high pretest SDLRS/LPA scores of the participants in this study could have had significant implications for the results of this study. Although a statistically significance difference was only noted between the control group and the adult average reported by Guglielmino, a majority of participants in both the control group and the experimental group ( $92 \%$ and $76 \%$ respectively) scored in the average or above average category for readiness for self-directed learning on the pretest SDLRS/LPA. The high percentage of average or above average scores might mean that there was less of an opportunity for posttest SDLRS/LPA scores to increase to a level high enough to produce statistical significance between the scores on the pre- and post-test for the experimental group. Furthermore, it might mean this group of learners was predisposed to the ability to reflect which contributed to the higher pretest scores. The high pretest scores could also 


\section{Reflective Practice and Readiness for Self-directed Learning}

mean that anesthesiology programs are already doing a good job of training their residents to be self-directed learners. Alternatively, it could mean that teaching learners skills that increase the readiness for SDL is taking place in medical school or earlier. Another possible explanation for the contradictory results could be the sample size. The researcher was able to obtain a set of data that included a limited pool of study participants whose program is a member of a small academic society. Given the timeline for this study, the researcher did not enroll more participants and therefore the sample size was small.

The results of this study could also have been affected by how long it took participants to guide themselves through the written reflective exercise. In a study conducted by Burnard (1995) nurse educators felt that the time required to reflect upon practice may hinder the ability to reflect using a structured reflection model. The reflective exercise in this study could have been seen as a tedious chore rather than a way to develop skills to recognize gaps in knowledge. Medical training can pose a barrier to participating in reflective exercises. Since anesthesiology residents often work long hours with a priority on patient care, the participants in this study may have found the task of writing reflections burdensome or in conflict with their other educational priorities. Often times, residents are focused on learning basic skills needed for their professional practice and managing patient care. Residents might have perceived that they did not have enough time to truly reflect using the reflective exercises because of these competing demands. 


\section{Reflective Practice and Readiness for Self-directed Learning}

Practitioners in the field of adult education hypothesize that self-directed learning develops over time (Guglielmino, Guglielmino \& Long, 1987). Therefore, the length of the study period could have influenced the study results. This study asked participations to engage in reflective exercises over a short duration of time, where the reflective exercises were separate from the participants' educational experience and not incorporated into the training program's curriculum. Reflective practice may not have been able to be developed in an eight-week study period. A longer study period or incorporating reflective practice into the training curriculum might be needed in order for participants to understand and know how to reflect upon their practice.

As previously mentioned, other studies looking at reflective exercises paired with other learning strategies, such as portfolios and on-line learning modules, increased the readiness for self-directed learning (Bravata, Hout, Abernathy, Skeff \& Bravata, 2003; Fung Kee Fung et al., 2000; Riley-Douchet \& Wilson, 1997; Schilling, Steiner, Lundahl \& Anderson, 2005; Williams, 2001). Reflective exercises alone, not paired with other leaning strategies, may not be enough to affect readiness for self-directed learning.

Although randomization of the sample occurred, there were clear differences in the demographic distribution between the control group and the experimental group which could have contributed to the findings of this study. Almost three-quarters (69\%) of the participants in the control group were male and less than half of the experimental group (44\%) were male. Additionally the distribution of non-white participants between the two groups was skewed. Of the control group, 31\% reported being non-white whereas 
Reflective Practice and Readiness for Self-directed Learning

only $8 \%$ of the experimental group reported being non-white. It may be that there are inherent differences in the way males and females and whites and non-whites reflect upon experiences or their predisposition for readiness for self-directed learning and the higher ratio of males to females and whites to non-whites in the control group versus the experimental group skewed the results of this study.

Finally the SDLRS/LPA could have affected the results of this study. Although the SDLRS/LPA has been used by hundreds of researchers across multiple disciplines and in several countries the instrument has been criticized regarding its validity and several researchers have suggested discontinuing its use (Candy 1991; Ellinger 2004; Field, 1989; Fisher et al., 2001). While other research supports its use as a valid and reliable measure of readiness for self-directed learning (Hassan, 1981; Finestone, 1984; Shokar et al., 2002) it may not be an appropriate measure for assessing readiness for selfdirected leaning in residents.

\section{Research Question 2: Does exposure to reflective practice affect anesthesiology residents' attitudes about reflective practice and the propensity to engage in future reflective practice?}

The first secondary question developed to address the second main research question, do participants in the control group and the experimental group differ on whether they engaged in reflective practice after the conclusion of the reflective exercises revealed that most participants in both the control group and the experimental group had not engaged in reflective practice since the conclusion of the reflective exercises $(94 \%$ 


\section{Reflective Practice and Readiness for Self-directed Learning}

and $81 \%$ respectively). This study found no statistically significant difference between the participants who participated in the reflective exercises and those who did not in terms of engagement in reflective practice.

The next secondary question, do participants in the control group and the experimental group differ in reporting that they plan on engaging in reflective practice in the future revealed no statistical difference between the control group and the experimental group. A majority of the respondents in the control group and the experimental group reported that they will engage in some form of reflective practice after the conclusion of the study ( $81 \%$ and $86 \%$ respectively).

Finally, the last secondary question, do participants in the control group and the experimental group differ on their attitudes about reflective practice revealed no statistically significant difference in attitudes between the control group and the experimental group. Specifically, $94 \%$ of the control group and $95 \%$ of the experimental group recommend that all physicians reflect upon their practice and $100 \%$ of the control group and $90 \%$ of the experimental group thought that engaging in reflective practice would have an impact on the quality of patient care provided by either them or their colleagues. Lastly, $100 \%$ of the control group and $81 \%$ of the experimental group thought that they would be more likely to learn throughout their career by engaging in reflective practice.

From the results outlined above, it can be concluded that exposure to reflective practice does not translate to engaging in future reflective practice, participation in or 
Reflective Practice and Readiness for Self-directed Learning

attitudes about reflective practice. However, in analyzing the data, it is evident the respondents for this study agree with Schön $(1983,1987)$ and others about the importance of reflective practice. Schön $(1983,1987)$ stipulated that learners need to understand their own strengths and weaknesses in order to direct their own learning throughout their professional practice. Reflection not only allows physicians to guild their learning but also to analyze their current practice against best practices in order to increase their quality of patient care (Plack, 2005).

\section{Implications for Medical Education}

There has been a call to action by various medical associations and professional organizations to develop a more self-directed, lifelong physician learner in order to increase patient safety and healthcare quality (Association of American Medical Colleges, 2010; American Medical Association Code of Ethics, 2009; Institute of Medicine, 2003; Liaison Committee on Medical Education, 2010; Melnick, 2004; Regnier, Kopelow, Lane, \& Alden, 2005). The participants in this study felt that all physicians should reflect upon their practice and that engaging in reflective practice would impact the care they provide to their patients. It is clear, based on the responses provided by participants in this study and the call to action by medical associations and professional organizations that there is a need and desire for residency programs to find a way to cultivate reflective, self-directed physicians that are able to learn throughout their lifetime in order to provide safe, quality patient care. 


\section{Reflective Practice and Readiness for Self-directed Learning}

A majority of the participants in this study believed that by engaging in reflective practice they were more likely to learn throughout their career. Since the literature provides no clear model on how to cultivate lifelong physician learners it is evident that the medical education community must continue to explore new and innovative ways to develop this trait in residents. The literature review in chapter 2 of this study articulates that the current model of medical education does not provide the training needed to develop lifelong learning skills in practicing physicians. This study provided guidance through its literature review and recommendations for future research to help guide future educational inquiry in order to develop models of reflective practice that may help increase physicians' readiness for self-directed, lifelong learning.

This study and its findings can be used to encourage programs to employ strategies to teach reflective practice in their curriculum. In the follow-up survey, an overwhelming majority of participants reported that they were going to engage in some form of reflective practice in the future but very few reported using reflective practice in the four-weeks between the last reflective exercise and the follow-up survey. However, since study participants reported that they will use reflective practice in the future it is important that training programs give them the tools they need to develop reflective practice skills so that their reflections can be meaningful and useful in order to increase the quality of patient care.

The term reflective practice might not resonate with medical trainees or the medical community. Perhaps the term "reflective practice" needs to be changed to 


\section{Reflective Practice and Readiness for Self-directed Learning}

another term that learners and medical professions can embrace. Instead of using the term "reflective practice" when teaching reflection, which to a learner could mean long exercises that have little to do with patient care, programs could use the term "case debriefing”, "patient review seminar", "practice review” or "peer teaching seminar". By coining new terminology for reflective practice that more closely relates to a trainees daily tasks or practice, programs may be able to entice their learners to engage in reflection because the learner does not view it as a task that is unrelated to their training or patient care priorities.

This study found that participating in reflective exercises alone did not increase the readiness for self-directed learning in these study participants however, the literature reviewed clearly articulated that there is a need for physicians to engage in reflective practice in order to be self-directed lifelong physician learners. Considering the results of this study, I recommend that the skill of reflection be taught throughout medical education, starting in medical school. By giving medical students the skills needed to become reflective learners, we are helping students prepare to be lifelong learners. Furthermore, reflective practice should be incorporated into residency program curricula so that residents have time to develop, practice and incorporate the skill of reflective practice into their professional practice. Lastly, reflective exercises should not be a stand alone activity. By interweaving reflective exercises into learning tools and daily activities that learners feel are a part of their training and patient care tasks, such as problem based 
Reflective Practice and Readiness for Self-directed Learning

learning discussions, case presentations, learning from peers and patient rounds, reflective practice will become a routine part of physician practice.

\section{Implications for Future Research and Next Steps}

Physician lifelong learning is vital to provide the best and safest care for patients. As medical technology and information proliferates it is important to for physicians to be self-directed in their learning so they can better care for their patients. In light of research on the effectiveness of formal continuing medical education programs and the current status of medical education discussed in chapter 2 , it seems that medical education needs to develop ways to help physicians become more self-directed in their learning to foster a greater propensity to engage in lifelong learning. Although previous studies have shown reflective practice to increase self-directed learning (Bravata, Hout, Abernathy, Skeff \& Bravata, 2003; Riley-Douchet \& Wilson, 1997; Schilling, Steiner, Lundahl \& Anderson, 2005; Williams, 2001) this study did not conclude with similar results. And, despite the heightened discussion of reflection as a topic of importance in the medical education literature, there is little evidence to help educators understand how to cultivate the skill of reflection in their learners (Mann, Gordon \& MacLeod, 2007).

This study sought to provide empirical evidence to address if participating in reflective exercises could be used as one method to increase self-directed learning among anesthesiology residents. This study also sought to determine if engaging in reflective exercises affected future reflective practice or attitudes about reflective practice. After analyzing the results of this study it is clear that more research needs to be done on ways 


\section{Reflective Practice and Readiness for Self-directed Learning}

to increase both reflective practice and the readiness for self-directed learning in anesthesiology residents. Future research needs to take into consideration factors which might have influenced the results of this study. Suggestions for future research include:

1) Replicating this study with a larger sample size. Including more institutions would be one way of gaining further insight into reflective practice and self-directed learning.

2) Future studies should look at other forms of reflective exercises to see if a different form of reflective exercise has an impact on self-directed learning. Perhaps a more social model of reflection, such as a physician faculty member questioning a trainee about patient care or a specific case, small group discussions, group debriefings, team-based reflections and/or critical incident analysis, could be used to elicit reflective thought (Cheethan \& Chivers, 2001; Lockyer, Gondoc \& Thivierge, 2005).

3) Future research should be conducted with programs that are known to intentionally teach reflective practice as part of the formal training program curriculum. The findings of this research could be used to help determine if reflective practice is better taught over time or by using a more hands-on approach as opposed to being a short duration of time and self-guided.

4) Bain, Mills, Ballantyne \& Packer (2002) assert that feedback on reflective writing is important in order to help learners attain a deep level of reflection. Research looking at both written and oral feedback from faculty on reflective writing from 
Reflective Practice and Readiness for Self-directed Learning residents would help us understand if feedback on reflection leads to higher posttest SDLRS/LPA scores than pretest scores. Further research using the openended reflective exercise responses from this study may help explain the lack of statistical significance among the results. Were the responses truly reflective? Did the participants identify ways to further their understanding of the incident in which they reflected? Did longer, more detailed responses lead to higher posttest SDLRS/LPA scores in participants?

5) Long-term longitudinal studies should be conducted to understand the impact of reflective exercises on physician future practice.

\section{Next steps.}

This study has inspired several next steps for this researcher. The next steps include:

1) Analyze the open-ended reflective exercise responses from this study in order to understand if the participants in this study truly reflected on their practice. In particular the researcher will focus on if longer, more detailed responses to the open-ended questions led to higher posttest SDLRS/LPA scores in participants?

2) Develop a study looking at the readiness for self-directed learning in anesthesiology trainees currently participating in problem-based learning discussions (PBLDs) at the institution in which the researcher works. The PBLD's were developed as a way to incorporate individual and peer reflection and feedback into the anesthesiology residency training curriculum. The researcher 
Reflective Practice and Readiness for Self-directed Learning

hypothesizes that the social reflection that occurs in the PBLDs, as opposed to the individual reflection used in this study, will increase readiness for self-directed learning.

3) Rerun this study with a larger group of participants across multiple specialties.

\section{Conclusion}

With the rapid advance of scientific and medical technologies, it is important for physicians to develop new ways of thinking and learning in order to address the challenges of patient care and safety (Drain, Primack, Hunt, Fawzi, Holmes and Gardner, 2007). The literature is calling for more techniques to teach self-directed, lifelong learning techniques to help improve patient safety and drive educational inquiry among medical professionals however, little is known about how to develop these traits during clinical training (Dolmans, De Grave, Wolfhagen \& van der Vleuten, 2005; Li, Paterniti, Patrick, West, 2010). Reflection has been posited as one way that physicians can evaluate what they know and do not know and mitigate gaps in their knowledge. Evaluating what they know and do not know and seeking to mitigate gaps in their knowledge is one way physicians can engage in self-directed, lifelong learning practices to best serve their patients (Izatt, 2007; Mazmanian \& Davis, 2002; Stewart, O’Halloran, Barton, Singleton, Harrigan \& Spencer, 2003).

Previous studies have shown that it is possible to increase self-directed learning tendencies in learners in graduate medical education through learning portfolios, problem based learning, goal articulation, web-based learning modules and reflection (Bravata, 
Reflective Practice and Readiness for Self-directed Learning

Hout, Abernathy, Skeff \& Bravata, 2003; Fung Kee Fung et al. 2000; Schilling, Steiner, Lundahl \& Anderson, 2005, Shokar et al., 2002). Although this study was unable to substantiate that a self-guided reflective exercise, based on Gibb's (1988) model of reflection, increased the readiness for self-directed learning in anesthesiology residents this study does add to the body of knowledge about reflection and self-directed learning. This study also helps direct future research. It is clear, based on the literature review in this study as well as the study findings that residents, professional organizations and medical associations are calling on residency programs to teach skills that help residents reflect upon their practice so that they may be self-directed, lifelong learners in order to improve patient quality and care outcomes. 
Reflective Practice and Readiness for Self-directed Learning

References

Accrediation Council for Graduate Medical Education. (n.d.). The ACGME at a glance.

Retrieved from

http://www.acgme.org/acWebsite/newsRoom/newsRM_acGlance.asp

Accreditation Council for Graduate Medical Education. (2005). Outcome project.

Retrieved from http://www.acgme.org/Outcome/

Accreditation Council for Graduate Medical Education. (2007, February 13). Common

program requirements: General competencies. Retrieved from

http://www.acgme.org/outcome/comp/GeneralCompetenciesStandards21307.pdf

Accreditation Council for Graduate Medical Education. (2010, September 29). Glossary

of terms. Retrieved from

http://www.acgme.org/acWebsite/about/ab_ACGMEglossary.pdf

Accreditation for Graduate Medical Education. (2008, July). ACGME program

requirements for graduate medical education in anesthesiology. Retrieved from

http://www.acgme.org/acWebsite/downloads/RRC_progReq/040_anesthesiology_ 07012008_u03102008.pdf

Ainoda, N., Onishi, H., \& Yasuda, Y. (2005). Definitions and goals of "self-directed learning" in contemporary medical education literature. Annals Academy Medicine Singapore, 34, 515-519.

Alexander, P. A. (1995). Superimposing a situation-specific and domain-specific 
Reflective Practice and Readiness for Self-directed Learning perspective on an account of self-regulated learning. Educational Psychologist, 30(3), 189-193.

American Board of Internal Medicine. (n.d.). Board certification guide. Retrieved from http://www.abim.org/certification/

American Medical Association. (n.d.). About the american medical association. Retrieved from http://www.ama-assn.org/ama/pub/about-ama.shtml American Medical Association. (2010). Medical ethics. Retrieved from http://www.ama-assn.org/ama/pub/physician-resources/medical-ethics/codemedical-ethics.shtml

Argyris, C., Schon, D. A. (1978). Organizational learning: A theory of action perspective. Reading, MA: Addison-Wesley.

Association of American Medical Colleges. (n.d.). General recommendations. Retrieved from https://www.aamc.org/initiatives/meded/lifelong/recommendations-nav/ Association of American Medical Colleges. (2004, July 1). Publications. Retrieved from Association of American Medical Colleges: http://services.aamc.org/publications/showfile.cfm?file=version27.pdf

Association of American Medical Colleges (2004). Educating doctors to provide high quality medical education: A vision for medical educaiton in the united states. Washington, DC: Author.

Atkins, S., \& Murphy, K. (1993). Reflection: A review of the literature. Journal of Advanced Nursing, 18, 1188-1192. 
Reflective Practice and Readiness for Self-directed Learning

Bain, J., Mills, C., Ballantyne, R. \& Packer, J. (2002). Developing reflection on practice through journal writing: Impacts of variations in the focus and level of feedback, Teachers and Teaching: Theory and Practice, 8(2), 171-195.

Beck, A. (2004). The Flexner report and the standardization of American medical education. The Journal of the American Medical Association, 291, 2139-2140.

Belfield, C., Thomas, H., Bullock, A., Eynon, R., \& Wall, D. (2001). Measuring effectiveness for best evidence medical education: A discussion. Medical Teacher, 23(2), 164-170.

Bennett, N. L., Casebeer, L. L., Zheng, S., \& Kristofco, R. (2006). Information-seeking behaviors and reflective practice. The Journal of Continuing Education in the Health Professions, 26(2), 120-127.

Bennett, N., Davis, D., Easterling, W., Friedmann, P., Green, J., Koeppen, B., et al. (2000). Continuing medical education: A new vision of the professional development for physicians. Academic Medicine, 75, 1167-1172.

Bloom, B. S. (2005). Effects of continuing medical education on improving physician clinical care and patient health: A review of systematic reviews. International Journal of Technology Assessment in Health Care, 21(3), 380-385.

Blumenthal, D., Gokhale, M., Campbell, E. G., \& Weissman, J. S. (2001). Preparedness for clinical practice. The Journal of the American Medical Association, 286, 1027-1034.

Bolhuis, S. (2003). Towards process-oriented teaching for self-directed lifelong learning: 
Reflective Practice and Readiness for Self-directed Learning A multidimensional perspective. Learning and Instruction, 13(3), 327-347.

Bowen, J. L., Salerno, S. M., Chamberlain, J. K., Eckstrom, E., Chen, H., \& Brandenburg, S. (2005). Changing habits of practice: Transforming internal medicine residency education in ambulatory settings. Journal of General Internal Medicine, 20, 1181-1187.

Branch, W. T., \& Paranjape, A. (2002). Feedback and reflection: Teaching methods for clinical settings. Academic Medicine, 77, 1185-1188.

Bravata, D. M., Hout, S. J., Abernathy, H. S., Skeff, K. M., \& Bravata, D. M. (2003). The development and implementation of a curriculum to improve clinicians' selfdirected learning skills: A pilot project. BioMed Central Medical Education, 3(7), $1-8$.

Brockett, R. G. (1985). Methodological and substantive issues in the measurement of self-directed learning readiness. Adult Education Quarterly, 36(1), 15-24.

Brockett, R. G., \& Hiemstra, R. (1991). Self-direction in adult learning: Perspectives on theory, research, and practice. London, England: Routledge.

Bulman, C., \& Schutz, S. (2004). Reflective practice in nursing (3rd ed.). Oxford: Blackwell Publishing.

Burton, S. (2000). A critical essay on professional development in dietetics through a process of reflection and clinical supervision. Journal of Human Nutrition and Dietetics, 13, 323-332.

Caffarella, R. S., \& Caffarella, E. P. (1986). Self-directedness and learning contracts in 
Reflective Practice and Readiness for Self-directed Learning adult education. Adult Education Quarterly, 36, 226-234.

Caffarella, R. S., \& O'Donnell, J. M. (1991). Judging the quality of work related, selfdirected learning. Adult Education Quarterly, 42(1), 17-29.

Candy, P. C. (1991). Self-direction for lifelong learning: A comprehensive guide to theory and practice. San Francisco, CA: Jossey-Bass.

Carney, P. A., Nierenberg, D. W., Pipas, C. F., Brooks, W. B., Stukel, T. A., \& Keller, A. M. (2004). Educational epidemiology: Applying population-based design and analytic approaches to study medical education. Journal of the American Medical Association, 292, 1044-1050.

Centers, C. T. (2002). Training tomorrow's doctors: The medical education mission of academic health centers. New York, NY: Commonwealth Fund.

Cleophas, T.J. \& Zwinderman, A.H. (2011). Non-parametric tests: Statistical analysis of clinical data on a pocket calculator. Amsterdam, Netherlands: Springer.

Committee on the Roles of Academic Health Centers in the $21^{\text {st }}$ Century (2003). Academic health centers: Leading change in the 21st century. Washington DC: Institute of Medicine.

Chassin, M. R., Galvin, R. W., \& The National Roundtable on Health Care Quality. (1998). The urgent need to improve health care quality: Institute of Medicine national roundtable on health care quality. Journal of the American Medical Association, 280, 1000-1006.

Chastonay, P., Brenner, E., Peel, S., \& Guilbert, J. J. (1996). The need for more effacacy 
Reflective Practice and Readiness for Self-directed Learning and relevance in medical education. Medical Education, 30, 235-236.

Cheetham G.J., \& Chivers G. (2001). How professionals learn the practice! What the empirical research found. Journal of European Industrial Training, 25, 270-292.

Choudhry, N. K., Fletcher, R. H., \& Soumeral, S. B. (2005). Systenatic review: The relationship between clinical experience and quality of health care. Annals of Internal Medicine, 142, 260-273.

Clouder, L. (2000). Reflective practice in physiotherapy education: A critical conversation. Studies in Higher Education, 25, 211-223.

Cooke, M., Irby, D. M., Sullivan, W., \& Ludmerer, K. M. (2006). American medical education 100 years after the Flexner report. New England Journal of Medicine, $355,1339-1344$.

Cox, E. (2005). Adult learners learning from experience: Using a reflective practice model to support work-based learning. Reflective Practice, 6, 459-472.

Creswell, J. W. (2005). Educational Research (Vol. 2nd). Columbus, OH: Pearson.

Dane, E. (2010). Reconsidering the trade-off between expertise and flexibility: A cognitive entrenchment perspective. The Academy of Management Review, 35, 579-603.

Daniels, E.B. (2011). The impact of an educational intervention on self-directed learning readiness and behaviors in undergraduate nursing students (Doctoral Dissertation). Retrieved from Dissertations and Masters Theses. (AAT 3450542)

Davis, D. A., Mazmanian, P. E., Fordis, M., Van Harrison, R., Thorpe, K. E., \& Perrier, 
Reflective Practice and Readiness for Self-directed Learning

L. (2006). Accuracy of physician self-assessment compared with observed measures of competence. Journal of the American Medical Association, 296, 1094-1102.

Davis, D. A., Thomson, M. A., Oxman, A. D., \& Haynes, B. (1995). Changing physician performance: A systematic review of the effect of continuing medical education strategies. The Journal of the American Medical Association, 274, 700-705.

Davis, D., Thomoson O'Brien, M. A., Freemantle, N., Wolk, F., Mazmanian, P., \& Taylor-Vaisey, A. (1999). Impact of formal continuing medical education. The Journal of the American Medical Association, 282, 867-874.

Dewey, J. (1933). How we think: A restatement of the relation of reflective thinking to the educative process. Boston, MA: Heath.

Dinkevich, E., \& Ozuah, P. (2003). Self-directed learning activities of pediatric residents. Medical Education, 37, 388-389.

Dolmans, D. H., De Grave, W., Wolfhagen, I., \& van der Vleuten, C. (2005). Problembased learning: Future challenges for educational practice and research. Medical Education, 39, 732-741.

Drian, P. K., Primack, A., Hunt, D. D., Fawzi, W. W., Holmes, K. K., \& Gardner, P. (2007). Global health in medical education: A call for more training and opportunities. Academic Medicine, 82, 226-230.

Duffy, D. F., \& Holmboe, E. S. (2006). Self-assessment in lifelong learning and improving performance in practice. The Journal of the American Medical 
Reflective Practice and Readiness for Self-directed Learning Association, 296, 1137-1139.

Duke, S., \& Appleton, J. (2000). The use of reflection in a palliative care programme: A quantitative study of the development of reflective skills over an academic year. Journal of Advanced Nursing, 32, 1557-1568.

Edwards, P., Roberts, I., Clarke, M., DiGuiseppi, C., Pratap, S., Wentz, R., et al. (2002). Increasing response rates to postal questionnaires: systematic review. British Medical Journal, 324, 1188-1196.

Ellinger, A. D. (2004). The concept of self-directed learning and its implecations for human resource development. Advances for Developing Human Resources, 6, $158-177$.

Elstein A. S., Shulman L. S., Sprafka S. A. (1978). Medical problem solving: An analysis of clinical reasoning. Cambridge, MA: Harvard University Press.

Elstein A. S., Shulman L. S., \& Sprafka S. A. (1990). Medical problem solving: A 10year retrospective. Evaluation \& the Health Professions, 13, 5-36.

Elwood, J., \& Klenowski, V. (2002). Creating communities of shared practice: The challenges of assessment use in learning and teaching. Assessment \& Evaluation in Higher Education, 3, 243-256.

Ernst, P. (1994). Varieties of constructivism: Their metaphors, epistemologies and pedagogical implications. Hiroshima Journal of Mathematics Education 2, 1-14.

Evans, A. W., Leeson, R. M., \& Petrie, A. (2007). Reliability of peer and self-assessment scores compared with trainers' scores following third molar surgery. Medical 
Reflective Practice and Readiness for Self-directed Learning

Education, 41, 866-872.

Field, L. (1989). An investigation into the structure, validity, and reliability of Guglielmino's self-directed learning readiness scale. Adult Education Quarterly, $39,125-139$.

Findley, B. W. (2009). The relationship of self-directed learning readiness to knowledgebased and performance-based measures of success in third-year medical students (Doctoral Dissertation). Retrieved from Dissertations and Masters Theses. (AAT 3370082)

Finestone, P. (1984). A construct validation of the Self-directed Learning Readiness Scale with labor education participants (Doctoral Dissertation). Retrieved from Dissertations and Masters Theses. (ATT NK65151)

Fisher, M., King, J., \& Tague, G. (2001). Development of a self-directed learning readiness scale for nursing education. Nurse Education Today, 21, 516-525.

Flexner, A. (1910). Medical education in the United States and Canada: A report to the Carnegie Foundation for the Advancement of Teaching. New York, NY: The Carnegie Foundation for the Advancement of Teaching.

Fung Kee Fung, M., Walker, M., Fung Kee Fung, K., Temple, L., Lajoie, F., Bellemare, G., et al. (2000). An internet-based learning portfolio in resident education: The KOALA multicentre programme. Medical Education, 34, 474-479.

Gibbs, G. (1988). Learning by doing: A guide to teaching and learning methods. London, England: Further Education Unit. 
Reflective Practice and Readiness for Self-directed Learning

Glaze, J. E. (2001). Reflection as a transforming process: Student advanced nurse practitioners' experiences of developing reflective skills as part of an MSc programme. Journal of Advanced Nursing, 34, 639-647.

Gonnella, J. S., Callahan, C. A., Louis, D. Z., Hojat, M., \& Erdmann, J. B. (2004). Medical education and health services research: The linkage. Medical Teacher, $26,7-11$.

Grol, R. (2002). Changing physicians' competence and performance: Finding the balance between the individual and the organization. The Journal of Continuing Education in the Health Professions, 22, 244-251.

Guglielmino \& Associates. (2010, January 14). Retrieved from http://www.guglielmino734.com

Guglielmino, L. M. (1978). Development of the Self-directed Learning Readiness Scale (Doctoral Dissertation). Retrieved from Dissertation Abstracts International. (AAT 7806004).

Guglielmino, L. M. (1989). Guglielmino responds to Fields' investigation. Adult Education Quarterly, 39, 235-240.

Guglielmino, P. J., Guglielmino, L., \& Long, H. B. (1987). Self-directed learning readiness and performance in the workplace. Higher Education, 16, 303-317.

Guglielmino, L. M., Long, H. B., \& Hiemstra, R. (2004). Self-directed learning in the United States. International Journal of Self-Directed Learning, 1 (1), 1-17. Hartree, A. (1984). Malcolm Knowles' theory of andragogy: A critique. International 
Reflective Practice and Readiness for Self-directed Learning Journal of Lifelong Education, 3, 203-210.

Harvey, J. B., Rothman, A. I., \& Frecker, R. C. (2003). Effect of an undergraduate medical curriculum on students' self-directed learning. Academic Medicine, 78, 1259-1265.

Hassan, A. J. (1981). An investigation of the learning projects of adults of high and low readiness for self-directed learning (Doctoral Dissertation). Retrieved from Dissertations and Masters Theses. (AAT 8128826)

Hazlett, C. B., Bachynski, J. E., \& Embleton, J. (1973). Evaluation of on-campus continuing medical education programs in Alberta. Canadian Medical Association Journal, 108, 1282-1287.

Hiemstra, R. (1975). The older adult and learning. (ERIC Document Reproduction Service No. ED 117 371).

Hoban, J. D., Lawson, S. R., Mazmanian, P. E., Best, A. M., \& Seibel, H. R. (2005). The self-directed leatning readiness scale: A factor analysis study. Medical Education, $39,370-379$.

Hoff, T. J., Pohl, H., \& Bartfield, J. (2004). Creating a learning environment to produce competent residents: The roles of culture and context. Academic Medicine, 79, $532-540$.

Hojat, M., Nasca, T. J., Erdmann, J. B., Frisby, A. J., Veloski, J., \& Gonnella, J. S. (2003). An operational measure of physician lifelong learning: Its development, components and preliminary psychometric data. Medical Teacher, 25, 433-437. 
Reflective Practice and Readiness for Self-directed Learning

Hojat, M., Veloski, J., Nasca, T. J., Erdmann, J. B., \& Gonnella, J. S. (2006). Assessing physicians' orientation toward lifelong learning. Journal of General Internal Medicine, 21, 931-936.

Holm, H. A. (1998). Quality issues in continuing medical education. British Medical Journal, 316, 621-624.

Horsley, T., O'Neill, J., McGowan, J., Perrier, L., Kane, G., \& Campbell, C. (2010, March 10). Interventions to improve question formulation in professional practice and self-directed learning (Review). Retrieved from The Cochrane Library: http://www.thecochranelibrary.com/view/0/index.html

Houle, C. O. (1961). The inquiring mind. Madison, WI: University of Wisconsin Press. Houle, C. O. (1972). The design of education. San Francisco, CA: Jossey-Bass. Institute of Medince. Kohn, L. (Ed.). (2003). Academic health centers: Leading the change in the 21st century. Washington, D.C.: The National Academic Press.

Institute of Medicine. Kohn, L. T., Corrigan, J. M., \& Donaldson, M. S. (Eds.). (1999). To err is human. Washington, DC: National Academy Press.

Izatt, S. (2007). Portfolios: The next assessment tool in medical education? NeoReviews, $8,405-408$

Jasper, M. (2003). Begining reflective practice. Cheltenham, PA: Nelson Thornes Ltd. Johns, C. (1994). Nuances of reflection. Journal of Clinical Nursing, 3, 71-75.

Kaufman, D. M. (2003, January 25). ABC of learning and teaching in medicine: Applying educational theory in practice. British Medical Journal, 326, 213-216. 
Reflective Practice and Readiness for Self-directed Learning

Kayes, D. C. (2002). Experiential learning and its critics: Preserving the role of experience in management education. Academy of Management Learning and Education, 1, 137-149.

Kilian, B. J., Binder, L. S., \& Marsden, J. (2007). The emergency physician and knowledge transfer: Continuing medical education, continuing professional development, and self-improvement. Academic Emergency Medicine, 14, 10031007.

Kneebone, R. L., (2009). An approch for simulation-based surgical and procedure training. The Journal of the American Medical Association, 12, 1336-1338.

Knowles, M. S. (1970). The modern practice of adult education: Andragogy vs. pedagogy. Chicago, IL: Association Press/Follett.

Knowles, M. S. (1975). Self-directed learning. New York, NY: Association Press.

Knowles, M.S. (1979). Andragogy revisited part II. Adult Education, 30, 52-53.

Knowles, M. S. (1980). The modern practice of adult education: From pedagody to andragogy (2nd ed.). New York, NY: Cambridge Books.

Knowles, M. (1984). Andragogy in action. San Francisco, CA: Jossey-Bass.

Kolb, D. A. (1984). Experiential learning: Experience as the source of learning and development. Englewood Cliffs, N.J.: Prentice-Hall, Inc.

Kolb, D. A., Boyatzis, R. E., \& Mainemelis, C. (1999, August 31). Experiential learning theory: Previous research and new directions. Cleveland, Ohio: Unpublished manuscript. 
Reflective Practice and Readiness for Self-directed Learning

Leeb, J. G. (1983). Self-directed learning and growth toward personal responsibility: Implecations for a framework for health promotion (Doctoral Dissertation). Retrieved from Dissertation and Masters Theses. (AAT 8410729)

Li, S.-T., Paterniti, D. A., Patrick, J. T., \& West, D. C. (2010). Successful self-directed lifeling learning in medicine: A conceptual model derived from qualitative analysis of a national survey or pediatric residents. Academic Medicine, 85, 1229-1236.

London, J. (1973). Adult education for the 1970's: Promise or illusion. Adult Education, 24(1), 60-70.

Loughran, J. J. (2002). Effective reflective practice: In search of meaning in learning about teaching. Journal of Teacher Education, 53, 33-43.

Lujan, H. L., \& DiCarlo, S. E. (2006). Too much teaching, not enough learning: What is the solution. Advances in Physiology Education, 30, 17-22.

Mackintosh, C. (1998). Reflection: A flawed strategy for the nursing profession. Nurse Education Today, 18, 553-557.

Mamede, S., \& Schmidt, H. G. (2004). The structure of reflective practice in medicine. Medical Education, 38, 1302-1308.

Mamede, S., \& Schmidt, H. G. (2005). Correlates of Reflective Practice in Medicine. Advances in Health Sciences Education, 10, 327-337.

Manning, P. R., \& Petit, D. W. (1987). The past, present, and future of continuing medical education: Achievements and opportunities, computers and 
Reflective Practice and Readiness for Self-directed Learning recertification. The Journal of the American Medical Association, 258, 35423546.

Mansouri, M., \& Lockyer, J. (2007). A meta-analysis of continuing medical education effectiveness. Journal of Continuing Education in the Health Professions, 27, 6-15.

Marinopoulos, S. S., Dorman, T., Ratanawongsa, N., Wilson, L. M., Ashar, B. H., Magaziner, J. L., et al. (2007). Effectiveness of continuing medical education. Johns Hopkins, Evidence-based Practice Center. Rockville, IN: Agency for Healthcare Research and Quality.

Mays, N., \& Pope, C. (2000). Qualitative research in health care: Assessing quality in qualtitative research. British Medical Journal, 320, 1-3.

Mazmanian, P. E., \& Davis, D. A. (2002). Continuing medical education and the physician as a leader: Guide to evidence. The Journal of the American Medical Association, 288, 1057-1060.

Mazmanian, P. E., Davis, D. D., \& Galbraith, R. (2009). Continuing medical education effect on clinical outcomes: Effectiveness of continuing medical education: American College of Chest physicians evidence-based educational guidelines. Chest, 135, 59-55.

McGlynn, E. A., Asch, S. M., Adams, J., Keesey, J., Hicks, J., DeCristofaro, A., et al. (2003). The quality of health care delivered to adults in the United States. The New England Journal of Medicine, 348, 2635-2645. 
Reflective Practice and Readiness for Self-directed Learning

Melnick, D. E. (2004). Physician performance and assessment and their effect on continuing medical education and continuing professional development. The Journal of Continuing Education in the Health Professions, 24, 38-49.

Merriam, S., Caffarella, R., \& Baumgartner, L. (2007). Learning in adulthood: A comprehensive guide (4th ed.). San Francisco, CA: Jossey-Bass.

Merriam-Webster. (n.d.). Retrieved from http://www.merriam- webster.com/ Miettinen, R. (2000). The concept of experiental learning and John Dewey's theory of reflective thought and action. International Journal of Lifelong Education, 19, 5472.

Muller, P. S., Barrier, P. A., Call, T. G., Duncan, A. K., Hurley, D. L., Multari, A., et al. (2006). Views of new internal medicine faculty of their preparedness and competence in physician-patient communication. BioMed Central Medical Education, 30, 1-7.

National Board of Osteopathic Medical Examiners. (n.d.). About NBOME. Retrieved from http://www.nbome.org/about.asp

Newby, R., Watson, J., \& Woodliff, D. (2003). SME survey methodology: Response rates, data quality, and cost effectiveness. Entrepreneurship Theory and Practice, 163-172.

O'Shea, E. (2003). Self-directed learning in nurse education: A review of the literature. Journal of Advanced Nursing, 43, 62-70. 
Reflective Practice and Readiness for Self-directed Learning

Oliveira, A.L., Silva, J.T., Guglielmino, L.M., \& Guglielmino, P.J. (2009). A crosscultural study of self-directed learning readiness, performance, creativity, and problem-solving in a sample from Portugal. International Journal of Self-Directed Learning, 6(2), 45 - 59.

Osler, W. (1900). An address on the importance of post-graduate study. The British Medical Journal, 2(2063), 73-75.

Osler, W. (1913). An introductory address on examinations, examiners and examinees. Lancet, ii, 1047-1050.

Paget, T. (2001). Reflective practice and clinical outcomes: Practitioners' views on how reflective practice has influenced their clinical practice. Journal of Clinical Nursing, 10, 204-214.

Patrick, H., \& Williams, G. C. (2009). Self-determination in medical education: Encouraging medical educators to be more like blues artists and poets. Theory and Research in Education, 7, 184-193.

Piget, J. (1952). The origins of intelligence in children. New York, NY: International Universities Press.

Pippalla, R., Riley, D., \& Chinburapa, V. (1995). Influencing the prescribing behavior of physicians: A meta-analysis. Journal of Clinical Pharmacy and Therapeutics, 20, 189-198.

Pilling-Cormick, J., \& Bulik, R. J. (1999). A preliminary study exploring the use of the self-directed learning perception scale in a clinical setting. In H. B. Long \& 
Reflective Practice and Readiness for Self-directed Learning Associates, Contemporary ideas and practices in self-directed learning (pp. 103116). Norman, OK: Public Managers Center, College of Education, University of Oklahoma.

Pilling-Cormick, J., \& Bulik, R. J. (2000). Further investigation into the use of the SDLRS in a clinical setting. In H. B. Long \& Associates, Practice \& theory in self-directed learning (pp. 219-230). Schaumburg, IL: Motorola University Press.

Plack, M. M. (2005). The reflective practitioner: Reaching for excellence in practice. Pediatrics, 116, 1546 - 1552.

Platzer, H., Blake, D., \& Ashford, D. (2000). An evaluation of process and outcomes from learning through refelctive practice groups on a post-registration nursing course. Journal of Advanced Nursing, 31, 689-695.

Rachal, J. R. (2002). Andragogy's detectives: A critique of the present and a proposal for the future. Adult Educaiton Quarterly, 52, 210-227.

Regnier, K., Kopelow, M., Lane, D., \& Alden, E. (2005). Accreditation for learning and change: Quality and improvement as the outcome. The Journal of Continuing Education in the Health Professions, 25, 174-182.

Reio, T. G., Jr., \& Davis, W. (2005). Age and gender differences in self-directed learning readiness: A developmental perspective. International Journal of Self-Directed Learning, 2(1), 40-49.

Riley-Doucet, C., \& Wilson, S. (1997). A three-step method of self-reflection using reflective journal writing. Journal of Advanced Nursing, 25, 964-968. 
Reflective Practice and Readiness for Self-directed Learning

Rose G.L., Brown, R.E. (2010). The impared anesthesiologist: Not just about drugs and alcohol anymore. Journal of Clinical Anesthesia, 22, 379-384.

Rolfe, G., Freshwater, D., \& Jasper, M. (2001). Critical reflection for nursing and the helping professions. Palgrave: Basing-stroke.

Ruth-Sahd, L. A. (2003). Reflective practice: A critical Analysis of data-based studies and implications for nursing education. Journal of Nursing Education, 42, 488497.

Ryan, J. (2003). Continuous professional development along the continuum of lifelong learning. Nurse Education Today, 23, 498-508.

Ryan, M. R., \& Deci, L. E. (2000). Self determination theory and the facilitation of intrinsic motivation, social development, and well-being. American Psychologist, 55, 68-78.

Sargeant, J. M., Mann, K. V., van der Vleuten, C. P., \& Metsemakers, J. F. (2009). Reflection: A link between receiving and using assessment feedback. Advances in Health Science Education, 14, 399-410.

Savery, J. R. (2006). Overview of problem-based learning: Definitions and distinctions. The Interdisciplinary Journal of Problem-based Learning, 1 (1), 9-20.

Schmidt, H.K., \& Rikers, M.J. (2007). How expertise develops in medicine: Knowledge encapsulation and illness script formation. Medical Education, 41, 1133-1139.

Schmidt, H. G., Vermeulen, L., \& van der Molen, H. T. (2006). Longterm effects of 
Reflective Practice and Readiness for Self-directed Learning problem-based learning: A comparison of competencies acquired by graduates of a problem-based and convential medical school. Medical Education, 40, 562-567.

Schon, D. A. (1983). The reflective practitioner: How professionals think in action. New York, NY: Basic Books.

Schon, D. A. (1987). Educating the reflective practitioner: Towards a new design for teaching and learning in the professions. San Francisco, CA: Jossey-Bass.

Seaman, J. (2008). Experience, reflect, critique: The end of the "learning cycles" era. Journal of Experiential Education, 31 (1), 3-18.

Sharp, L. K., Wang, R., \& Lipsky, M. S. (2003). Perception of competency to perform procedures and future practice intent: A national survey of family practice residents. Academic Medicine, 78, 926-932.

Shaughnessy, A., \& Slawson, D. (1999). Are we providing doctors with the training and tools for lifelong learning? British Medical Journal, 319, 1-3.

Shepard, L. (2000). The role of assessment in a learning culture. Educational Researcher, 29(7), 4-14.

Shokar, G. S., Shokar, N. K., Romero, C. M., \& Bulik, R. J. (2002). Self-directed learning: Looking at outcomes with medical students. Family Medicine, 34, 197-200.

Sfard, A. (1998). On two metaphors and the dangers of choosing just one. Educational Researcher, 27(2), 4-13.

Sobral, D. T. (2000). An appraisal of medical students' refection-in-learning. Medical 
Reflective Practice and Readiness for Self-directed Learning Education, 34, 182-187.

Sparling, L. (2001). Enhancing the learning in self-directed learning modules. Journal for Nurses in Steff Development, 17, 199-205.

Spivey, B. E. (2005). Continuing medical education in the United States: Why it needs reform and how we propose to accomplish it. The Journal of Continuing Education in the Health Professions, 25, 134-143.

Steeh, C., Kirgis, N., Cannon, B., \& DeWitt, J. (2001). Are they really as bad as the seem? Nonresponse rates at the end of the twentieth century. Journal of Official Statistics, 17, 227-247.

Schilling, L. M., Steiner, J. F., Lundahl, K., \& Anderson, R. J. (2005). Residents' patientspecific clinical questions: Opportunities for evidence-based learning. Academic Medicine, 80, 51-56.

Stewart, J., O'Halloran, C., Barton, J. R., Singleton, S. J., Harrigan, P., \& Spencer, J. (2003). Clarifying the concepts of confidence and competence to produce appropriate self-evaluation measurement scales. Medical Education, 34, 903-909.

The American Board of Anesthesiology. (n.d.). About the ABA. Retrieved from http://www.theaba.org/Home/About

The Blue Ridge Academic Group. (2003). Reforming medical education: Urgent priority for academic health centers in the new century. Atlanta, GA: Robert W. Woodruff Health Sciences Center.

Tough, A. (1971). The adult's learning projects: A fresh approach to theory and practice 
Reflective Practice and Readiness for Self-directed Learning in adult learning. Toronto, Ontario: Ontario Institute for Studies in Adult Education.

Tough, A. (1979). The adult's learning projects: A fresh approach to theory and practice in adult learning (2nd ed.). Toronto, Ontario: Ontario Institute for Studies in Adult Education.

Towle, A., \& Cottrell, D. (1996). Self directed learning. Diseases in Childhood, 74, 357359.

The Common Wealth Fund (2002). Training tomorrow's doctors: The medical education mission of academic health centers. New York, NY: The Common Wealth Fund.

Vygotsky, L.S. (1978). Mind in society: The development of higher psychological process. Cambridge, MA: Harvard Univeristy Press.

Ward, M., MacRae, H., Schlachta, C., Mamazza, J., Poulin, E., Reznick, R., et al. (2003). Resident self-assessment of operative performance. The American Journal of Surgery, 185, 521-524.

Westberg, J., \& Hilliard, J. (2001). Fostering Reflection and Providing Feedback: Helping others learn from experience. New York, NY: Springer Publishing Company Inc.

Williams, B. (2001). Developing critical reflection for professional practice through problem-based learning. Journal of Advanced Nursing, 34, 27-34.

Williamson, J. W., Alexander, M., \& Miller, G. E. (1967). Continuing education and patient care research. Journal of the American Medical Association, 201, 938-942. 
Reflective Practice and Readiness for Self-directed Learning

Williamson, J. W., Alexander, M., \& Miller, G. E. (1967). Continuing education and patient care research: Physician response to screening test results. The Journal of the American Medical Association, 201, 118-122.

Williams, R., \& Wessel, J. (2004). Reflective journal writing to obtain student feedback about their learning during the study of chronic musculoskeletal conditions. Journal of Allied Health, 33, 17-23. 
Reflective Practice and Readiness for Self-directed Learning

Appendix A: Definition of Terms

Accreditation Council for Graduate Medical Education (ACGME) - The

ACGME is a private, not for profit organization that evaluates and accredits medical residency and fellowship programs in the United States. The mission of the ACGME is to is to improve healthcare by assessing and advancing the quality of graduate medical education through the accreditation process (Accreditation Council for Graduate Medical Education, 2010).

American Medical Association (AMA) - The AMA is a professional organization whose membership consists of physicians and medical students. The mission of the AMA is to protect the interests of American physicians, advance public health and support the growth of medical science. The AMA engages in medical research on drugs, foods, cosmetics and other substances and sponsors health education programs. The AMA also publishes the Journal of the American Medical Association (JAMA) (The American Medical Association, 2010).

American Board of Anesthesiology $(A B A)$ - The ABA is the professional board for physicians practicing anesthesiology that "examines and certifies physicians who complete an accredited program of anesthesiology training in the United States" (The American Board of Anesthesiology, 2010).

Anesthesia Knowledge Test - A set of three standardized tests, one given during month 1, month 6 and month 24 of residency to assess an anesthesiology residents fund 
Reflective Practice and Readiness for Self-directed Learning

of anesthesia knowledge. The test is administered to approximately 1,500 anesthesiology residents annually.

Allopathic: Graduates from allopathic medical schools receive a medical doctorate degree (M.D.) and are legally and professionally able to practice medicine in the United States. The allopathic training system of medicine is one used to treat diseases using drugs or surgery (Merriam-Webster, 2010).

Attending - Used to describe a medical doctor who has completed all graduate medical education and who is responsible for guiding residents in both technical procedures and learning.

Board Certification - Certification demonstrates that a physician has the knowledge and expertise to provide exemplary patient care. Medical certification in the United States is voluntary for all specialties (The American Board of Anesthesiology, 2010).

Clinical Anesthesia Year 1(CA1) - An anesthesiology residents' first year of anesthesia training (Association for Graduate Medical Association, 2010).

Clinical Anesthesia Year 2 (CA2) - An anesthesiology residents' second year of anesthesia training (Association for Graduate Medical Association, 2010).

Clinical Anesthesia Year 3 (CA3) - An anesthesiology residents' third and final year of anesthesia training (Association for Graduate Medical Association, 2010).

Core Competencies - The core competencies are six competencies that have been identified by the ACGME to serve as the foundation for medical education and training. 


\section{Reflective Practice and Readiness for Self-directed Learning}

The six competencies are (1) patient care - residents must learn to provide patient care that is compassionate, appropriate and effective for the treatment of health problems and the promotion of health; (2) medical knowledge - residents must demonstrate knowledge of established and evolving biomedical, clinical, epidemiological and social-behavioral sciences, as well as the application of this knowledge to patient care; (3) practice-based learning and improvement - residents demonstrate the ability to investigate and evaluate their care of patients, to appraise and assimilate scientific evidence, and to continuously improve patient care based on constant self-evaluation and life-long learning; (4) interpersonal and communication skills - demonstrate interpersonal and communication skills that result in the effective exchange of information and collaboration with patients, their families, and health professionals (5) professionalism - residents must demonstrate a commitment to carrying out professional responsibilities and an adherence to ethical principles; (6) systems based practice - residents must demonstrate an awareness of and responsiveness to the larger context and system of healthcare, as well as the ability to call

effectively on other resources in the system to provide optimal healthcare (Accreditation of Graduate Medical Education, 2010).

Didactic- A kind of systematic instruction by means of planned learning experiences, such as conferences or grand rounds.

Faculty - Any person who has been assigned to teach resident or fellow physicians (Accreditation of Graduate Medical Education, 2010). 
Reflective Practice and Readiness for Self-directed Learning

Intern - A designation for individuals in his or her first year of graduate medical education training (Accreditation of Graduate Medical Education, 2010).

In-Training Exam - A standardized exam taken by anesthesiology residents throughout the country, once per year, that mimics the anesthesiology board exam.

Learner: A learner is a resident currently participating in a graduate medical training program such as a residency or fellowship.

Maintenance of Certification (MOCA) - MOCA is a ten year voluntary program that anesthesiologists with time-limited certification status must complete before their current certification expires in order to maintain their certification status. This process is coordinated through the American Board of Anesthesiology and is not required for state licensure to a medical specialty (The American Board of Anesthesiology, 2010).

Re-certification - Re-certification, also known as Maintenance of Certification promotes lifelong learning and the enhancement of the clinical judgment and skills essential for high quality patient care (American Board of Internal Medicine, 2010).

Osteopathic: A physician of osteopathy (D.O.) has the equivalent training of a medical doctor and is legally and professionally able to practice medicine in the United States. Osteopathic medicine has been recognized as placing an emphasis on a holistic approach to medicine which utilizes a range of manual and physical interventions in the treatment of ailments.

Trainee - A medical doctor in training to become board certified in a medical specialty such as anesthesiology. 


\section{Reflective Practice and Readiness for Self-directed Learning}

Appendix B: Reflective Practice Exercise

The questions below are intended to help guide you through a reflective exercise. Please choose one event that took place this past week, within the scope of your residency training that caught you by surprise, caused you confusion or made you feel uncertain about what you were doing. Please answer the questions below to help guide you through the reflective exercise.

1. Description - what happened

2. Feelings - what were you thinking and feeling

3. Evaluation - what was good and bad about the experience

4. Analysis - what sense can you make of the situation

5. Conclusion - what else could you have done

6. Action plan - if the situation arose again, what would you do? What skills, if any do you need to learn/acquire in order to carry out your action plan? How would you learn these skills? 
Reflective Practice and Readiness for Self-directed Learning

Appendix C: IRB-approved Email Message to Residents to Solicit Participation

Dear Resident,

Oregon Health \& Science University (OHSU) Department of Anesthesiology $\&$ Perioperative Medicine is conducting a research study to see if a relationship exists between reflective practice and the propensity for self-directed learning in anesthesia residents. Reflective practice is a method used to look critically at a specific event in order to gain greater understanding and learn from experience.

The study will involve approximately 150 CA1-CA3 residents from across the country. Half of the residents will be randomly selected to participate in a very short self-guided reflective exercise once per week for 8 weeks. A short, 6-question reflective practice guide will be sent via email weekly to those participants selected to participate in the reflective practice exercise. The 6-question guide is meant to help guide participants through the exercise.

All residents will also complete a short survey two times during the 8 week period. Residents will also complete a short 6-question survey 4-weeks after the last reflective exercise. All reflective exercises and surveys will be administered online. All surveys should not take longer than 10-15 minutes each to complete. Residents who agree to participate will receive a $\mathbf{\$ 2 0 . 0 0}$ Visa Gift Card as a token of our appreciation. All data collected will be confidential.

Attached you will find an information form with more study details. Please read over the form completely. If you agree to participate, please email your program coordinator.

Both your Program Director and Department Chair have agreed to have your program participate in this study. However, in order for this study to be successful your help is needed. We really appreciate your willingness to participate. Please do not hesitate to contact us at juvea@ ohsu.edu or 503-494-4205 with questions.

Sincerely, Chris Swide, M.D. \& Amy Miller Juve. M.Ed.

eIRB \# 5166 
Reflective Practice and Readiness for Self-directed Learning

Appendix D: Participant Information Form

OHSL

Oregon Health \& Science University

Information Sheet

IRB\#: 00006818

Protocol Approval Date:

\title{
OREGON HEALTH \& SCIENCE UNIVERSITY
}

\author{
Information Sheet
}

TITLE: Reflective Practice and Self-Directed Learning

PRINCIPAL INVESTIGATOR: $\quad$ Christopher Swide, M.D. (503) 494-1058

\section{CO-INVESTIGATOR: $\quad$ Amy Miller Juve, M.Ed. (503) 494-4205}

This form contains important information about the study in which you are being invited to participate. Please read the form carefully, ask questions of the investigators or others who are obtaining your consent to participate in the study, and take time to think about your participation. You may want to discuss the study with your family or friends before agreeing to be in the study.

What is the purpose of this study?

The purpose of this study is to determine if reflective practice has an impact on an anesthesiology residents' tendency to engage in self-directed learning.

What is required to participate in this study?

To qualify for this study, you must meet the following criteria: 
Reflective Practice and Readiness for Self-directed Learning

1. You must be an anesthesiology resident currently training in a US training program.

2. You must not be participating in a formal reflective practice curriculum.

\section{What can I expect as a study participant?}

The study will last for 8 weeks and will require participants to complete one self-guided reflection exercise once per week as well as complete a learning preference survey at the beginning, midpoint and end of the study.

If you have any questions regarding this study now or in the future, contact Dr. Christopher Swide (503) 494-1058 or Amy Miller Juve (503) 494-4205.

\section{What effect will this study have on my care?}

Participation in this study will not affect the medical care you receive at OHSU.

\section{How will my privacy be protected?}

We will protect your privacy in the following ways:

1. Your name and other protected information will not be used. Instead, we will identify you by a number.

2. The principal investigator will not be able to access identifiable data associated with anesthesia residents at OHSU.

3. Only the principal investigator and co-investigator and will be able to access your information.

4. Your residency program faculty and staff will not have access to any identifiable or program specific information.

Research records may be viewed and copied by the OHSU Institutional Review Board at the Office for Human Research Protections.

\section{What are the possible risks of participating in this study?}

Although we have made every effort to protect your identity, there is a minimal risk of loss of confidentiality.

\section{What are the possible benefits of participating in the study?}


Reflective Practice and Readiness for Self-directed Learning

You may benefit from being in this study by learning skills that will help you reflect upon your practice. Also, by serving as a subject, you may help us learn more about the adult learning process which may benefit trainees across the country and impact patient care in a positive manner.

\section{Will it cost anything to participate?}

You will receive a $\$ 20.00$ Visa gift card for participating.

\section{What are my rights as a participant?}

If you have any questions regarding your rights as a research subject, you may contact the OHSU Research Integrity Office at (503) 494-7887. You do not have to join this or any research study. If you do join, and later change your mind, you may quit at any time. If you refuse to join or withdraw early from the study, there will be no penalty or loss of any benefits to which you are otherwise entitled.

The participation in OHSU research is completely voluntary and you are free to choose not to serve as a research subject in this protocol for any reason. If you do elect to participate in this study, you may withdraw from the study at any time without affecting your relationship with OHSU, the investigator, the investigator's department, or your grade in any course.

Please keep a copy of this form. If you lose it, please feel free to contact the researchers for another copy. 
Reflective Practice and Readiness for Self-directed Learning

Appendix E: Email Message to the Program Coordinator

Hi XXX,

Below are the details of the reflective practice study. Ideally we would like to enroll 40 participants per institution and we'd like to start collecting data March $28^{\text {th }}$. Thank you so much for all of your help! This is a big research project and it wouldn't be possible without your help!

Details:

Resident participants will be randomly broken into 2 groups - a control group and a reflective practice group.

Here is a breakdown of what each participant group will be responsible for:

\begin{tabular}{|c|c|}
\hline Control Group & Reflective Practice Group \\
\hline No reflective practice exercises & $\begin{array}{l}\text { Short weekly reflective exercises (1 time per } \\
\text { week for } 8 \text { weeks) } \sim 10-15 \mathrm{~min}\end{array}$ \\
\hline $\begin{array}{l}1 \text { learning preference survey at week } 1 \\
-10-15 \mathrm{~min}\end{array}$ & $\begin{array}{l}1 \text { learning preference survey at week } 1-10-15 \\
\text { min }\end{array}$ \\
\hline $\begin{array}{l}1 \text { learning preference survey at week } 8 \\
-10-15 \mathrm{~min}\end{array}$ & $\begin{array}{l}1 \text { learning preference survey at week } 8-10-15 \\
\text { min }\end{array}$ \\
\hline $\begin{array}{l}1 \text { post study survey } 4 \text { weeks after end } \\
\text { of study - } 10-15 \text { min }\end{array}$ & $\begin{array}{l}1 \text { post study survey } 4 \text { weeks after end of study - } \\
10-15 \text { min }\end{array}$ \\
\hline
\end{tabular}

\section{Points to note:}

1) Although the study timeframe is 8 weeks each survey or reflection is short (no longer than 15 minutes each)

2) Survey's will be sent via an electronic survey software so residents will not have to $\log$ into a website to complete study related survey's

3) Participants will receive a $\$ 20.00$ Visa giftcard at the beginning of the study as a token of our appreciation.

\section{What we would like to receive from your program (you):}

I've attached a spreadsheet called "participant information" that outlines the information we need to collect from your program (you). Once you have enrolled all of your participants, if you could send me the completed spreadsheet I will contact your participants and start the study. I don't anticipate needing anything further from you once the study is underway. 
Reflective Practice and Readiness for Self-directed Learning

\section{Materials to go to residents to solicit participation:}

I've copied and pasted the IRB approved email to solicit participants. I've also attached a "study information sheet" which has also been approved by our IRB. Can you please send both the email and the study information sheet to your residents.

Thank you for participating in this study! If you have questions, please do not hesitate to contact me. 
Reflective Practice and Readiness for Self-directed Learning

Appendix F: Self-directed Learning Readiness Scale/Learning Preference Assessment

This is a questionnaire designed to gather data on learning preferences and attitudes towards learning. After reading each item, please indicate the degree to which you feel that statement is true of you. Please read each choice carefully and choose/highlight the response which best expresses your feeling.

There is no time limit for the questionnaire. Try not to spend too much time on any one item; however, your first reaction to the question will usually be the most accurate.

2. Name of the medical school you graduated from

Please indicate your ethnicity:

White (not Hispanic or Latino)

Two or more races (not Hispanic or Latino)

- Black or African American

- Hispanic (all other races)

- Asian (not Hispanic or Latino)

- Hawaiian or Pacific Islander

- American Indian/Alaskan Native

O Hispanic (White race only)

Other - not listed

Please indicate your age range

younger than 24

25-30

(1) $31-35$

$36-40$

41-45

older than 46

Responses 
Reflective Practice and Readiness for Self-directed Learning

1 = Almost never true of me; I hardly ever feel this way. 2 = Not often true of me; I feel this way less than half the time. 3 = Sometimes true of me; I feel this way about half the time. 4 = Usually true of me; I feel this way more than half the time. 5 = Almost always true of me; there are very few times when I don't feel this way.

\section{Items}

1. I'm looking forward to learning as long as I'm living.

2. I know what I want to learn.

3. When I see something that I don't understand, I stay away from it.

4. If there is something I want to learn, I can figure out a way to learn it.

5. I love to learn.

6. It takes me a while to get started on new projects.

7. In a classroom situation, I expect the instructor to tell all class members exactly what to do at all times.

8. I believe that thinking about who you are, where you are, and where you are going should be a major part of every person's education.

9. I don't work very well on my own. 
Reflective Practice and Readiness for Self-directed Learning

1 = Almost never true of me; I hardly ever feel this way. $2=$ Not often true of me; I feel this way less than half the time. 3 = Sometimes true of me; I feel this way about half the time. 4 = Usually true of me; I feel this way more than half the time. $5=$ Almost always true of me; there are very few times when I don't feel this way.

Items

10. If I discover a need for information that I don't have, I know where to go to get it.

11. I can learn things on my own better than most people.

12. Even if I have a great idea, I can't seem to develop a plan for making it work.

13. In a learning experience, I prefer to take part in deciding what will be learned and how.

14. Difficult study doesn't bother me if I'm interested in something.

15. No one but me is truly responsible for what I learn.

16. I can tell whether I'm learning something well or not.

17. There are so many things I want to learn that I wish there were more hours in a day.

18. If there is something I have decided to learn, I can find time for it, no matter how busy I am. 


\section{Reflective Practice and Readiness for Self-directed Learning}

19. Understanding what I read is a problem for me.

\section{Responses}

1 = Almost never true of me; I hardly ever feel this way.

$2=$ Not often true of me; I feel this way less than half the time.

3 = Sometimes true of me; I feel this way about half the time.

4 = Usually true of me; I feel this way more than half the time.

5 = Almost always true of me; there are very few times when I don't feel this

way.

\section{Items}

20. If I don't learn, it's not my fault.

21. I know when I need to learn more about something.

22. If I can understand something well enough to get by, it doesn't bother me if I still have questions about it.

23. I think libraries are boring places.

24. The people I admire most are always learning new things.

25. I can think of many different ways to learn about a new topic.

26. I try to relate what I am learning to my long-term goals.

27. I am capable of learning for myself almost anything I might need to know. 


\section{Reflective Practice and Readiness for Self-directed Learning}

28. I really enjoy tracking down the answer to a question.

29. I don't like dealing with questions where there is not one right answer.

\section{Responses}

1 = Almost never true of me; I hardly ever feel this way.

2 = Not often true of me; I feel this way less than half the time.

3 = Sometimes true of me; I feel this way about half the time.

4 = Usually true of me; I feel this way more than half the time.

$5=$ Almost always true of me; there are very few times when I don't feel this

way.

Items

30. I have a lot of curiosity about things.

31. I'll be glad when I'm finished learning.

32. I'm not as interested in learning as some other people seem to be.

33. I don't have any problems with basic study skills.

34. I like to try new things, even if I'm not sure how they will turn out.

35. I don't like it when people who really know what they're doing point out mistakes that I am making. 


\section{Reflective Practice and Readiness for Self-directed Learning}

36. I'm good at thinking of unusual ways to do things.

37. I like to think about the future.

38. I'm better than most people are at trying to find out the things I need to know.

39. I think of problems as challenges, not stop-signs.

\section{Responses}

1 = Almost never true of me; I hardly ever feel this way. $2=$ Not often true of me; I feel this way less than half the time. 3 = Sometimes true of me; I feel this way about half the time. 4 = Usually true of me; I feel this way more than half the time. $5=$ Almost always true of me; there are very few times when I don't feel this way.

\section{Items}

40. I can make myself do what I think I should.

41. I'm happy with the way I investigate problems.

42. I become a leader in group learning situations.

43. I enjoy discussing ideas.

44. I don't like challenging learning situations. 


\section{Reflective Practice and Readiness for Self-directed Learning}

45. I have a strong desire to learn new things.

46. The more I learn, the more exciting the world becomes.

47. Learning is fun.

48. It's better to stick with the learning methods that we know will work instead of always trying new ones.

49. I want to learn more so that I can keep growing as a person.

\section{Responses}

1 = Almost never true of me; I hardly ever feel this way.

$2=$ Not often true of me; I feel this way less than half the time.

3 = Sometimes true of me; I feel this way about half the time.

4 = Usually true of me; I feel this way more than half the time.

5 = Almost always true of me; there are very few times when I don't feel this

way.

Items

50. I am responsible for my learning - no one else is.

51. Learning how to learn is important to me.

52. I will never be too old to learn new things.

53. Constant learning is a bore. 
Reflective Practice and Readiness for Self-directed Learning

54. Learning is a tool for life.

55. I learn several new things on my own each year.

56. Learning doesn't make any difference in my life.

57. I am an effective learner in a classroom situation and on my own.

58. Learners are leaders.

\section{You have completed the questionnaire!}

(C) 1977, Dr. Lucy M. Guglielmino

Self-scoring format ( 1982 , Drs. Paul J. and Lucy M. Guglielmino

Electronic format () 2004, Drs. Paul J. and Lucy M. Guglielmino

This instrument is copyrighted. The reproduction of any part of it by mimeograph, photostat, electronic, or in any other form, whether the reproductions are sold or furnished free for use, is a violation of copyright law. 
Reflective Practice and Readiness for Self-directed Learning

Appendix G: Follow-Up Survey

$$
\text { Follow-Up Survey }
$$

Thank you for participating in our study looking at reflective practice and self-directed learning. We are interested in learning how this study may or may not impact your future professional practice. Can you please take a few minutes to fill out this short questionnaire? Thank you!

When filling out this survey please keep in mind the following definition of reflective practice: reflective practice is a thoughtful way to critically review and analyze an action, problem or process in order to make changes to your future practice. Reflective practice can be done individually or in a social context. Reflective practice does not have to be in written form (similar to the reflective practice exercise used in this study). Reflective practice can be done with peers, mentors or other learners or it can be done individually through an internal mental process.

1) Did you participate in written reflective practice during this study? Yes/No

a. If yes, did you complete at least 6 of 8 written reflective exercises? Yes/No

i. If you did not participate in 6 of 8 reflective exercises can you please explain why:

1) Do you think you will engage in any form of reflective practice now that this study has concluded? Yes/No

a. Please explain why or why not:

2) Would you recommend that all physicians reflect upon their practice? Yes/No

a. Please explain why or why not:

3) Do you think you think engaging in reflective practice would have an impact on the quality patient care you or your colleagues provide? Yes/No

a. Please explain your answer:

4) Do you think, by engaging in reflective practice, you will be more or less inclined to learn throughout your career? More/Less

a. Please explain your answer:

5) Have you engaged in written reflective practice since the conclusion of this study? Yes/No 